\title{
The medical resident as a teacher : teaching and learning in the clinical workplace
}

Citation for published version (APA):

Busari, J. O. (2004). The medical resident as a teacher : teaching and learning in the clinical workplace. [Doctoral Thesis, Maastricht University]. Universiteit Maastricht. https://doi.org/10.26481/dis.20041215jb

Document status and date:

Published: 01/01/2004

DOI:

10.26481/dis.20041215jb

Document Version:

Publisher's PDF, also known as Version of record

\section{Please check the document version of this publication:}

- A submitted manuscript is the version of the article upon submission and before peer-review. There can be important differences between the submitted version and the official published version of record.

People interested in the research are advised to contact the author for the final version of the publication, or visit the DOI to the publisher's website.

- The final author version and the galley proof are versions of the publication after peer review.

- The final published version features the final layout of the paper including the volume, issue and page numbers.

Link to publication

\footnotetext{
General rights rights.

- You may freely distribute the URL identifying the publication in the public portal. please follow below link for the End User Agreement:

www.umlib.nl/taverne-license

Take down policy

If you believe that this document breaches copyright please contact us at:

repository@maastrichtuniversity.nl

providing details and we will investigate your claim.
}

Copyright and moral rights for the publications made accessible in the public portal are retained by the authors and/or other copyright owners and it is a condition of accessing publications that users recognise and abide by the legal requirements associated with these

- Users may download and print one copy of any publication from the public portal for the purpose of private study or research.

- You may not further distribute the material or use it for any profit-making activity or commercial gain

If the publication is distributed under the terms of Article $25 \mathrm{fa}$ of the Dutch Copyright Act, indicated by the "Taverne" license above, 
The Medical Resident as a Teacher

Teaching and Learning in the Clinical Workplace 


\section{Dedication,}

For my uncle, Kolawole Badaru

Cover: Sil-online, Silvia Hoffland

Printed by: Uitgeverij Buijten \& Schipperheijn, Amsterdam

ISBN: $\quad 90-9018812-6$

이 2004 J.O. Busari

No part of this thesis may be reproduced or transmitted in any form or by any means, electronic or mechanical, including photocopy, recording or otherwhise without permission of the author. 


\section{The Medical Resident as a Teacher}

\section{Teaching and Learning in the Clinical Workplace}

\section{PROEFSCHRIFT}

ter verkrijging van de graad van doctor

aan de Universiteit Maastricht,

op gezag van de Rector Magnificus

Prof. mr. G.P.M.F. Mols

volgens het besluit van het College van Decanen,

in het openbaar te verdedigen op

woensdag is december 2004 om 14.00 uur

door

Jamiu Oladimeji Busari

geboren op 28 juni 1968 te Londen (United Kingdom) 
Promotores:

Prof. Dr. A.J.J.A. Scherpbier

Prof. Dr. C.P.M. van der Vleuten

Prof. Dr. G.G.M. Essed

Beoordelingscommissie: Prof. Dr. E. Heineman (Voorzitter)

Prof. Dr. O. P. Bleker (Academisch Medisch Centrum, Amsterdam)

Dr. J. van Dalen

Prof. Dr. H.S.A. Heymans (Emma Kinderziekenhuis, Amsterdam)

Prof. Dr. G. Kootstra

PARANIMFEN:

Drs. N. M. Weggelaar

Drs. I.P. de Boer 
Do not believe in anything simply because you ve beard it.

Do not believe in traditions because they have been handed down for many generations.

Do not believe in anything because it is spoken and rumoured by many.

Do not believe in anything simply because it is found in your religious books.

Do nor believe in anything merely on authority of your teachers and elders.

But after observation and analysis, if you find anything agrees with reason

and is conducive to the good and benefit of one and all then accept it and live up to it.

- Buddha (6th century Bc)

Anguttara Nikaya III -65 


\section{Contents}

1. Introduction and aims of the study

2. Theoretical background

3. Residents' perception of their role in teaching undergraduate students in the clinical setting (Medical Teacher, Vol. 22, No. 4, 2000:348-53) study (Medical Teacher, Vol. 24, No. 1,$2002 ; 57-6 t$ )

5. The perceptions of attending physicians on the role of residents as teachers of undergraduate clinical students (Medical Education, Vol. 37, 2003: 241-7)

6. How medical residents perceive the quality of supervision provided by attending doctors in the clinical setting (Accepted, Medical Education)

7. Why medical residents should teach: A literature review (Journal of Postgraduate Medicine, Vol. so, No 3, 2004: 205-210)

8. Designing the training program: A guideline for Course Developers

9. A two-day workshop on teaching skills for medical residents: A description (Submitted)

10. A two-day teacher-training program for medical residents: Investigating the impact on teaching ability (Submitted)

II. General discussion

12. Summary

13. Samenvatting 
15. Curriculum vitae

16. List of Publications

176

17. Acknowledgements 



\section{Chapter I}

INTRODUCTION AND AIMS OF THE STUDY 


\section{Chapter I}

Almost all doctors are teachers to some extent, involved in the formal or informal training or supervision of students, junior staff and other professionals. But perhaps because everyone does it, teaching has a traditionally low status in the medical world. Changes in the sort of education required by students mean that a more professional attitude to seaching must be developed.

(S. Lowry, 1993 Teaching the teachers, British Medical Journal)

\section{Medicine as a profession}

About two decades ago, McGlothlin (1961) observed that professions varied widely in the way they used their experiences to teach their apprentices'. In addition, the activities and responsibilities of instructors among the professions varied significantly. Professional education has undergone significant transformation since then; which as Blauch (1962) described, has passed through three stages of evolution. These stages include the stage of professional training based entirely on apprenticeship, the stage of professional training in formal settings separated from the profession's practice and lastly the stage of theory-based programs incorporating both traditionally taught subject matter and integrated apprenticeship experiences ${ }^{2}$. It is probably helpful at this point to take a closer look at the concept of "profession" in the context of medical practice. The development of theory is characteristic of any profession, and this reliance on theory, is what distinguishes a profession from a trade (or craft) ${ }^{3}$. Professions develop the theories and actions by which they are performed as well as how their educational programs are conducted". The different definitions of professions and consequently, the different ways their experiences are applied in practice and in teaching may also contain moral and/or ethical implications for the individual towards his/her profession. One of the several distinctions of professions is the professional's "service" role that requires him/her to set aside personal beliefs and preferences in favor of the client's best interests, as observed in the medical profession. Some professions define it operationally e.g. as in an engineer who should have specific technical knowledge in his chosen discipline; and it is this knowledge that makes him a professional ${ }^{5}$, while other professions distinguish between what their profession is and what it is not e.g. an engineer is a user of knowledge while a scientist is a pursuer of knowledge.

Besides the evolution and definition of professions, the transmission of professional expertise also received attention. Its objective was to transform the students gestalt from confusion to familiarity, so that the students could inhabit the professional world ${ }^{67}$. This transformation was embodied in the theory-based practice of an apprenticeship e.g. medical clerkships and specialist training programs. During the apprenticeship, the aspiring professional learns many facets of the profession from the master or expert. Cognitive and intellectual learning ranging from the simplest levels of factual knowledge acquisition to the complexities of synthesis, evaluation and 
reasoning form the essence of the training. The learner also encounters and assimilates the rich fabric of socialization, interpersonal skills, moral reasoning and attitudes that distinguish the profession's members from others. Furthermore, it is expected that a high level of technical skills should be learnt for the competent professional to be able to fulfill the profession's responsibilities3. In this dissertation, we shall focus on the contribution of medical residents in the abovementioned process and on how the quality of their contributions can be improved.

\section{STAKeholders}

The history of the medical profession shows that the responsibility of teaching the apprentice (or students) has always been that of the master (or physician). Hippocrates, the famous Greek physician (460-337 BC) who is known for his sound principles of medical practice, first emphasized this responsibility explicitly in the Hippocratic oath.

Tswear by Apollo the physician... that by precept, lecture and every other mode of instruction. I will impart a knowledge of the Art to my sons, and those of my teachers, and to disciples bound by a stipulation and oath to the law of medicine...."

In the last two decades, many changes have been witnessed in the practice of the medical profession. These changes have included the diversification of the profession into (sub-) specialties, and the expansion of the apprenticeship to include among others, the training of graduate physicians (i.e. medical residents). They have also resulted in the modifications that have occurred in the form and content of training programs and/or curricula of various medical institutions" 14 . Along with these developments, is also, the observed increase in teaching responsibilities being delegated to medical residents ${ }^{12-15}$. Upholding the standards of practice in a profession like medicine, which continuously undergoes change and reform, demands that its beneficiaries or stakeholders are actively involved in the process. Educational experts believe that the main stakeholders in this process are the specialist-physicians, medical students and medical residents. On a broader scale though, the beneficiaries of the services also include, patients, faculty administrators, government policy makers and the community as a whole. The various interests of the different stakeholders also determine the extent to which they are involved in the medical educational process; however, the details of the different interests shall not be discussed here, as they fall beyond the scope of the dissertation.

The relationship that exists among a few stakeholders in the medical educational process i.e. the physicians (i.e. medical residents), medical students and patients is however worth mentioning. There are studies in the literature that show the sort of benefits medical residents and medical students (can) derive from each other, through the professional and educational activities they share ${ }^{12-17}$. There are also studies that show the high quality of medical care provided by medical 


\section{Chapter I}

residents, and the high level of patient satisfaction associated with it ${ }^{18-21}$. There is the possibility however that the position of the medical resident in the health care setting can cause confusion and frustration, especially for those patients who perceive them as barriers to communication between them and those higher up in professional hierarchy. This is probably due to the difficulties many patients have with differentiating among students, interns, residents, fellows and attending physicians on one hand, and on the other, the different expectations they have based on the respective positions in the hierarchy of the profession ${ }^{22}$. Nonetheless, it has been shown that the educational exercises that occur in association with the care that medical residents provide tend to be received positively by the patients ${ }^{20}$. Also, it is necessary to note that the role of patients as stakeholders in the process of medical education is significant; that the majority of patients consider it important to help educate future specialists and that they are comfortable with having medical residents involved in the care of their well-being ${ }^{22}$.

The stakeholders that we shall focus on in this dissertation include those directly involved in the active educational process in the clinical setting. They include the students who we shall regard as the recipients of medical education, and the medical residents who we would regard as the providers. The stakeholder of particular interest is the medical resident. We shall be examining the contribution of medical residents to the education of medical students, focusing on 1) the benefits they (medical residents) derive from teaching, 2) the problems they encounter during teaching, and 3 ) how to improve their contribution to the education of medical students.

\section{Medical residents as teachers}

There is enough evidence that residents (can) contribute to the education of medical students in the clinical setting ${ }^{12 \cdot 15,17}$. A number of studies have reported that as much as $70 \%$ of the information medical students receive are provided by medical residents ${ }^{13}, 14,16$. Other studies conducted to investigate the medical residents' role as teachers have shown that they were prepared and willing to teach medical students ${ }^{23-26}$. The medical students on the other hand appreciated being taught by medical residents, rating the teaching abilities by the latter positively ${ }^{12}, 27,28,29$. Furthermore, it has been demonstrated, that assertiveness, facilitation, negotiation, counseling and appraisal of medical students are essential teaching skills clinical teachers should improve ${ }^{30,31}$, and that the possession of good clinical, pedagogical and personal abilities are important skills clinical teachers need to teach effectively ${ }^{32}$.

The consensus from many of these studies $28,29,38,34,35$ favors the development of training programs that are designed to improve the teaching abilities of clinical teachers (and medical residents). Experts in the field of medical education are already propagating that medical residents should receive instruction in didactic skills, and that it should form a part of their 
residency training $30.95,95,90$. They argue that if residents can teach effectively, it could improve their individual professional and educational abilities. They also claim that it would result in an improvement in the quality of teaching in undergraduate medical education ${ }^{25}, 3 \%$. As has been seen in a few institutions where such training programs have been implemented, the effects on

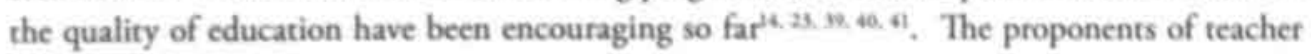
training programs for medical residents, believe that through teaching, medical residents would be compelled to re-evaluate pertinent parts of their knowledge (and problem-solving strategies) before explaining them to students ${ }^{15}$. Consequently, they would be stirred to review and update their knowledge and skills, which reinforces any pre-existent knowledge, skills or competencies they may have.

\section{THE REQUiREMENTS FOR EFFECTIVE TEACHING}

The teaching environment in medicine is not limited to the classrooms alone, but includes the medical wards, outpatient clinics and operating theaters where an appreciable amount of teaching and learning takes place. According to Yinger ${ }^{22}$, complexiry, unpredictability and a fast pace characterize such environments requiring that medical residents possess the appropriate knowledge and (teaching) skills, in order to function effectively as teachers. The skills of effective teaching however, are distinct entities that are separate from the skills of clinical proficiency. They constitute a set of definable instructional behaviours, informed by principles of teaching and learning, and which have been shown to promote student learning. These skills are not innate and there is reason to believe that teacher-training programmes provide an effective mechanism for developing this instructional expertise, and also increase the awareness of the learning process. It is logical then, to want to design a teacher-training course for medical residents based on the above-mentioned reasons.

When designing a teacher-training course, the goal should be to strive for a balance between the new skill that has to be learnt and the understanding of the principles and theories that constitute the performance of the skill. A course that only stresses skills aimed at having learners (i.e. medical resident) learn how to do things but not understanding the principles behind what he or she is doing is not ideal. Neither is the course, which only stresses the understandings that may equip the learner with a set of ideas but leave him or her without any competencies. Based on this premise, the objective of anyone planning to design a teacher-training program for medical residents should be:

1) To increase the awareness of teaching, as an important aspect of the medical residents' professional responsibility. This entails that medical residents should be provided with a clear understanding of what their professional responsibilities are i.e. their different roles as physicians, teachers, and learners in the teaching hospital setting. 
2) To acknowledge the professional responsibilities of the medical residents. This is by bearing in mind the dynamics of the different roles of the medical resident in the clinical setting when planning educational programs.

3) To expose the residents to the ideas and concepts of what they have to learn (cognition) i.e. the theory of education and the process of teaching and learning, and

4) To provide medical residents with tools that not only improves their practical didactic skills, but also enhances their individual learning.

Such tools should be simple, easy to implement, cost effective, and cover the basic skills for effective teaching. The skills such tools should address include cognitive, affective and psychomotor skills. Cognitive skills refer to the residents' ability to utilize the learnt ideas or concepts when faced with a problem, for example being able to explain difficult concepts to students. The affective skills on the other hand, refer to their ability to exhibit the behaviors that reflect certain desired behaviors e.g. treating students with respect and stimulating them to learn. Finally, the psychomotor skills are those physical or perceptual competencies that medical residents are expected to possess after completing such a training e.g. demonstrating effective physical examinations at the bedside.

\section{Aim OF THE STUDY}

In clinical medicine, the majority of physicians commence their careers with little or no formal exposure on how to teach. Many of them cultivate their teaching styles through trial and error and by reflecting on personal experience ${ }^{43}, 4$. Others acquire a working knowledge of the principles of teaching through observation, adopting positive and rejecting negative examples of clinical instruction ${ }^{45}$. There is a reasonable amount of information on the theories of adult learning in the medical literature that show that clinical teachers require basic teaching skills to be able to teach effectively ${ }^{45} \cdot 45$. Furthermore, the conventional view that a sound knowledge of ones discipline alone is sufficient and the only prerequisite required for becoming a good clinical teacher is not tenable anymore. Experts in medical education and clinical teachers now agree that educational knowledge, knowledge of the general principles of teaching, and the proper understanding of ones clinical discipline, are important features that constitute the core principles of teaching. It is therefore crucial that clinical teachers understand these educational principles properly, if they intend to be effective teachers ${ }^{40,36.49}$. Regardless of this understanding, the role of medical residents as teachers and their contribution to the (medical) educational process still necds extensive exploration.

The focus of our investigation in this dissertation is on medical residents' participation in undergraduate medical education. We were particularly interested in three aspects of their contribution to the educational process, namely, 1) the extent to which they are involved in teaching, 2) 
the factors that facilitate or hinder their contributions and 3) how a valid educational tool aimed at improving medical residents' teaching abilities could be developed. 'The main research questions of the dissertation therefore included:

1. To what extent are medical residents involved in teaching undergraduate medical students?

2. What are the factors that hinder medical residents effective contribution to teaching undergraduate medical students?

3. How can an effective educational program be designed as a form of intervention for improving medical residents' teaching skills?

4. How can the feasibility and appropriateness of such an educational program be assessed?

5. How can the impact of such a program on the teaching skills of medical residents be measured?

\section{OUtLiNe OF THE Dissertation}

The outline of this dissertation shows how the questions generated in the aim of the study have been addressed. Chapter 1 revisits the concept of professionalism, which we describe using the context of the medical profession. At the same time, we (re-) define the duties of medical residents and highlight why and how teaching by medical residents is important for undergraduate medical education. Chapter 2 goes on to provide more insight into the fundamental theories of education described in chapter $\mathrm{t}$. For the novice who is unfamiliar with these theories of education, a few general principles and concepts are explained that help illustrate the educational process. The next four chapters of the dissertation provide answers to the first and second research questions. Chapter 3 investigates the medical residents' own perceptions of their teaching responsibilities, the factors that hinder their contribution and their personal recommendations on how to improve it. The qualitative study described in chapter 4 elaborates their perceptions and recommendations on how to improve their teaching abilities. The perceptions of attending-physicians on the teaching role of medical residents are investigated in chapter 5, and their recommendations on how to improve the teaching skills of medical residents are provided.

Chapter 6 illustrates how medical residents perceive the quality of supervision they receive from attending-physicians and describes the qualities that the effective teacher should possess. An additional value of these first four chapters was the recommendations that were provided in them. These recommandations were made use of in developing the teacher-training program described in the later chapters of this dissertation. Chapter 7 provides a synopsis of chapters 1 to 6 as to why medical residents should teach. An update of the available evidence in the literature is used to demonstrate this, and a theoretical description of what occurs in the teaching and learning process is provided. Chapter 8 answers the third research question of this dissertation. In this 
chapter, a description is provided of how an educational program aimed at improving the teaching skills of medical residents can be developed. Using a needs assessment strategy, the findings and recommendations described in the previous chapters, are combined with the principles and theories in medical education, to develop a training workshop in teaching. Chapter 9 answers the fourth research question. Here the feasibility and appropriateness of the training program as a two-day workshop is investigated. In chapter 10, we investigate the impact of the workshop on the teaching abilities of medical residents. The results of the study presented here provide answers to the fifth research question. Finally, chapter In provides a general discussion of the findings in this dissertation in the conclusion. Additional suggestions and recommendations for future research are also provided.

\section{REFERENCES}

1. McGLOTHLIN, W.J. (1961). Insights from one profession which may be applied to other professions. In G.K. Smith (Ed.) Current Isues in higher Education. Washington, DC, Association for Higher Education.

2. BL.AUCH, L.E. (1962). A century of the professional school. In W.W. BRICKMAN \& S. LEHRER (Eds.) A century of higher education. New York: Society for the Advancement of Education.

3. DINHAM, S.M. \& STRITTER, F.T. (1986), Research on Professional Education. In M.C. WTTTROCK (Ed.) Handbook of Reseanch in Teaching 952-70, New York: Macmillan

4. ARGYRIS, C. \& SCHON, D.A. (1974). Theory in practice: Increasing professional effectiveness. San Francisco: Josey-Bass.

5. LANCASTER, O.E. (1976). The future of engineering education in Land-grant universities. In G.L. ANDERSON (Ed.) Land-grant universities and their continuing challenge. East Lansing: Michigan state university press.

6. JEVONS, F.R. (1969). The Teaching of science, London: Allen \& Unwin

7. KUHN, T.S. (1970). The structure of scientific revolutions. Chicago: University of Chicago Press.

8. FRIEDMAN, C.P., De BLIECK, R., GREER, D.S., MENNIN, S.P., NORMAN, G.R., SHEPS, C.G., SWANSON, B.D. \& WOOLWARD, C.A. (1990). Charting the Winds of Change: Evaluating Innovative Medical Curricula. Academic Medicine, 65: 8-14

9. PATEL, V.L., GROEN, G.J. \& NORMAN, G.R. (1991). Effects of Conventional and Problem-Based Medical Curricula on Problem solving. Academic Medicine, 66:380-89

to. ALBANESE, M.A. \& MITCHELL, S. (1993). Problem Based Learning, a Review of Literature on Its Outcomes and Implementation Issues. Academic Medicine, 68: $52-8 \mathrm{I}$

II. BUSARI, J.O., SCHERPBIER, AJ.J.A. \& BOSHUIZEN, H.P.A. (1997). A Comparative Study of Medical Education as Perceived by Students ar Three Dutch Universities. Aduances in Health Sciences Education, I: $141-51$ 
12. BARROW, M.V. (1966). Medical students' opinions of the house officer as a medical educator. Josmal of Medical Education, 41: 807-10.

13. BROWN, R.S. (1970). House staff attitudes toward teaching Journal of Medical Edwoation, 45:156-59

4. MELECA, C.B. \& PEARSOL. J.A. (1988). Teaching surgery residents to teach. In J.C. EDWARDS \& R.L. MARIER (Eds.) Clinical Teaching for Medical Residents: Roles, Tedbniquer and Pregrams, 187-200, New York: Springer Verlag.

15. STEWARD, D.E. \& FELTOVICH, P.J. (1988). Why residents should teach: the parallel processes teaching and learning In J.C. EDWARDS \& R.L. MARIER (Eds.) Clinical Teaching for Medieal Residents: Roles, Techniques and Prognums, 3-14, New York: Springer Verlag.

16. STENCHEVER, M.A., IRBY, D.M. \& O'TOOLE, B. (1979). A national survey of undergraduate teaching in Obstetrics and Gynaecology. Journal of Medical Education, 54:467-70.

17. THOMAS, P.S., HARRIS, P., RENDINA, N. \& KEOGH, G (2002). Residents as Teachers: Outcomes of a brief training programme. Edacation for Healtb: Change in Learning o Practice, $15(1): 71-78$

18. MATTHEWS, D.A., SLEDGE, W.H. \& LIEBERMAN, P.B. (1987). Evaluation of intern performance by medical inpatients. American Jeurnal of Medicine, 83: 938-44

19. SHEETS, K.J., CARUTHERS, B.S. \& SCHWENK, T.L. (1991), Patients satisfaction with gynaecologic care provided by family practice resident physicians. Family Pract Res Journal, II:421-28

20. O'MALLY, P.G., OMORI, D.M., L.ANDRY, F.., et al. (1997). A prospective study to assess the effect of ambulatory teaching on patient satisfaction. Academic Medicine, $72: 1015-17$

21. WACHTER, R.M., KATZ, P. SHOWSTACK, J., et al. (1998). Reorganizing an academic medical service: impact on cost, quality, patient satisfaction, and education. JAMA, 279:1560-65

22. COWLES, R.A., MOYER, C.A., SONNAD, S.S., et al. (2001). Doctor-Patient Communication in Surgery: Artitudes and Expectations of General Surgery Patients about the Involvement and Education of Surgical Residents. Journal of American College of Surgeons, 193: 73-80

23. JEWETT, L.S., GREENBERG, L.W. \& GOLDBERG, R.M. (1982). Teaching residents how to teach: a one-year study, Journal of Medical Education, 57: 361-66.

24. GREENBERG, L.W., GOLDBERG, R.M. \& JEWETT, L.S. (1984). Teaching in the clinical setting: factors influencing residents' perceptions, confidence and behavior. Medical Education, 18: 360-65

25. APTER, A., METZGER, R. \& GL.ASSROTH, J. (1988). Residents' perception of their role as teachers. Journal of Medical Education, 63:185-88.

26. BING-YOU, R.G. \& HARVEY, B.J. (1991). Factors related to residents' desire and ability to teach in the clinical setting. Teaching and Learning in Medicine, 2: 95-100,

27. BARROW, M.V. (1965). The house officer as a medical educator, Journal of Medical Education. 40: 712-14.

28. BING-YOU, R.G. \& SPROUL, M.S. (1992). Medical students' perceptions of themselves and residents as teachers. Medical Teacher, 14: 133-38.

29. NKANGINIEME, K.E.O \& IHEKWABA, A.E. (1998). Students' perception of the house officer as a teacher. Medical Teacher, $20(2)$ : 109-13 
30. TONESK, X. (1979). The house officer as a teacher: what schools expect and measure. Journal of Medical Education, 54: 613-616.

31. CHAL.LIS, M., WILLIAMS, J. \& BATSTONE, G. (1998). Supporting pre-registration house officers: The needs of educational supervisors of the first phase of post-graduate medical education. Medical Education, 32: $177-80$

32. COTE, L. (1993). Supervision of family medicine residents. Competencies and qualities [French]. Canadian Family Physician, 39: 366-72

33. GENERAL MEDICAL COUNCIL (1993). Tomorrow's Docton: Recommendations on Undengraduate Medical Education (London, General Medical Council).

34. PARLE, J., WALL, D., HOLDER, R. \& TEMPLE, J. (1995). Senior registrars' communication skills: attitudes to and need for training, British Journal of Hospital Medicine. 53(6): $257-60$.

35. PORTER, N. (1997). Clinical supervision: The art of being supervised. Nurring Standard, 11: 44-45.

36. DUNNINGTON, G.L. \& DAROSA, D. (1998). A prospective randomised trial of a residents-as-teachers training program. Academic Medicine, 73: 696-700.

37. BORLEFFS, J.C.C., CATE, Th.J. ten, BRUIJNZEEL-KOOMEN, C.A.F.M. \& ERKEL.ENS, D.W. (2002). (Dutch). A proposal for the introduction of an internship in clinical didactics into residency training. Dutch Journal of Medical Education, 2t: 25-32.

38. KATES, N.S. \& LESSER, A.L. (1985). The resident as a teacher: a neglected role, Canadian Journal of Pyychiatry. 30(6): 418-21.

39. L.AWSON, B.K. \& HARVILL. L.M. (1980). The evaluation of a training program for improving residents teaching skills, Journal of Medical Education, 55: 1000-05.

40. CAMP, M.G. \& HOBAN, J. D. (1988). Teaching medicine residents to teach. In J.C. EDWARDS \& R.L. MARIER (Eds.) Clinical Teaching for Medical Residents: Roles. Techniques and Programs, 201-213. New York: Springer Verlag

41. EDWARDS, J.C., KISSI.ING, E.G., PLAUCHE, C.W. \& MARIER L.R. (1988). Developing and evaluating a teaching improvement program for residents. In J.C. EDWARDS \& R.L. MARIER (Eds.) Clinical Teaching for Medical Residens: Roles. Techniques and Programs, 157-174 New York: Springer Verlag.

42. YINGER, R.J. (1978), Fieldwork as a basis for theory building in research on teaching East Lansing: Institute for Research on Teaching, Michigan

43. McL.EOD, P.J. \& HARDEN, R.M. (1985). Clinical teaching strategies for physicians. Medical Teacher, 7: 173-89.

44. LOWRY, S. (1993). Teaching the teachers. British Medical Journal, 306: 127-30.

45. WILKERSON, L. \& IRBY, D.M. (1998). Strategies for improving teaching practices: a comprehensive approach to faculty development. Academic Medicine, 73: 387-96

46. RIPPEY, R.M. (1981), The Evaluation of Teaching in Medical Schools. New York: Springer

47. IRBY, D.M. (1993). Faculty development and academic vitality. Academic Medicine, 68: 760-63

48. WOOLFOLK, A.E. (t998), Educational Posbology. 7 th edn. Boston: Allyn \& Bacon

49. CONN. J.]. (2002). What can dinical teachers learn from Harry Potter and the Philosopher's Stone? Medioal Educarion, 36:1176-81 
Addendum - Chapter I

Characteristics of the professional. 


\section{Characteristics of the professional}

- One who exhibits committment to work as a career, such that his work becomes part of his identity and who places emphasis on public service rather than private profit.

(Friedson, E. (1975). Chapter 3: The Medical Division of Labour. Profession of Medicine: A study of the sociology of Applied Knowledge, 47-70, New York: Dodd, Mead \& Company)

- An individual or group of individuals who apply esoteric knowledge to particular cases. They have undergone an elaborate system of instruction and training, together with admission by examination and other formal prerequisites. They possess and enforce a code of professional ethics and in addition to this exhibit dominance and autonomy rather than collegiality and trust.

(Abbott, A. (1988). Chapter 1: Introduction. The System of Profession. An Essay on the Division of Expert Labon, 1-31, Chicago: University of Chicago Press)

- An individual or group who show belonging to a corporate occupational group with some special skills, and exhibit mobility projects aimed at control of work.

(Abbott, A. (1988). Work, Jurisdiction and Competition. The System of Profession. An Essay on the Division of Expert Labour. 33-58, Chicago: University of Chicago Press)

- One who possesses authority based upon his superior competence i.e. Professional authority, and hence can be depended upon. He also exhibits power and influence.

(Starr, P. (1982). The Social Origins of Professional Sovereignty. The Social Transformation of American Medicine, 3-29, New York: Basic Books)

- A professional is seen as someone who possesses more professional knowledge, but more Talent, Wisdom, Intuition, or Artistry.

(Schon, D.A. (1987). Chapter 1: Preparing Professionals for the Demands of Practice. Educating the Reflective Practitioner. 3-17, San Francisco: Jossey-Bass Publishers) 
- An individual who has undergone certain form of training (for a specified period of time) to perform a particular task or job; a task which is often complex, non-rationalised, but partly recorded and specified. He tends to identify more with his profession than with the organisation where he practises it. Furthermore, one who has control on his own work, and secks collective control (with his colleagues in the profession) on the administrative decisions that affects him (and/or his colleagues).

(Mintzberg, H. (1979). The Design Parameters. The Professional bureaucracy The Structuring of Organisations. 357-358, Prentice-Hall International Editions) 

Chapter 2

THEORETICAL BACKGROUND OF (MEDICAL) EDUCATION 


\section{THE THEORETICAL BACKGROUND OF TEACHING}

\section{INTRODUCTION}

Providing learners with the necessary materials and experiences that will facilitate their individual learning is an important function of the educational process. A number of studies now reflect that the proper understanding of ones clinical discipline alone, is insufficient to make one a good teacher ${ }^{1-6}$. The knowledge of how to teach (didactic knowledge) and knowledge of the general principles of teaching are prerequisite tools for effective teaching. Together, they form the core principles of teaching along with the proficiency in the teacher's clinical discipline. Learning on the other hand, is not an automatic process and in order to teach effectively, a clearer understanding of the different principles of teaching is necessary?. It is important to understand how teaching and learning occurs, what factors are important in the process, and why things (often) go wrong.

At present, the resources that are available for understanding the educational process include the theoretical foundations of learning and instructional theory. They underlie our ability to guide applied research in education as well as analyse and diagnose educational problems. In addition, at a more practical level, there is the knowledge and expertise about the conduct of education, drawn from practical experience and research in educational settings. In this chapter, we shall be concerned primarily with the theoretical foundations of education. The aim is to provide the novice with an idea of a few (important) theoretical concepts of education, which we shall illustrate using basic educational principles. A theoretical and abstract explanation of three processes in education, unrelated to specific educational situations, are described that highlight how:

1. Knowledge is attained and how it is categorized into different forms (Knowledge acquisition)

2. Knowledge is gathered and organized before it is applied. (Knowledge compilation)

3. Learners operationalise the knowledge they acquire (Approach to learning)

\section{KNOWLEDGE ACQUISITION}

Research on the information processing system of the human mind has shown that memory is not a whole piece, but comprises of several major subsystems ${ }^{8.9}$. Aspects of the organisation of memory can therefore be anticipated from a consideration of the ways in which it must contribute to various cognitive activities and the constraints under which it must operate. The most basic constraint is that mental processes take time, and in fact, are very slow when compared for example, to the operation of a computer. A second constraint is that for the information in memory to be useful, it must be organised for retrieval. The process of sifting, classifying and entering information into memory in a way that makes recovery reasonably efficient over time 
is referred to as knowledge acquisition. For a better understanding of this illustration, we refer the reader to the schematic diagram provided in figure $\mathrm{I}$.

Fig. I SChematic Representation OF THE LEARNING PROCESSS

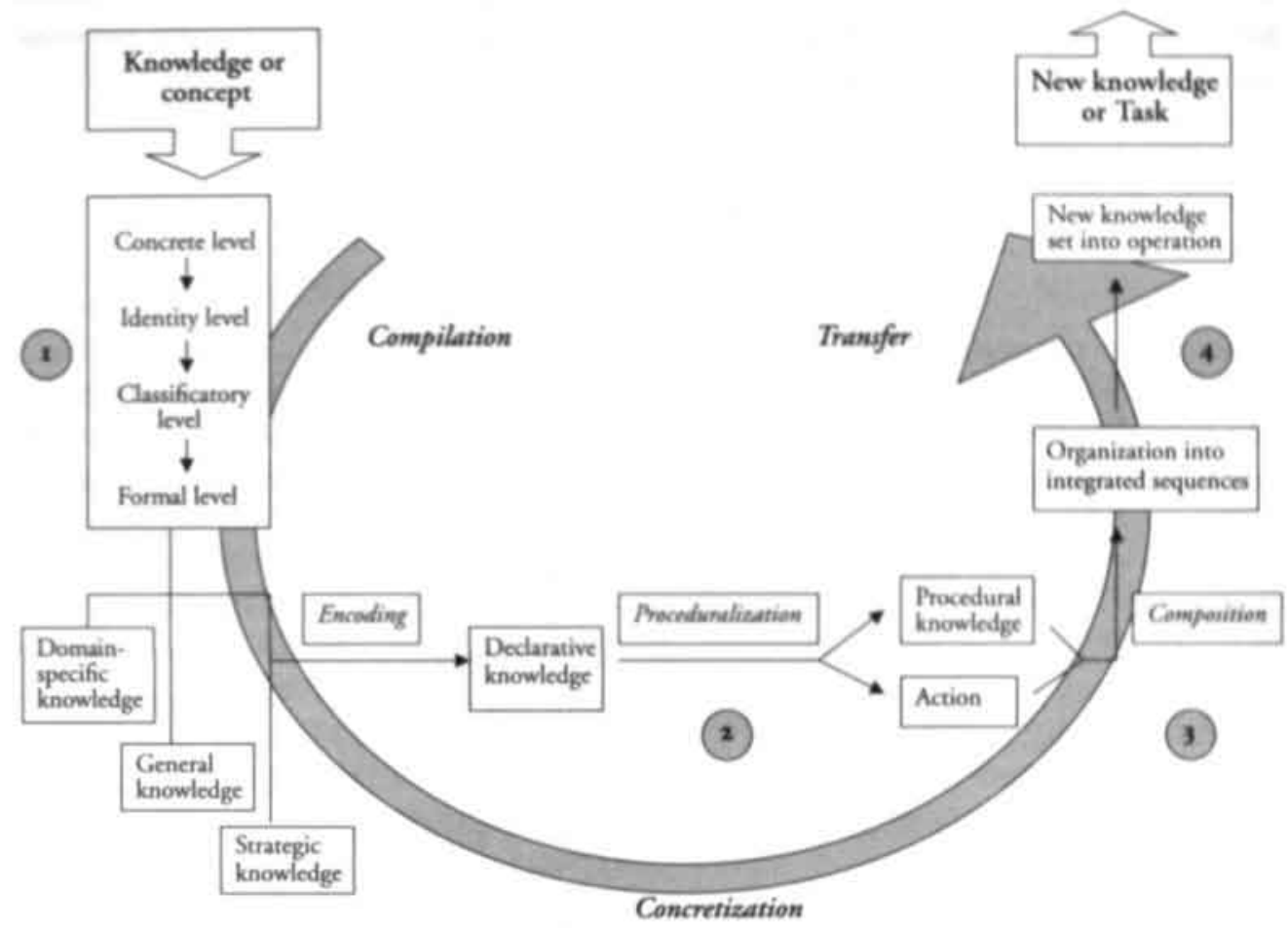

According to Klausmeier ${ }^{10}$, concept attainment (1) occurs at four stages of learning, namely concrete, identity, classificatory and formal levels. These levels of understanding involve discriminating an item as an entity from its surrounding (concrete level) and later recognizing it as the same entity when it is either in the same spatial orientation or other context. Identifying and recognizing the same entity in a different spatial orientation or other context refers to the identity level. Generalizing two or more examples of a concept as equivalent is the classificatory level and being able to apply the concept(s) in understanding a topic and/or solving a problem is the formal level. This formal level completes the process of learning (or conceptualization). A proper understanding of this process therefore, helps the tutor prepare and choose the appropriate strategy for teaching.

When Knowledge is attained, it can be categorized into different conceptual forms i.e. domain-specific, general and strategic knowledge. Domain-specific knowledge refers to information about a specific topic to be learnt, or task to be performed. General knowledge is knowledge that is not directly related to understanding the task to be performed, however essential for the com- 
pletion of the task. Finally, Strategic knowledge is knowledge about the manner in which tasks are completed. It involves the skills of combining the prior two forms of knowledge in such a way as to produce a product satisfactory to the learner and to other potential audiences ${ }^{n}$. When attempting to facilitate effective learning in students, it is important that the different forms of knowledge are appropriately applied. This is because the application of any one of these various forms of knowledge singly or in combination in the learning process determines how easily the topic to be learnt is transferred and acquired".

\section{Knowledge Compilation}

Having discussed how knowledge is attained and differentiated we shall now explain the process of knowledge compilation. There are many theories known that explain this process. A basic similarity these theories share is their explanation of how knowledge is acquired and compiled. They explain that acquired knowledge has to be bundled and packaged in such a way that it is easily retrievable for application by the learner when solving problems ${ }^{12-16}$. In this dissertation, the Neves and Anderson's theory of knowledge compilation ${ }^{15}$ is used to explain this operational process 2. This theory explains, that knowledge is compiled in three steps, which can be described as

1. Encoding, in which a set of facts is committed to memory

2. Proceduralization, in which the facts are turned into procedures

3. Composition, in which procedures are made faster with practice

It further claims that all knowledge is encoded initially as a set of facts within a network that is referred to as declarative knowledge. This declarative knowledge requires time to interpret and to turn into action. Having interpreted and activated the encoded knowledge, it is then utilized i.e. transformed into procedures. This knowledge now becomes procedural knowledge that can be directly executed and requires no interpretation. At this stage of proceduralization, the knowledge becomes implicit in the action, and the memory load diminishes. Having acquired the procedural knowledge, the actions that originate have to be integrated and combined. This combination process is referred to as composition as the procedures learnt are now organized into integrated sequences 3 . The setting into operation of the newly attained procedural knowledge and the performance of new tasks completes this process. At this stage of application, the newly learnt knowledge or skill is put into use $\mathbf{( 4 .}$.

The implication of this educational model is that the performance on any cognitive activity will be awkward and slow in the beginning, since the knowledge is not yet proceduralized i.e. implicit knowledge being put into action. However, if learning proceeds, the knowledge of facts transforms into knowledge of how to use those facts. This new knowledge of how to use facts (i.e. procedural knowledge) then becomes much more readily available for use. The subsequent 
compilation of the available proceduralized knowledge, integrating and (re-) combining them, later results in efficient mental (and procedural) tasks over time. As a result, performance that appears halting initially, improves to a reasonable level of competency over time.

Summarily, going from a macro- to a micro level of organization, knowledge exists in different forms. Attaining these forms of knowledge requires the process of understanding (i.e. conceptualization), which occurs at four different levels (i.e. concrete, identity, classificatory and formal levels). Having attained this knowledge, it is then applied or set into operation. At this operational stage, the process of acquisition has already occurred. However, the way this acquired knowledge is set into operation is influenced by the motivation of students' towards learning.

\section{Approach to Learning}

When dealing with teaching and learning in adult learners, it is important to pay extra attention to the mechanism(s) involved in the actual process of learning. Medical students/residents as learners undergo the processes of transforming and activating their encoded prior knowledge, proceduralizing them and integrating them into combined tasks. This occurs as either an active or passive process whereby the learner can always choose how he/she intends to learn a particular subject or topic. It is therefore useful if the clinical teacher has a prior understanding of how this process occurs and how it is manifested in practice i.e. operationalized. The way learning takes place demonstrates that there is a relation between the learner and the material being learned. This raises the concept of approach to learning that describes the qualitarive aspect of the learning process and how people experience and organize the subject matter of a learning task. Approach to learning is about "what" and "how" learners learn, rather than "how much" they remember.

In the literature, there are two different aspects of the approach to learning that are described. The first aspect refers to deep and surface approaches and is concerned with whether or not the learner is engaged with the learning task or searching for meaning. The second aspect is focuses on the differences in how the learner organizes the information, and if the framework of a task is distorted or segmented ${ }^{17}$. For example if the learner confuses the authors argument with the evidence used to support it, and sees each separate component as a single sequence of "facts" then the approach is referred to as atomistic. On the other hand, if the structure is maintained through integrating the whole and the parts, the approach is then called holistic". 


\section{UNDERSTANDING THE STUDENTS APPROACH TO LEARNING}

\section{Different Approaches to learning}

\section{Deep Approach}

- Intention: To understand the task or concept (Student maintains structure of task)

- Focus on "what is signified" (e.g, authors argument/concepts applicable for solving problem)

- Relate Prior knowledge to new knowledge

- Relate knowledge from different courses

- Relate theoretical ideas to everyday experience

- Relate and distinguish evidence and argument

- Organize and structure content into a coherent whole

- Emphasis in learning is internal
Surface Approach

- Intention: Only to complete task requirements (Student distorts structure of task)

- Focus on "the signs" (c.g. the words and sentences of the text/ the formula to solve the problem)

- Focus on unrelated aspect of the task

- Memorize information for assessments

- Associate facts and concepts unreflectively

- Fail to distinguish principles from examples

- Treat the task as an external imposition

- Emphasis in learning is external

The term "approach", as used in this context, therefore describes a relation between the learner and the learning he or she is doing. It comprises elements of both the situation as perceived by the learner and of the learner himself, and cannot be limited to the sum of the two sets of elements separately. It is about whether the learner is learning unrelated facts/procedures, or learning the facts in relation to the concept. For medical residents as teachers of undergraduate students, it is important for them to understand the distinction between the characteristics of students and the nature of the different approaches to learning. The implication of this runs right through the process of teaching through to the outcome of learning that eventually takes place in the students. It has been shown that the outcome of students' learning and the amount of satisfaction they experience in the process is associated with the approaches used in learning. Students who used deep approaches in learning are found to retain more factual material over a longer period time than those who use surface approaches. Furthermore, while deep approaches are more enjoyable and related to higher quality outcomes and better grades, surface approaches are dissatisfying and are associated with lower grades and poorer outcomes ${ }^{19,20}$. Knowledge of the different approaches to learning may therefore be helpful for equipping clinical teachers with extra didactic skills to teach effectively.

\section{HOW CAN THE KNOWLEDGE OF EDUCATIONAL THEORY}

\section{BENEFIT MEDICAL RESIDENTS}

Generally, medical residents are enrolled in a professional training to become specialists in a particular field of interest. During their training however, they are required to conduct teaching tasks without having had any prior training in teaching. This extra duty is often performed alongside their own personal learning/apprenticeship as physicians. 
It is the assumption in this dissertation, that by educating medical residents in the fundamental theories of education (and also acquainting them with the different forms of knowledge), they shall gain a better understanding of how the process of knowledge compilation occurs within them, as well as in the undergraduate students they teach. The medical residents shall also understand how the information they transfer is processed and would thereby be able to relate better with the learning difficulties of medical students. The medical resident as a teacher, would learn the theoretical principles of teaching and learning, and be equipped with the skills to apply this knowledge in practice.

As teachers, it is assumed that when medical residents are acquainted with the different forms of knowledge described above, they would gain a better understanding of their own knowledge, which they intend to transfer. As learners on the other hand, they would be able to learn and/or improve their individual skills of ordering and compiling knowledge and easily transferring them to others. In summary, medical residents would benefit from the new knowledge as they (would) acquire new skills that enhance their individual learning and teaching. Medical students on the other hand would benefit from the process by the improved quality of teaching they would receive from the medical residents.

\section{REFERENCES}

1. EDINBUGH DECLARATION (1988) Lancet, ii, 462-464

2. SCOPME (1994) Teaching hospital doctors and dentists to teach.

3. SCOPME (1998) Continuing professional development for doctors and dentists: recommendations for hospital consultants and draft principles for all doctors and dentists

4. GMC (1999) The Doctor as Teacher (London, General Medical Council)

5. GIBSON, D.R. \& CAMPBEL.L, R.M. (2000) Promoting effective teaching and learning: hospital consultants identify their needs. Medical Education, 34:126-30.

6. BENOR, D.E. (2000) Faculty development, teacher training and teacher accreditation in medical education: twenty years from now. Medical Teacher, 22: 503-12

7. CONN, J.J. (2002). What can clinical teachers learn from Harry Potter and the Philosopher's Stone? Medical Education, 36:1176-81

8. STERNBERG, S. (1966). High-speed scanning in human memory. Srience, 153: 652-54.

9. ESTES, W.K. (1989). Learning theory. In A. LESGOLD \& R.GLASER (Eds.) Foundation for a Pyychol. ogy of Educations, 1-49 New Jersey: Erlbaum

10. KLAUSMEIER, H.J. (1990). Conceptualizing. In: B.F. JONES \& L.IDOL (Eds.), Dimensions of thinking and cognitive instruction, 139-75. Hillsdale NJ: Erlbaum

iI. GLOVER, J.A., RONNING, R.R. \& BRUNNING, H.R. (1990). The Necessity of Knowledge. In R. Miller (Ed.) Cognitive Pyychology for Teacher, 13-28, New York: Macmillan Publishing company

12. THORNDIKE, E.L. (1932). The fundamentals of Learning. New York: Teachers college, Columbia Universiry 
13. NEWELL, A. \& ROSENBLOOM, P.S, (1981). Mechanisms of skill acquisition and the law of practice. In J.R.ANDERSON (Ed.) Cognitive shills and their acquisition, 251-272, Hillsdale, NJ: Erlbaum

14. UNDERWOOD, B.J. (1957). Interference and forgetting. Pychological revieu, 64: 49-60

15. NEVES, D.M. \& ANDERSON, J.R. (1981). Knowledge compilation: Mechanisms for the automatization of cognitive skills. In J.R.ANDERSON (Ed.) Cognitive skills and their acquirition, 86-102, Hillsdale, NJ: Erlbaum

16. BARROWS, H. (1988). The Tuterial Process. Springfield, IL: SIU School of Medicine

17. RAMSDEN, P. (1992). Chapter 4: Approaches to learning. In Learning To Trach In Higher Education, 38-62, London: Routledge

18. MARTON, F. \& SAL.JO, R. (1988). Describing and Improving Learning, In R.R. SCHMECK (Ed.) Perpectiver on individual Differencer, 53-82, New York \& London: Plenum press

19. MARTON, F. \& SALJO, R. (1984). Approaches to learning. In F. MARTON, D.HOUNSEL.L \& N. ENTWISTLE (Eds.) The experience of learning, 36-55, Edinburgh: Scottish academic press

20. ENTWISTLE, N \& RAMSDEN, P. (1983). Undentanding student learning London: Croom Helm 


\section{Chapter 3}

RESIDENTS PERCEPTION OF THEIR ROLE

IN TEACHING UNDERGRADUATE STUDENTS IN THE CLINICAL SETTING

Jamiu O. Busari, Albert J.J.A. Scherpbier,

Cees P.M. van der Vleuten, Gerard G.M. Essed

Medical Teacher, 2000; 22: 348-53 


\section{SUMMARY}

Fifty-one residents from four major clinical specialties were inter viewed using a questionnaire to assess how they perceived their teaching responsibilities toward undergraduate medical students. The residents' teacher characteristics, teaching effectiveness and abilities in certain aspects of teaching were examined. The residents perceived themselves as good teachers with adequate teacher characteristics. However, they rated themselves better as clinicians than as teachers. They scored themselves highly on attitude towards medical students (interpersonal skills) and technical skills.

Their perception of teaching was significantly influenced by their clinical knowledge and their clinical ability. Communication was the best predictor of overall perceived teaching effectiveness. The residents agreed, however, that their teaching skills could be improved.

\section{INTRODUCTION}

In the past three decades, interest in the teaching tasks of residents has increased'. The teaching load and responsibilities that residents have been made to take up in recent times have increased, resulting in them playing a more conspicuous role in (clinical) medical education. A few studies have explored what residents themselves think of this often unexpected but added burden of teaching ${ }^{2}$. These studies have shown that residents enjoy teaching, would prefer to teach more if service responsibilities were reduced, and feel that teaching improves their medical knowledge'. Residents' confidence as teachers has been correlated with certain attitudes toward teaching ${ }^{\dagger}$ and confident resident teachers have been characterized as individuals, who prefer to give and take orders'. Studies evaluating medical students' expectations and opinions of residents as tutors showed that a high number of students felt that the resident contributed significantly to their medical training in all the services ${ }^{6}$. Students conceded that as much as $25-30 \%$ of their training was derived from rounds with residents. At the same time they indicated that each department should have minimum requirements regarding the residents' teaching responsibilities.

Although it has been shown that residents like to teach ${ }^{3-5}$, residents' teaching skills, unlike other clinical competences, are not explicitly evaluated in most graduate training programmes? Some investigators have argued that, if the teaching role is regarded as an important element in the graduate training programme, earlier and more gradual preparation of the medical student or beginning resident for that role is needed ${ }^{\mathrm{s} .}$.

Residents are apparently routinely involved at various levels in teaching medical students. However, from the studies conducted so far, it is not clear if all residents perceive their teaching role uniformly. The aim of our study was to identify how residents perceive these teaching responsibilities and to explore ways of improving their teaching. We were of the opinion that there is a need for greater acknowledgement by medical schools of residents' teaching responsibilities 
and for the development of strategies whereby residents are better prepared and can effectively teach medical students alongside their clinical work. We explored the way residents perceived their teaching activities by focusing on a number of issues and examined for differences that might be of interest for further research, bearing in mind the differences between residents in clinical specialiry, experience, and demographic characteristics. The issues we investigated were categorized and formulated as the following questions:

- What are the perceived potential benefits of teaching tasks to residents' clinical competence?

- Do residents feel a need for guidance with respect to their teaching responsibilities?

- What factors influence residents' desire to teach?

- What factors contribute to residents' effective teaching?

- What attributes do residents (dis)approve of in the attitudes of medical students?

\section{Methods}

The subjects in the study were clinical residents in the departments of surgery, obstetrics and gynaecology, paediatrics and internal medicine at the teaching hospital of the University of Mastricht, The Netherlands. Informed consent was sought from the heads of all the participating departments, the clinical coordinators, and from the participants through the representative body of the hospital's clinical residents.

A questionnaire was developed to assess teaching in the clinical setring, adapted from that used by Bing-You \& Harvey ${ }^{10}$. Our questionnaire contained two sections. The first section comprised demographic items on the respondents and the second section consisted of two components examining the 'resident as a teacher'. The first component contained items reflecting ( 1 ) teacher characteristics and (2) aspects of teaching. The teacher characteristics included knowledge, technical skills, clinical judgement, clinical skills and attitude. Aspects of teaching that were examined included residents' perceptions of their teaching tasks and how they would evaluate themselves as tutors and clinicians. The second component consisted of 20 items rating perceived teaching effectiveness in the following areas: communication, clinical skills, attitude and teaching skills. All these items used a Likert scale ranging from strongly disagree (I) to strongly agree (s). At the end of the questionnaire, there was an open-ended section for comments on areas where the residents encountered problems when teaching students, namely, communication, attitude, knowledge and skills.

\section{STATISTICAL ANALYSIS}

Cronbach's alpha was used to examine the internal consistency of the questionnaire. Mean scores of residents' perceptions of teaching characteristics were calculated, and of their percep- 
tions of overall teaching effectiveness. Analysis of variance (ANOVA) was carried out to examine for any significant differences across the clinical specialities.

Spearman rho rank-order correlations were used to identify any relationship among the residents' desire to teach, specific individual attitudes and teaching behaviours. This was also done for the overall perceived teaching effectiveness and characteristics of effective teaching. Multiple regression analysis was used to determine which factors best-predicted residents' desire to teach and their perceived teaching effectiveness. Chi-square tests were used to assess the association between residents' perceptions of teaching students and their demographic characteristics. Fisher's exact test was used where indicated.

\section{RESULTS}

Out of 69 residents eligible to participate in the study, 51 residents (surgery $=13$ [65\%], internal medicine $=11$ [50\%], paediatrics $=14$ [100\%], obstetrics and gynaecology $=13[100 \%]$ ) completed and returned the questionnaires. The total response rate was $74 \%$. The tests of reliability on the items in the questionnaire revealed a high internal consistency. The cluster of items on residents' perceptions of overall teaching effectiveness yielded an alpha of 0.81 ; perceptions of effective teaching characteristics gave alphas of 0.75 on communication, 0.73 on clinical skills, 0.81 on attitude and 0.68 on teaching skills. The reliability coefficient for the entire questionnaire was 0.91 . Table I gives the residents' demographic characteristics.

Thirty-five (75.5\%) residents claimed to have had some prior teaching experience. The prior teaching experience referred to, however, were related to teaching activities on the wards with medical students and nursing staff. None of the residents had received any formal teaching instruction.

The results revealed that all the respondents had undergone or still were in the pre-residency phase of their professional training, i.e. the phase of clinical training prior to the graduate specialization programme. The mean period spent in pre-tesidency was 2.02 years ( $S D=1.36$ ), and, based on the number of years after graduation, $24(48 \%)$ of the residents had 4.5 (or less) years of clinical experience (mean $=1.52 \mathrm{yrs}, \mathrm{SD}=0.5 \mathrm{1}$ ). A relatively large number of the residents were graduates from the University of Maastricht $(n=12,24 \%)$. Owing to the unequal representation of residents from other medical institutions $(\mathrm{n}=39,76 \%$ ), these residents were combined into one group for data analysis. There were no significant differences between residents from Maastricht and those from other institutions. 


\section{Table I. Characteristics of residents}

\begin{tabular}{|c|c|c|}
\hline Category & Number $(n=51)$ & Percentage (\%) \\
\hline \multicolumn{3}{|l|}{ Sex } \\
\hline Male & 22 & 43 \\
\hline Female & 29 & 57 \\
\hline \multicolumn{3}{|l|}{ Prior teaching experience* } \\
\hline Yes & 12 & 26 \\
\hline No & 35 & 74 \\
\hline \multicolumn{3}{|l|}{ Department } \\
\hline Paediatrics & 14 & 28 \\
\hline Obs. \& Gyn. & 13 & 25 \\
\hline Internal Medicine & $n$ & 22 \\
\hline Surgery & 13 & 25 \\
\hline \multicolumn{3}{|l|}{ Level of residency } \\
\hline Pre-residency & 9 & 18 \\
\hline Residency & 42 & 82 \\
\hline \multicolumn{3}{|l|}{ Years of clinical experience" } \\
\hline 4.5 years or less & 24 & $4^{8}$ \\
\hline$>4.5$ years & 26 & $\$ 2$ \\
\hline \multicolumn{3}{|l|}{ School of graduation } \\
\hline Univ. of Maastricht & 12 & 24 \\
\hline Others & 39 & 76 \\
\hline
\end{tabular}

Note: * Percentages adjusted for missing values.

\section{Residents' perception of their teacher characteristics}

Table 2 presents the residents' self-evaluations of their teacher characteristics. In general, the residents rated their teacher characteristics as fair to good (on a scale from very poor [1] to very good [5]), and in particular they gave themselves good ratings for attitude (mean $=4.06, \mathrm{SD}=$ $0.56)$ and technical skills (mean $=4.04, S D=0.73$ ). Their perception of their teaching ability was rather neutral (mean $=3.42, \mathrm{SD}=0.64$ ), while their self-ratings as clinicians were much more positive (mean $=3.77, \mathrm{SD}=0.47$ ). Spearman's rank order showed significant correlations between all the teaching characteristics and overall perceived teaching effectiveness at the o.or level. Also, there was a significant correlation observed between residents' ratings of themselves as teachers and as clinicians $(r=0.49, p=0.01)$. Multiple linear regression analysis revealed that possessing adequate clinical knowledge and perceived clinical ability were the characteristics that best predicted residents perceptions of good teaching $(F=20.1, p=0.00$ ). These characteristics accounted for $47 \%$ of the total variance, $\left(R^{2}=0.472\right)$. A breakdown of the results by clinical speciality and demographic characteristics did not reveal any significant relationship. 
Table 2. RESIDENTS' PERCEPTION OF THEIR TEACHER CHARACTERISTICS

\begin{tabular}{|l|c|c|}
\hline & \multicolumn{2}{|c|}{ Residents' self evaluations } \\
\hline Residents' teacher characteristics & Mean & sd \\
\hline Knowledge of medical science & 3.55 & 0.73 \\
Knowledge related to resident' clinical domain & 3.65 & 0.64 \\
Attitude (e.g. interpersonal skills) & 4.06 & 0.56 \\
Technical skills (e.g. clinical procedures) & 4.04 & 0.73 \\
Clinical skills (e.g. physical exams) & 3.94 & 0.48 \\
Clinical judgement (e.g. patient management) & 3.77 & 0.47 \\
How would you rate your ability as a teacher & 3.42 & 0.64 \\
How would you rate your ability as a doctor/clinician & 3.77 & 0.47 \\
Overall teaching effectiveness & 3.75 & 0.39 \\
\hline
\end{tabular}

Noter: $n=4^{8}$ ratings: 1 = very poot, 5 = very good. * Best predictors of residents' teacher characteristics $\left(R^{2}=\right.$ 0.47).

\section{Factors influencing desire to teach}

'Table 3 presents the results of the Spearman rank correlation between residents' perceptions of effective teaching and several factors that influence their desire to teach. Only the statistically significant factors are listed. Residents' speciality, residency level and prior teaching experience were not significantly associated with residents' desire to teach. Also, departmental emphasis on teaching, prior training in teaching, knowledge of the medical school's medical curriculum and formal evaluation of their teaching responsibilities by faculty were not significantly associated with desire to teach. The factors that were significantly correlated with residents' desire to teach were those related to their enjoyment of working with and teaching medical students/peer s, their ability to communicate easily with medical students, and their attitude towards their role as teachers. Factors that best predicted residents' desire to teach were residents perceiving their clinical knowledge as being adequate for teaching and their being able to give positive feedback and praise to medical students for good performance/knowledge $(\mathrm{F}=20.4, \mathrm{p}=0.00)$. In the multiple stepwise regression analysis, the latter two accounted for $55 \%$ of the total variance $\left(\mathrm{R}^{2}=0.549\right)$. 


\section{Table 3. FACTORS CORRELATING WITH RESIDENTS' DESIRE TO TEACH}

\begin{tabular}{|l|c|}
\hline Variables & $r$ \\
\hline Teaching & \\
I enjoy working with and teaching medical students/peers & $0.43^{* *}$ \\
I feel that my knowledge in the area that I am expected to teach is adequate & $0.66 *$ \\
Managing medical students' clinical learning experiences is a role that suite me & $0.57^{* *}$ \\
Communioation & $0.66^{* *}$ \\
I possess adequate knowledge of my specialty to be able to teach medical students & $0.42^{* *}$ \\
I am comfortable pointing out deficiencies in a student's knowledge/performancet & $0.56^{* *}$ \\
I am comfortable praising a student's knowledge/performance & $0.52^{* *}$ \\
I can communicate easily with medical students & \\
Atritude & $0.67^{* *}$ \\
I am confident in my role as a teacher & \\
I am comfortable when a student confronts me regarding medical suggestions I have & $0.40^{* *}$ \\
made & $0.52^{* *}$ \\
I feel that students respect my clinical knowledge & $0.14^{*}$ \\
I give students the opportunity to ask me questions & \\
Skills & $0.48^{* *}$ \\
\hline
\end{tabular}

Note: "p $<0.05$, " $\mathrm{p}<0.01$.

† Factors that best predicted residents' desire to teach $\left(R^{2}=0.55\right)$.

\section{Residents' perceptions of effective teaching}

As shown in Table 4, all four components of effective teaching showed significant correlations with the residents' perceptions of overall teaching effectiveness. Communication, however, demonstrated the strongest association. Multiple regression was performed to identify which (combination of) component(s) was a good predictor of perceived teaching effectiveness. Communication was shown by the residents to be the best predictor of overall perceived teaching effectiveness ( $F=40.10, p=0.00$ ), accounting for $55 \%$ of total variance ( $R^{2}=0.548$ ). Addition of the other components did not significantly improve the prediction. The residents were asked a number of specific questions to evaluate how they perceived their teaching responsibilities (Table 5). Residents disagreed that they were better suited for teaching medical students than full-time attending staff (mean $=2.5$ ) and agreed that their teaching skills could be improved (mean $=3.98, \mathrm{SD}=0.87$ ). They also claimed to regularly provide prompt and systematic feedback to medical students on their performance (mean $=3.31, \mathrm{SD}=0.56$ ). This variable showed a significant positive correlation with attitude and clinical specialities of residents and also with their perceived knowledge of the undergraduate medical curriculum of the university (problembased curriculum). Although $61 \%$ of the residents felt that their departments should emphasize their teaching roles, only $31 \%$ of them felt that their teaching abilities should be considered in 
their annual evaluation during residency; $51 \%$ of the residents felt that prior training in teaching skills might have been helpful for them in teaching medical students.

\section{Table 4. COMPONENTS OF TEACHING CORRELATING WITH RESIDENTS' OVERALL PERCEIVED TEACHING EFFECTIVENESS}

\begin{tabular}{|l|c|}
\hline Components of teaching & $r$ \\
\hline Teaching & $0.31^{*}$ \\
Communicationt & $0.71^{* *}$ \\
Atritude & $0.52^{* *}$ \\
Clinical skills & $0.35^{*}$ \\
\hline
\end{tabular}

Note: "p $<0.05, " * p<0.01$.

$\uparrow$ Component of teaching that best predicted overall perceived teaching effectiveness $\left(R^{2}=0.55\right)$.

Chi-square tests revealed that residents' perceptions of the benefit of prior training in teaching was not independent of their clinical speciality $\left(\mathrm{R}^{2}=10.5, \mathrm{P}=0.015\right)$ and residency level $\left(\mathrm{R}^{2}=\right.$ 5.16, $\mathrm{p}=0.02$, Fisher's exact test $=0.05)$. Significantly more residents in obstetrics and gynaecology overall perceived teaching effectiveness did not feel prior training might have helped them, more residents in paediatrics felt that it might have helped, while roughly half the residents questioned in internal medicine and surgery felt so. Examination of the residency level of the respondents showed that $56 \%$ of the residents in the residency programme did not feel prior training might have helped them, while $87.5 \%$ of the residents in pre-residency did feel so. Asked if they understood the educational approach and the curriculum in the first four years of the medical school, $57 \%$ of the residents claimed they did. The residents felt that teaching medical students helped them to be better clinicians (mean $=3.49, \mathrm{SD}=1.08$ ), and also felt that literature on teaching could be helpful to them in improving their teaching skills (mean $=3.00, \mathrm{SD}=$ 0.85 ). There were no significant correlations observed between these factors and their perceived teaching abilities. The residents were asked how much time they spent on average in teaching medical students per day. They claimed they spent 1.29 hours per day out of the allocated time for their normal clinical work and learning, but the standard deviation was quite large (1.36). The ideal teaching time per day perceived by the residents was $1.52 \mathrm{hrs}(\mathrm{SD}=0.89$ ). Spearman's rank-order correlation revealed a significant relationship berween the average time residents spent in teaching and their perceived ideal time for teaching.

\section{What residents (dis)approve of in teaching medical students}

In the open section of the questionnaire, the residents were asked to comment on the difficulties often encountered when teaching medical students in the areas of communication, artitude, knowledge and clinical skills, and to provide brief explanations. Their responses revealed that 
they very often encountered difficulties with regard to the medical students' level of knowledge. Analysis of their comments showed 'the lack in students' knowledge of basic sciences' as cited most frequently. Though they claimed that the knowledge of medical students improved as they progressed in the clerkship, the residents felt that medical students spent insufficient time studying and had difficulty applying learned theoretical concepts to clinical practice.

In general, communicating with medical students, their attitude and their clinical skills gave no rise to concern for the residents. They particularly found that the medical students' practical clinical skills were adequate during their rotations. A few problems highlighted, however, were related to medical students' participation in patient management, e.g. paucity of initiative and interest on the wards, absentecism and passive participation. Other problems were related to uncertainty, shyness and fitting into the clinical setting as well as the professional language medical students were exposed to. Spearman's rank-order correlations revealed no significant correlation between these factors and the residents' perceived teaching effectiveness or desire to teach. 


\section{Table 5. RESIDENTS' RESPONSES TO VARIOUS ASPECTS OF TEACHING MEDICAL STUDENTS}

\begin{tabular}{|c|c|c|c|c|c|}
\hline \multirow[b]{2}{*}{ Aspect of teaching } & \multicolumn{5}{|c|}{ Residents' responses } \\
\hline & & Mean & sd & $n$ & $\$ 6$ \\
\hline $\begin{array}{l}\text { - Residents are more suited than full-time attending staff for } \\
\text { teaching medical studentst }\end{array}$ & & 2.50 & 1.07 & 51 & NA \\
\hline - I feel that my teaching skills could be improved $†$ & & 3.98 & 0.87 & 51 & NA \\
\hline - I feel that my teaching helps me be a better cliniciant & & 3.49 & 1.08 & 51 & NA \\
\hline $\begin{array}{l}\text { - Literature on teaching could be helpful to me in improving my } \\
\text { teaching skillst }\end{array}$ & & 3.00 & 0.85 & 51 & NA \\
\hline $\begin{array}{l}\text { - I give medical students direct and systematic feedback on their } \\
\text { performancett }\end{array}$ & & 3.31 & 0.56 & $4^{8}$ & NA \\
\hline $\begin{array}{l}\text { - How much time in hours (average) do you spend in teaching } \\
\text { activities per day }\end{array}$ & & 1.29 & 1.36 & 49 & NA \\
\hline $\begin{array}{l}\text { - How much time (average) would you ideally wish to spend in } \\
\text { teaching activities per day }\end{array}$ & & 1.52 & 0.89 & 43 & NA \\
\hline - Should your department emphasise your role as a teacher? & Yes & & & 30 & 61 \\
\hline & No & & & 19 & 39 \\
\hline - Should your teaching abilities constitute part of your evalua- & Yes & & & 16 & 31 \\
\hline rion each year? & No & & & 35 & 69 \\
\hline - Would prior training in teaching skills have been helpful for & Yes & & & 23 & $\$ 1$ \\
\hline you? & No & & & 22 & 49 \\
\hline & Yes & & & 28 & 57 \\
\hline $\begin{array}{l}\text { - Do you understand the method of teaching the curriculum of } \\
\text { this medical school requires? }\end{array}$ & No & & & 21 & 43 \\
\hline
\end{tabular}

Notes: $\uparrow \mathrm{t}$ - strongly disagree, $5=$ strongly agree; $\dagger+1=$ never, $5=$ always; NA $=$ not applicable.

\section{Discussion}

It has been shown in prior studies that residents wish to teach and would prefer to devote more time to teaching than they actually $\mathrm{do}^{\text {s. }}{ }^{10}$. Our findings support this. In our study residents perceived themselves as good teachers and felt that they possessed adequate teacher characteristics to teach medical students. The characteristics on which they rated themselves highly were their attitude towards the students (interpersonal skills) and their technical skills in performing certain clinical procedures. Our findings showed that residents rated themselves much better as clinicians than as teachers. Their perception of teaching was significantly influenced by how they perceived themselves as clinicians, as well as by their perceived clinical proficiency and abilities in their related speciality. We could not examine how prior training in teaching might have influenced their perception as teachers, since we could not compare groups of residents with and without formal training in teaching. 
The residents agreed that teaching medical students helped them improve their clinical skills, which supports the findings of other studies' ${ }^{10}$, and also that their teaching skills could be improved. With regard to the different clinical specialities, more residents in obstetrics and gynaecology did not feel prior training would have helped them, while more of their counterparts in paediatrics did take this view. We have no explanation for this finding. The residents also felt that they were not better suited than teaching staff to teach medical students. This finding was contrary to our expectation based on the recommendations by Steward \& Feltovich (1988)". Our results revealed that the residents' desire to teach was characterized by their enjoyment in working with medical students and their ability to communicate easily with them. Their proficiency in their respective clinical domains and ease with pointing out students' deficiencies were the strengths identified as influencing desire to teach.

The respondents in our study agreed that teaching and evaluating medical students are important responsibilities of a resident. However, there was a wide variability observed in their responses and the correlation was poor with their desire to teach. This agreed only in part with the findings of Bing-You $\&$ Harvey ${ }^{10}$, in which the residents felt teaching and evaluating medical students were important responsibilities for residentsı. The results on perceived teaching effectiveness showed that, in general, residents felt they were effective teachers and that teaching effectiveness correlated best with their ability to communicate easily with students. The other components of teaching examined, i.c. attitude, clinical skills and teaching skills, correlated significantly with their perceptions on teaching effectiveness.

Our results provide no evidence that the clinical specialities, level of residency, sex, or any other demographic variable influenced residents' perceived teaching effectiveness. Another interesting finding is that residents feel that their teaching roles should be emphasized by their clinical departments but should not form part of their evaluation during the residency programme. If teaching conditions were ideal, residents claimed they would wish to spend I.s hours per day teaching medical students alongside the allocated time for clinical work. Our study showed that, on average, they spent 1.3 hours per day teaching medical students on the wards. However, the results also revealed a wide variability in the number of hours they would wish to spend in teaching and the number of hours they actually did spend in teaching.

Residents judged the knowledge of medical students as an issue of concern, particularly in the area of basic medical sciences. They claimed that medical students spent insufficient time studying and had difficulty applying prior learned theoretical concepts in practice in the clinical setting. There were no difficulties encountered with the attitude of medical students, their clinical skills and in communicating with them. None of the mentioned attributes had any influence on residents' teaching effectiveness or desire to teach.

In conclusion, this study demonstrates that residents perceive teaching medical students as beneficial for them. It shows that residents acknowledge the need for training and guidance to teach more effectively. Communication, adequate knowledge and proficiency in domain-related skills are factors that influence resident' desire to teach as well as effective teaching. The results show that clinical speciality and level of residency do not influence the perceived teaching ef- 
fectiveness and desire to teach. On the other hand, a number of findings in this study require further in-depth investigation. Contrary to the expectation that residents should feel better suited than faculty staff to teach medical students, they felt otherwise. This finding suggests that it may be necessary to validate the assumption that residents (should) feel better suited to teach medical studentsir. A way to do this would be to compare the findings from this study with students' views on residents' teaching. Such a study would also enable a comparison between perceived teaching effectiveness and actual teaching effectiveness.

Apart from the size of the study groups, further research should explore other factors that may explain the difference. The same conclusion holds for the finding that more residents in obstetrics and gynaecology felt that they did not need prior training in teaching as opposed to their counterparts in paediatrics. The residents' wish for more departmental acknowledgement of their teaching roles yet not wanting it to form part of their evaluation appears contradictory. Since they are very likely to be involved in teaching medical students later on in their professional career, it is logical to assume that there is a need for additional training on how to teach, as well as increased departmental emphasis on teaching. Equally, we believe that there should be some form of evaluation (formative/summative) to assess the quality of what is being taught. Finally, there is also a need to find out why the residents' actual and ideal teaching times exhibited a wide variability.

The attention that has been devoted in recent years to methods of evaluating residents' teaching and ways of improving their teaching demonstrates the important role of teaching by the resident-teacher. Our study not only reaffirms the importance of evaluating residents' teaching abilities, but also demonstrates the need for developing structured training programmes for residents prior to or during residency. Like other studies ${ }^{3-5}$, we have shown that residents like and wish to Teach medical students. They feel that prior training in teaching might be helpful for them in teaching medical students. Based on the findings from this study, a number of issues have been generated which require in-depth investigation. The objective of our proposed supplemental qualitative study will be not only to clarify these issues, but also to develop a strategy for a teacher-training programme based on the residents' recommendations.

\section{Practice points}

\section{Residents:}

- crijoy teaching

- see themselves as good teachers

- rate themselves higher as clinicians than as teachers

- do not wish their teaching role to be included in residency cvaluation

- want more attention for their teaching workload

- think that medical students have difficulty applying theoretical concepts in practice

- expect their teaching performance to benefir from additional training 


\section{REFERENCES}

1. BARROW, M.V. (1965). The house officer as a medical educator. Jeurnal of Mndical Edwoation, 40: 712 14.

2. BROWN, R.S. (1970) House Staff Artitudes toward Teaching, Journal of Medical Edwation, 45: 156-59

3. APTER, A. METZGER, R. \& GL.ASSROTH. J. (1988), Residents' perception of their role as teachers. Journal of Medical Education, 63: 185-88.

4. GREENBERG, LW., GOLDBERG, R.M. \& JEWETT, L.S. (1984) Teaching in the clinical setting: factors influencing residents' perceptions, confidence and behavior. Mndioal Edwation, 18: 360-65.

5. JEWETT, L.S., GREENBERG, L.W. \& GOLDBERG. R.M. (t982). Teaching residents how to teach: a one year study. Journal of Medical Edwcation, 57: 36t-66.

6. BARROW, M.V. (1966) Medical students' opinions of the house officer as a medical educator. Jeicrnal of Medical Education, 4: 807-810.

7. ANDERSON, K., ANDERSON, W. \& SCHOLTEN, D, (1990) Surgical residents as teachers. Currmt Sargerin, $47(3): 185-88$.

8. TONESK, X. (1979). The house officer as a teacher: what schools expect and measure. Journal of Medical Education, 54: 615-16.

9. DUNNINGTON, G.L. \& DAROSA. D. (1998). A prospective randomised trial of a residents-as-teachers training program. Academic Medicine, 73: 696-700.

10. BING-YOU, R.G. \& HARVEY, B.J. (1991). Factors related to residents' desite and ability to teach in the clinical setting. Teaching and Learning in Medicine, 2: 95 -100

11. STEWARD, D.E. \& FELTOVICH, P.J. (1988), Why residents should teach: the parallel processes teaching and learning, In J.C. EDWARDS \& R.L. MARIER (Eds.) Clinical Teaching for Medical Residents: Roles, Techniques and Programs, 3-14, New York: Springer Verlag. 



\section{Chapter 4}

HOW RESIDENTS PERCEIVE THEIR TEACHING ROLE IN THE CLINICAL SETTING: A QUALITATIVE STUDY

Jamiu O. Busari, Katinka J.A.H. Prince, Albert J.J.A. Scherpbier, Cees P.M. van der Vleuten, Gerard G.M. Essed

Medical Teacher, 2002; 24: 57-61 


\section{SUMMARY}

Residents play an important role in teaching and they consider teaching medical students as one of their primary responsibilities. Teaching is, however, limited due to lack of teaching skills and the time constraints involved in preparing and conducting teaching. Eighteen residents involved in teaching medical students and who took part in an initial study on teaching were interviewed on the perceived benefits of teaching and the role of residents in the teaching process. They also provided recommendations on how a training programme for residents could be created. The findings showed that enthusiasm and enjoying teaching were qualities of good teachers. Lack of time and support from attending staff were factors that contributed considerably to poor quality of teaching. There was a need for basic teaching skills and the recommendations provided included literature on teaching, training workshops, constructive evaluation and feedback and interactive sessions with experts.

\section{INTRODUCTION}

It is known that residents play an important role in teaching, and in many educational institutions the attention is focused not only on developing training programmes for residents to improve teaching but also on the strategies for implementing such programmes ${ }^{1-3}$. The perceptions of residents on their teaching roles show that they contribute significantly to the training of medical undergraduates ${ }^{4}$, and that they also benefit from teaching medical students. In an earlier study we investigated how residents perceived teaching medical undergraduate students. Our goal was not only to investigate the residents' perceived benefits in teaching, but also to gain more insight in the needs of residents for training and guidance to teach more effectively ${ }^{6}$.

We found that, despite the general assumption that teaching is an important role for residents, residents themselves did not share this opinion. They wished for more departmental acknowledgement of their teaching roles, yet they did not want these roles to be included in their evaluation. They demonstrated a willingness to teach medical students, and yet did not wish to be evaluated for their teaching roles. The study also supported the findings of Apter et al. residents perceived teaching medical students as beneficial for themselves and acknowledged the need for training and guidance to teach effectively. More residents in obstetrics and gynaecology, however, felt that they did not require prior training in teaching. The study also showed that residents' perception of teaching is significantly influenced by their clinical knowledge and their clinical ability, while communication, adequate knowledge and proficiency in domainrelated skills are also factors that influence their desire and ability to teach. They claimed they would ideally wish to spend 1.5 hours/day teaching medical students, although a substantial variation in the individual values was found ranging from 0.5 to 2 hours. As suggested by Stewart \& Feltovich?, we expected that because residents are recent graduates and closer to medical students they should feel better suited to teach medical students than faculty staff. The findings 
from our initial study did not support this claim and generated a number of questions requiring further explanation:

(t) Why do the residents not feel better suited than the medical staff to teach medical students as suggested by Stewart \& Feltovich??

(2) Why do some residents feel that they do not need prior training in teaching and others that they do?

(3) Why do the residents wish for more departmental acknowledgement of their teaching roles and yet do not want it to form part of their evaluation?

(4) Why was there a wide variability in the actual and ideal teaching times the residents provided?

In an attempt to find the answers to these questions, we decided to conduct a qualitative study. We selected residents who had provided exceptional responses to an item or category in the questionnaire from our initial study (extreme/deviant case sampling) ${ }^{6}$. The qualitative study was aimed at searching for in-depth reflective descriptions that would explain and further clarify the four questions generated above, as well as provide answers to three main research issues, namely:

(x) What is the role of the resident in teaching undergraduate medical students?

(2) Is there need for formative and/or summative assessment of teaching?

(3) How can the teaching skills of residents be improved?

\section{MethoD}

In our initial study, more residents in paediatrics felt that (prior) training in teaching might be of benefit to them in teaching medical students, while more residents in obstetrics and gynaecology felt otherwise 6 . Residents from the departments of surgery and internal medicine were equally split on this factor. We therefore chose to select the participating residents from the departments of paediatrics and obstetrics and gynaecology. The residents selected were those who provided exceptional responses to teaching time (i.e. extremely short or long hours for teaching: $<1$ hr or $>2$ hrs) compared with their colleagues. The study was carried out at the teaching hospital of the University of Maastricht, the Netherlands. Eighteen residents involved in teaching medical students and who took part in our initial study were selected; to residents were from the department of paediatrics and eight from the department of obstetrics and gynaecology. Prior to implementation of the study, written informed consent was sought from the heads of the respective departments and the participaring residents. The study was carried out through interviews and the respondents were expected to provide answers to specific questions on teaching undergraduate students in the clinical setting. The residents were also expected to elaborate on their answers provided in the initial study related to the benefits of teaching and the role of residents in the teaching process. The interviews, which lasted $1-2$ hours, were conducted by one interviewer using an interview format based on the findings from our quantitative study. 
The respondents were required to elaborate and clarify their initial responses to the items in the interview format, and also provide recommendations on how a training programme for residents could be created. The interviewer, guided by the interview format, could direct questions in such a manner as to facilitate more elaboration and insight on the respondents' answers.

The scripts from the interviews were analysed in four stages. In the first stage all the scripts were read and modified for readability. The second stage involved studying the script and identifying important comments relevant to the objective of the study. After identifying these comments, they were summarized into phrases that best described their content. Finally, these phrases were clustered together to form themes and these themes were appropriately allocated to subsections of the interview format.

An example of such an edited comment in the phrase 'importance of teaching' was as follows:

- Phrase: 'Residents stimulated to reflect on clinical knowledge.'

- Theme: 'Residents are involved in a learning process.'

- Subsection of interview format: 'Teaching medical students is a primary responsibility of the resident.'

Two investigators carried out the analysis independently. Their independent results were compared and the identified phrases common to both investigators were used for further analysis.

\section{Table I. INTERVIEW FORMAT}

1. Importance of teaching

- How would you rate yourself as a teacher?

- Is teaching and evaluating medical students an important role for the resident

- If not, whose is it?

- Do you think residenrs could benefit from a programme that provides an opportunity to imptove teaching skills?

-If allocated the time in your residency for teaching, would you teach medical students?

2. Evaluation of teaching

- Do you feel better suited to teach medical students than teaching staff?

- Why? Do speciality/clinical/teaching experience play a role?

- Does the need for prior training in teaching relate to residents' clinical speciality?

- Why do you not wish to be evaluated for your teaching abilities?

- Under what conditions would you wish to?

- For whom is it beneficial? How $\&$ why?

- In what way does time influence your desire and ability to teach?

3. Recommendations

- How do you think teaching by residents could be improved?

- Give at least three suggestions on how to implement/improve training programmes for residents 


\section{Results}

Of the initial 18 residents selected to participate in this study, ${ }^{10}$ were surveyed. Two residents had completed their programmes and had left the institution, one had switched residency programme, and the remaining five were doing external rotations and were unavailable to be interviewed. Eight of the residents surveyed were female and there was an equal departmental representation (five paediatrics and five obstetrics and gynaecology residents). Three residents had not yet begun the official residency training while the mode of the number of years post graduation was 5 years.

\section{Importance of teaching}

There were a total of $\$ 1$ distinct phrases coded under four subsections in the category "importance of teaching'. In the subsection 'Teaching medical students is a primary responsibility of the resident', the majority of the residents (seven) used the phrase 'residents readily available (more contact)', indicating that the availability of residents on the ward was an important factor contributing to importance of teaching. Five used the phrase '(also) responsibility of the attending staff. In the subsection 'influence of time on teaching by resident', seven respondents used the phrase 'I would teach more if time were available' indicating that available teaching time influenced the perceived importance of teaching. A closer look at the responses on the importance of teaching revealed the following:

- The residents noted that proficiency in teaching was important for effective teaching. The elements (themes) constituting teaching proficiency included:

$\rightarrow$ teaching skills $(\mathrm{n}=5)$;

$\rightarrow$ giving feedback $(n=4)$;

$\rightarrow$ attitude to teaching $(\mathrm{n}=5)$;

$\rightarrow$ teaching experience $(n=5)$;

$\rightarrow$ influence of time $(n=4)$.

Notably, the influence of time on teaching was described using comments such as 'insufficient time to teach', and in one case 'insufficient time to prepare for teaching'.

- The residents acknowledged teaching medical students as a primary responsibility for residents. They supported their views with comments that reflected the benefits of selflearning in the process of teaching $(n=4)$, the unique position of residents $(n=7)$ and that teaching is an integral responsibility of one's function in a teaching hospital $(n=7)$. The residents, however, expressed also that this integral responsibility of teaching medical undergraduates is more a function of the attending staff. They illustrated this point with the argument that residents have less time and insufficient know-how to teach effectively compared with attending staff $(n=5)$.

- They agreed that a programme, which could improve their teaching skill, would be beneficial and should be incorporated into the residency programme. They supported their 


\section{Chapter 4}

views with statements such as 'You learn how to teach and transfer knowledge', 'You learn problem solving skills', 'I would undertake such training if available', 'such training should be incorporated in the beginning of the residency:

- The influence of time on the importance of teaching was reflected by the amount of time available for teaching $(n=9)$; 'I would teach more if time were available', 'More time is spent on clinical responsibilities', 'No extra time available for teaching'. Interestingly, factors motivating teaching influenced the amount of time residents invested in teaching. Some of these factors included the input by students themselves, whether or not residents felt that teaching was part of the residency programme or if they primarily had an inherent motivation towards teaching.

\section{Evaluation of teaching}

In this section we report on the residents' perceptions of their quality of teaching, how they perceived their teaching tasks were being evaluated and how they felt they should be evaluated. A total of $\$$ distinct phrases were coded and sorted into five subsections. The phrase 'Artending staff possess more theoretical knowledge' was used by eight, reflecting why residents did not feel better suited than attending staff to teach medical students, while five used the phrase 'Staff have more teaching experience'. On whether teaching helps residents to be a better clinician, eight used the phrase 'It [i.e. teaching] stimulates critical thinking and reflection' and when asked if the department should emphasize their role as teachers, five of the respondents used the phrases 'Staff nonchalant, give insufficient feedback' and 'need for more clarity and formal teaching responsibilities', respectively. A closer look at the responses on the evaluation of teaching revealed the following:

- Residents provided arguments to support as well as refute the assumption that they are better suited for teaching medical students than attending staff. They backed their disagreement by citing inadequate theoretical (clinical) knowledge and experience in teaching to effectively teach; 'Staff possess more control/oversight in teaching' $(n=2)$, 'Staff have more teaching experience' $(n=4)$, 'Staff possess more theoretical knowledge' $(n=8)$. Arguments used to support this view included the residents' position in relation to students making them readily available on the wards $(n=3)$, good role models $(n=1)$ and being able to relate better to problems students encounter $(n=1)$. Residents were better suited to teach students the practical aspects of clinical work; 'Residents are better for practical aspects of teaching' $(n=3)$, 'Residents are better in coaching students how to clerk patients' $(n=3)$.

- They felt that their teaching skills could be improved, especially as regards how to transfer knowledge to students and how to add more structure to their teaching. Comments included 'lt could help me improve on how to present information' $(n=1)$, 'on how to transfer knowledge' $(n=1)$, 'on how to explain things better and improve my teaching skills' $(n=3)$.

- Residents supported the notion that teaching students helped them in being better clinicians. Their views were supported by comments reflecting the theory that teaching 
stimulated critical thinking and reflection on knowledge $(n=8)$ and that it improved their teaching skills and knowledge $(n=5)$.

- The residents' responses to the departments' role in emphasizing their activities as teachers showed that none of the obstetrics and gynaecology residents supported this view. Poor staff commitment appeared to be a reason: 'Staff nonchalant, give insufficient feedback' ( $(n=4)$, 'Residents made to do the dirty work' $(\mathrm{n}=1)$. 'little guidance/training on how to teach'. Residents in paediatrics supported the view, however, with conditions that there should be improved staff commitment and that teaching responsibilities be clearly defined. In general, departmental emphasis on teaching increased their awareness on teaching and its benefits.

- The residents were prepared to have their teaching abilities form part of their evaluation, provided the evaluation was objective and clearly defined and that there was improved staff commitment. They felt that being evaluated would stimulate learning and improve teaching skills. It was observed again that mainly the paediatric residents shared this view.

\section{Recommendations}

We asked residents for their recommendations on how to improve teaching and what, if necessary, should be included in a teacher training programme. The responses were as follows: Literature on teaching $(n=8)$, training workshops $(n=7)$, evaluation and feedback $(n=3)$ and interactive sessions with experts $(n=3)$ were recommendations made to improve teaching. Their elaborations on the training workshops revealed that these should be integrated into the residency programme $(n=3)$, preferably at an early phase of the residency $(n=2)$ and should constitute (a few hours') training in teaching skills $(\mathrm{n}=2)$. The contents of such training should include:

$\rightarrow$ how to present information;

$\rightarrow$ how to transfer knowledge;

$\rightarrow$ how to explain concepts;

$\rightarrow$ how to give feedback to students.

\section{Discussion}

Although one might begin by questioning the validity of the findings in this study based on the number of residents interviewed, the study being a further exploration of deviant case samples from a larger sample in our initial quantitative study compensates partly for this. We looked for explanations to the four questions raised from the initial study as well as the three research questions, i.e. ( $\mathrm{t}$ ) what is the role of the resident in teaching undergraduate medical students? (2) Is there need for formative and/or summative assessment of teaching? (3) How can the teaching skills of residents be improved?

Remarkably, this study showed that residents consider teaching medical students to be one of their primary responsibilities and that they themselves learn in the process of teaching. Teach- 


\section{Chapter 4}

ing is, however, limited owing to time constraints involved in preparing and conducting teaching as well as a lack in teaching skills.

The views of Stewart \& Feltovich ${ }^{7}$ that residents are in a unique position to teach and evaluate students because of their proximity to the students was also confirmed. Some of the residents' views supporting this included 'Residents are readily available and have more contact with students', 'Residents are in a better position to evaluate students', 'Residents are easily approachable for students', and 'Residents can explain things better from the student's perspective'. Although there was a general agreement that teaching students is a primary responsibility for residents, the lack of adequate know-how and insufficient time for teaching were arguments provided to refute it as their major responsibility and place it as more that of attending staff. Also residents noted that in teaching medical students they were often stimulated to reflect critically on their knowledge. This served as a motivator for them to constantly keep their clinical knowledge up to date and enhanced the process of self-learning.

The results also reflected the fact that residents were willing to participate in training programmes on how to teach more effectively. Effective transfer of knowledge and structured teaching were some of the highlighted needs. They were willing to be evaluated for their teaching activities provided such evaluations were objective and clearly outlined, and provided there is more acknowledgement from faculty and attending staff. Statements used to support this view included 'Yes, provided the form of evaluation is objective and constructive': 'Yes, provided residents' teaching roles are clearly defined'; and 'No, because there is little/no acknowledgement from attending staff on residents' teaching'. Notably, the residents were prepared to have the assessment of their teaching abilities constitute part of their residency programme, although it was a view shared mainly by residents in paediatrics. We examined the content of the responses in the interviews to explain why residents in obstetrics and gynaecology did not share this view and found that there was a general discontent with the commitment to and acknowledgement of teaching from attending staff in obstetrics and gynaecology. Apparently, the educational climate in a department is quite important for the values that residents place on being involved in the teaching process. We could not explain why in our initial study the residents in obstetrics and gynaecology felt that they did not need prior training to be able to teach more effectively. From our findings there was no clear identifiable reason and we can only assume that their response might be in part related to the poor motivation towards teaching due to the educational climate of the department.

We also examined the influence of time on the desire to teach and the quality of teaching as perceived by the residents. There was a general agreement that they were willing to teach more, provided there was more time available. Availability of time was also observed to be a motivator to teach for residents. Currently, residents' time spent teaching medical students comes out of the time actually allocated for normal clinical duties ${ }^{\circ}$.

In our initial quantitative study, we observed a difference between the ideal and actual teaching time given by residents from both specialties. There was wide variation, particularly 
in the amount of time residents in obstetrics and gynaecology claimed they spent on teaching. We were able to explain why there was such a wide variance from some of the explanations the respondents provided in the interviews. The nature of the postings in obstetrics and gynaecology were less homogenous and inconsistent in nature when compared with that of paediatric postings. Obstetrics and gynaecology postings included outpatient clinics, ward-based and surgical rotations compared with the mostly outpatient and ward-based rotations in paediatrics. Furthermore, paediatrics rotations had the unique element of more extensive communication, i.e. with parents (and/or patients) at all times. In obstetrics and gynaecology the length of time needed differed when a patient was being prepared for surgery, being attended to in the outpatient infertility clinics, or during labour. As a result, the amount of time the obstetrics and gynaecology residents claimed they spent teaching medical undergraduates was strongly influenced by the nature of the rotation they were in at the time the survey was conducted. This accounted for the large variance in the amount of teaching time they provided. Obstetrics and gynaecology residents had relatively more time to teach when they were on the wards than during their surgical rotations.

'The residents' recommendations reflected a strong need for guidance and coaching on how to effectively transfer knowledge and give feedback to students. There was a desire for constructive assessment methods of a formative Residents' teaching role in the clinical setting nature and with clearly defined objectives. Furthermore, there was a need for more commitment from attending staff and faculty, and allocation of time for teaching duties.

Finally, this study has raised a number of issues that are worth highlighting. The teaching carried out by residents has not received its due credit and attention. Attending staff and faculty exhibit a general attitude that undermines the residents' position in the (medical) educational process. The findings of Wall \& McAleer show that there are questions on the teaching and guidance being provided by attending staff. Key themes mentioned in their study included 'attending staff giving feedback constructively', 'assessing the trainee', 'assessing the trainee's learning needs', and 'teaching practical skills'. These themes share similarities with some of the comments residents provided in our study. Gibson \& Campbell' also investigated the needs of hospital consultants to promote effective teaching and learning. Their findings showed that enthusiasm and enjoying teaching were qualities of good teachers and that lack of time was a barrier to effective teaching. There was also need for basic teaching skills. Their findings, similar to what we found in this in-depth study and in our earlier survey, suggest that there are problems with the quality of teaching by both junior and senior doctors in the medical educational process. Lack of time and support from attending staff has been demonstrated to be factors contributing considerably to the poor quality of teaching.

We know that training residents to teach is necessary and that both residents and students would be beneficiaries from such a programme. We have also shown how staff commitment and time are essential motivating factors for such training. Some of the questions we have raised, however, include: Would such a programme work? Will it be cost effective? Would it produce a 
better quality of training? Would it stimulate and increase the importance of medical teaching? These questions and many more should be the focus of resident training and faculty development in this new millennium.

\section{PraCtice points}

- Residents see teaching medical students as a primary responsibility and learn from it.

- Lack of time, teaching skills and staff commitment are barriers to residents' commitment to teaching.

- The educational climate in a department affects residents' willingness to teach and be evaluated for their teaching.

- Teacher training programmes for residents will benefit both residents and students.

\section{REFERENCES}

L. TONESK, X. (1979). The house officer as a teacher: what schools expect and measure. Journal of Medical Education, 54 : $613-16$.

2. JEWETT, L.S., GREENBERG, L.W. \& GOLDBERG, R.M. (1982). Teaching residents how to teach: a one year study, Journal of Medical Education, 57: 36r-66.

3. DUNNINGTON, G.L. \& DAROSA, D. (1998). A prospective randomised trial of a residents-as-teachers training program. Academic Medicine, 73:696-700.

4. BARROW, M.V. (1966) Medical students' opinions of the house officer as a medical educator. Journal of Medical Education, 41:807-810.

5. APTER, A. METZGER, R. \& GLASSROTH, J. (1988). Residents' perception of their role as teachers. Journal of Medical Education, 63:185-88.

6. BUSARI, J.O. SCHERPBIER, A.J.J.A. VAN DER VLEUTEN, C.P.M \& ESSED, G.E. (2000) Residents' perception of their role in teaching undergraduate students in the clinical setting. Medical Teacher, $22(4): 34^{8-53 .}$

7. STEWARD, D.E. \& FELTOVICH, PJ. (1988). Why residents should teach: the parallel processes teaching and learning. In J.C. EDWARDS \& R.L. MARIER (Eds.) Clinical Teaching for Medical Residents: Roles, Tesbniques and Prognams, 3-14, New York: Springer Verlag.

8. WALL. D. \& MCALEER. S, (2000). Teaching the consultant teachers: identifying the core content. Medical Education, 34:13t-38.

9. GIBSON, D.R. \& CAMPBELL., R.M. (2000) Promoting effective teaching and learning: hospital consultants identify their needs. Medical Education, 34:126-30. 


\section{Chapter 5}

THE PERCEPTIONS OF ATTENDING PHYSICIANS ON THE ROLE OF RESIDENTS AS TEACHERS OF UNDERGRADUATE CLINICAL STUDENTS

Jamiu O. Busari, Albert J.J.A. Scherpbier,

Cees P.M. van der Vleuten, Gerard G.M. Essed

Medical Education 2003; 37: 241-247 


\section{SUMmary}

Introduction Much of undergraduate clinical teaching is provided by residents. An earlier study showed the attitude of residents towards teaching to be generally positive. Little is known, however, about attending doctors' views on their own and residents' roles as teachers of medical students.

Objectives 'To examine attending doctors' perceptions of the (dis)advantages of resident teaching, their own teaching abilities and the need for a teacher training programme for residents.

Method A questionnaire survey of 76 attending doctors was carried out in the Departments of Obstetrics \& Gynaecology and Paediatrics at the teaching hospitals of the Universities of Maastricht and Amsterdam, the Netherlands.

Results Artending doctors perceive teaching by residents to be beneficial for students and residents alike. Although they consider themselves to be better suited than residents to teach medical students, they see teaching as an integral part of residency training and feel it should be recognised as such by departments and medical schools. Atrending doctors are in favour of a teacher-training programme for residents, which should include communication, clinical and teaching skills as well as skills such as time management and (self-) assessment.

Discussion Despite the uneven distribution of participants between the departments, no significant differences were found between departments. It is interesting that attending doctors perceive teacher training as beneficial to residents' teaching skills, but provide more feedback on residents' attitudes than on their teaching. The results show that, in general, attending doctors share residents' views that teaching is an important component of residency and that a teachertraining programme for residents is to be recommended.

\section{INTRODUCTION}

Research in medical education has shown that residents (i.e. preregistration house officers and junior doctors) play an important role in teaching medical undergraduates ${ }^{1.2}$.They spend substantial time (and effort) in teaching undergraduate students, although most residency programmes do not allocate specific time for this activity. Medical students claim that up to a third of their education is derived from residents and feel that each department should provide minimum guidelines for residents' teaching responsibilities'. Although residents are willing to teach and consider teaching to be beneficial to themselves, they perceive that their teaching efforts are neither acknowledged nor appreciated by attending doctors (i.e. consultants or specialists) ${ }^{2}$. In previous studies we found that residents indicated that teaching objectives were not clearly defined and attending staff showed insufficient commitment towards residents' teaching responsibilities. Residents felt they would be better teachers if they received some form of teacher training. In their opinion, attending doctors were better suited to teach medical students than they were ${ }^{2 \cdot 4}$. 
We know that teaching improves the learning of residents', We also know that, upon completion of their specialist training, new medical specialists are expected to undertake teaching responsibilities for both medical students and residents in many medical institutions. It is therefore not surprising that the need for a teacher-training programme for residents as well as the demand for more acknowledgement of the resident's role as a teacher has been increasing steadily, $2,6,7$. The perceived educational needs pertaining to teaching by residents have been studied by surveying residents' and medical students' opinions ${ }^{1.4}$. The views of attending doctors and / or medical school faculty on this issue have, however, not been objectively investigated $^{24}$. Therefore, we explored attending doctors' perceptions of the teaching roles of residents in undergraduate medical education. We were interested in the views of attending doctors on the present state of affairs in teaching by residents. These included the possible (dis)advantages of teaching for residents, the need for improvement of residents' teaching competencies, the roles of attending doctors and departments in supporting teaching carried out by residents, the roles of attending doctors as teachers of undergraduate students and residents, and suggestions for measures to improve residents' teaching performance. As a result, we formulated the following research questions about attending doctors' perceptions:

- What are the perceived potential benefits on his / her clinical competence for the teaching resident?

- Should residents be trained in how to teach?

- Do residents need guidance with respect to their teaching responsibilities?

- Should teaching undergraduate students be an integral part of residency training?

- How do attending doctors perceive their own teaching characteristics and which of these contribute most to perceived teaching ability?

- In what ways can a teaching programme be incorporated into a residency programme?

\section{Method}

The subjects in the study were attending doctors in the Departments of Obstetrics \& Gynaecology and Paediatrics at the teaching hospitals of Maastricht University and the University of Amsterdam, the Netherlands. Respondents were recruited from different departments because earlier studies on teaching by residents found interdepartmental differences. For example, more residents in obstetrics and gynaecology than in paediatrics felt they did not need prior training in teaching ${ }^{2}$. Informed consent was sought from the heads of the participating departments.

For this study we adapted a questionnaire that we had previously used in a study to assess residents' perceptions of teaching ${ }^{2}$. The questionnaire to explore the attending doctors' perceptions consisted of three sections, two of which contained quantitative items while the third contained qualitative questions.

In the first section to questions sought attending doctors' perceptions of the benefits of teaching for residents and the need for a teacher-training programme. The questions had to be 
answered on a Likert scale ranging from strongly disagree ( $\mathrm{t}$ ) to strongly agree ( $\mathrm{s}$ ). The second section examined how attending doctors perceived residents' teaching abilities referred to as teacher characteristics). It contained eight items modified from questions in a previous study, with a Likert scale ranging from very poor (1) to very good (5) $)^{4}$.The teacher characteristics investigated were: knowledge, attitude, technical skills, clinical skills and clinical judgement of attending doctors. Means were calculated for each characteristic separately and for all characteristics combined. The latter score was used as a measure of perceived overall teaching ability. In addition, five yes/no questions, adapted from a questionnaire used in an earlier study, explored whether the doctors thought that a teacher training course should be part of residency training and whether residents needed guidance in their teaching taskst. The last two items in section two examined the attending doctors' views on how much time residents (should) spend on teaching.

In the third section of the questionnaire, qualitative questions addressed attending doctors' views on important components of a teacher-training programme for residents. The attending doctors were requested to provide five suggestions on aspects of teaching that should be addressed in such a programme.

\section{ANALYSIS}

Cronbach's alpha was calculated to examine the internal consistency of the questionnaire items. We used descriptive statistics to interpret the responses of the attending doctors. Means and standard deviations were calculated for the attending doctors' ratings of the benefits of teaching for residents, whether or not residents should be trained to teach, and their own perceived teacher characteristics. Confidence intervals were not calculated, as the purpose of the study was to obtain descriptive data. The frequency and percentages of the responses to the specific yes / no items in the questionnaire were calculated. Spearman rho rank-order correlations were used to investigate any significant correlations between the attending doctors' rankings of the different teacher characteristics and perceived overall teaching ability. We used multiple regression analysis to identify the characteristics (i.e. knowledge, attitude, technical skills, clinical skills and clinical judgement) that best predicted overall teaching ability. We used analysis of variance (ANOVA) to examine the perceptions of attending doctors on residents' teaching responsibilities and abilities. We investigated for any significant differences across and within clinical specialities (and universities). Using chi-square analysis, we also investigated whether the personal characteristics of the attending doctors influenced some of their responses. The attending doctors' recommendations for teacher training programmes were analysed by two investigators independently. The comments were clustered by theme based on similarity of content. In areas where disagreement arose, consensus was reached through discussion. 


\section{ResUlts}

A total of $\mathrm{n} 6$ attending doctors from the Departments of Paediatrics and Obstetrics/Gynaecology at the teaching hospitals of Mastricht University and the University of Amsterdam were eligible for participation. At the Mastricht teaching hospital, six doctors from the Department of Paediatrics (30\%) and nine doctors from the Department of Obstetrics/Gynaecology (100\%) participated. At Amsterdam, participation by the corresponding departments amounted to 51 $(77 \%)$ and $10(50 \%)$ doctors, respectively. In all, 76 attending doctors completed and returned the questionnaire, giving a total response rate of $66 \%$.

The estimated reliability of the items investigating perceived teacher characteristics and perceptions of residents' teaching responsibilities and abilities revealed a moderate internal consistency. The calculated reliability coefficient was 0.72. Widespread participation at the Department of Paediatrics at the University of Amsterdam constituted $67 \%$ of overall participation (Table 1). The majority of respondents had not received any prior formal teaching instruction and they agreed that such instruction would have been beneficial.

\section{Table I. Demographic CHARACTERISTICS OF THE ATTENDING DOCTORS}

\begin{tabular}{|c|c|c|}
\hline Category & $\begin{array}{c}\text { Number } \\
(\mathrm{N}=76)\end{array}$ & $\begin{array}{c}\text { Percentage } \\
\text { (\%) }\end{array}$ \\
\hline \multicolumn{3}{|l|}{ Sex } \\
\hline Male & $\$ 2$ & 68.4 \\
\hline Female & 24 & 31.6 \\
\hline \multicolumn{3}{|l|}{ Prior formal teaching instruction } \\
\hline Yes & 29 & 38.2 \\
\hline No & 47 & 61.8 \\
\hline \multicolumn{3}{|l|}{ Department } \\
\hline \multicolumn{3}{|l|}{ Maastricht University } \\
\hline Paediatrics & 6 & 7.9 \\
\hline Obstetrics \& Gynaecology & 9 & 31.8 \\
\hline \multicolumn{3}{|l|}{ University of Amsterdam } \\
\hline Paediatrics & & 67.1 \\
\hline Obstetrics \& Gynaecology & $\begin{array}{l}51 \\
10\end{array}$ & 13.2 \\
\hline \multicolumn{3}{|l|}{ Formal teaching instruction beneficial } \\
\hline Yes & 47 & 61.8 \\
\hline No & 14 & 18.4 \\
\hline \multicolumn{3}{|l|}{ Years of professional experience } \\
\hline <years & 29 & 38.2 \\
\hline 5-10 years & 14 & 18.4 \\
\hline$>10$ years & 32 & 42.1 \\
\hline
\end{tabular}

- Totals may not equal 76 due to missing data 


\section{Attending doctors' perceptions of residents' teaching responsibilities}

The attending doctors thought that residents spent an average of $\mathrm{r.13}$ hours / day (SD 0.85, range 4 hours) teaching medical students. If service responsibilities were ideal, they felt that residents should spend an average of 1.67 hours / day (SD 0.97 , range 4.85 hours) on teaching activities. More than half ( $55 \%)$ of the attending doctors felt that their department considered teaching medical students to be part of the residency-training programme. A majority thought that:

1) departments should emphasise the importance of teaching;

2) residents' teaching ability should be part of their clinical evaluation;

3) teaching is a part of residency, and

4) residents would benefit from prior training in how to teach (Table 2).

\section{Table 2. ATTENDING DOCTORS' PERCEPTIONS OF RESIDENTS' TEACHING RESPONSIBILITIES}

\begin{tabular}{l} 
Questions on teaching responsibility \\
\cline { 2 - 5 }
\end{tabular}

- Totals may not equal 76 due to missing values 


\section{Attending doctors' perceptions of residents' teaching abilities}

The views of attending doctors were examined on a number of specific items concerning residents' teaching abilities. There was general agreement among staff that residents should teach medical students (Table 3 ). They also felt strongly that teaching was a primary responsibility for residents. The results showed that attending doctors held strong opinions that residents' teaching skills could be improved (mean $=4.05, \mathrm{SD}=0.59$ ) and that residents would bencfit from a programme to improve teaching skills $($ mean $=3.96, S D=0.77$ ). They did not think, however, that residents were better suited to teach students than they were (mean $=2.76, \mathrm{SD}=1.13$ ). The attending doctors indicated that they provided less immediate feedback to residents about teaching (mean $=2.60, S D=0.93$ ) than about attitude $($ mean $=3.92, S D=0.84)$.

\section{Table 3. ATTENDING DOCTORS' OPINIONS ON RESIDENTS' TEACHING ABILITIES (I=TOTALLY DISAGREE; S=TOTALLY AGREE)}

\begin{tabular}{lccc}
\hline Aspects of teaching & Mean & SD & N \\
\hline $\begin{array}{l}\text { 'Teaching medical students/peers is one of the primary responsibilities of the } \\
\text { resident }\end{array}$ & 4.21 & 0.77 & 76 \\
If feel the teaching skills of residents can be improved & 4.05 & 0.59 & 75 \\
$\begin{array}{l}\text { Many residents could benefit from a programme that provides an opportunity } \\
\text { to improve teaching skills }\end{array}$ & 3.96 & 0.77 & 76 \\
I give residents prompt feedback on aspects of their attitude & 3.92 & 0.84 & 74 \\
I feel that teaching helps residents become better clinicians & 3.78 & 0.93 & 74 \\
I feel that the residents' knowledge in the area that they have to teach is & 3.53 & 0.80 & 74 \\
adequate & & & \\
Lirerature on teaching could be helpful in improving residents' teaching skills & 3.31 & 0.99 & 75 \\
Evaluating medical students performance is part of a resident's responsibility & 3.20 & 1.00 & 75 \\
Residents are more suited for teaching medical students than full-time attend- & 2.76 & 1.13 & 75 \\
ing staff & & & \\
I give residents prompt feedback on aspects of their teaching & 2.60 & 0.93 & 72 \\
\hline
\end{tabular}

\section{Attending doctors' perceptions of their own teacher characteristics}

In general, the attending doctors rated their own teacher characteristics highly (on a scale where $\mathrm{I}=$ very poor and $5=$ very good), particularly in terms of their knowledge related to the clinical domain (mean $=3.97, \mathrm{SD}=0.52$ ), technical skills (mean $=3.95, \mathrm{SD}=0.49$ ) and clinical skills (mean $=3.99, \mathrm{SD}=0.53$ ). Spearman's rank order showed a positive correlation between attending doctors' perceived abilities as teachers and as clinicians $(\mathrm{r}=0.30, \mathrm{P}=0.05)$. Multiple linear regression analysis showed that perceived good teaching ability was best predicted by perceived adequate clinical skills and ability as a tutor $(\mathrm{F}=168.0, \mathrm{P}=0.00)$. The two variables accounted for $83 \%$ of the total variance $\left(R^{2}=0.827\right.$ ) (Table 4$)$. 


\section{Table 4. AtTENDING DOCTORs' PERCEPTION \\ OF THEIR TEACHER CHARACTERISTICS}

$\mathrm{N}=76$, ratings: 1 = very poor; 5 = very good. Correlations were calculated using Spearman rho rank correlation. All correlations between perceived overall teaching ability and perceived teacher characteristics were significant $(p<.01)$.

\begin{tabular}{lcc}
\hline Teacher characteristics & \multicolumn{2}{c}{ Ratings attending doctors } \\
& N=76 \\
\cline { 2 - 3 } & Mean & SD \\
\hline Knowledge of basic medical science & 3.67 & 0.55 \\
Knowledge related to attending physician's clinical domain & 3.97 & 0.52 \\
Artirude (e.g. interpersonal skills) & 3.84 & 0.54 \\
Technical skills (e.g. clinical procedures) & 3.95 & 0.49 \\
Clinical skills (e.g. physical exams)* & 3.99 & 0.53 \\
Clinical judgement (e.g. parient management) & 3.63 & 0.65 \\
How would you rate your ability as a tutor* & 3.76 & 0.54 \\
How would you rate your ability as a doctor/clinician & 3.87 & 0.41 \\
Overall teaching ability & 3.83 & 0.37 \\
\hline
\end{tabular}

-Best predictors of perceived overall teaching ability using multiple linear regression $\left(R^{2}=0.83\right)$

\section{Attending doctors' suggestions for developing a training programme}

The attending doctors offered extensive suggestions in response to the open questions in this section. After reviewing all suggestions, four main themes (or aspects of teaching) were identified, namely: teaching skills, clinical skills, communication and attitude. The attending doctors in all four departments considered these aspects essential components of a teacher-training programme. With regard to communication, attending doctors mentioned the ability to interact better with medical students, the ability to give feedback easily and the ability to transfer knowledge effectively. With regard to teaching skills, attending staff felt residents should learn how to set teaching objectives, develop problem-solving skills, and stimulate students to learn.

They also felt residents should be trained in how to structure and maintain an overview of their teaching activities. Attending doctors felt that residents should be trained in how to perform and teach clinical skills effectively. These skills included history taking, physical examination and diagnosis. Residents were also expected to be able to conduct literature searches and teach medical students how to do so. Finally, attending doctors felt that the training programme should address attitude and appropriate professional conduct towards students, patients and nursing staff. Other interesting suggestions included skills relating to time management, professional responsibility, self-assessment and evaluation of peers and students. 


\section{Discussion}

Prior studies have examined how residents perceive their teaching responsibilities and their desire for training, departmental recognition and staff guidance ${ }^{2.2 .5 .9 .9}$. In this study, we investigated the views of attending doctors on residents' teaching activities and the potential advantages and disadvantages for both residents and students. We also investigated whether attending doctors agreed that a teacher training programme for residents should be incorporated into the residency programme and asked for their suggestions as to the content of such a programme.

Attending doctors agreed that teaching medical students was beneficial for residents and helped them become better clinicians. They agreed that teacher training would be beneficial, corroborating the views of residents on the need for training to promote better teachingt. It was evident from the results that, in most departments, teaching was not considered to be an integral part of residency training, although most of the attending doctors felt it should be. They also felt that the departments should acknowledge residents' contribution to teaching and faculty should emphasise the importance of teaching. The amount of time attending doctors considered ideal for normal teaching activities by residents was 1.7 hours / day. This was close to the amount of time (L.5 hours / day) residents themselves felt they would need to carry out teaching activities alongside allocated clinical work ${ }^{2}$.

Attending doctors thought that residents were suited to teach medical students, but not more so than they themselves were. It seems logical to assume that attending doctors' perceptions in this respect are prompted by their more extensive professional and clinical experience. Nevertheless, the response to this item showed a large standard deviation (SD 1.13), indicative of differences of opinion. In the Netherlands, attending staff may be composed of a heterogeneous mix of doctors with respect to affinity for teaching and ability to teach. While the academic obligations of attending doctors include health care service, research and education, in practice some attending doctors are primarily research-oriented and have little involvement in teaching. This latter group would tend to support the notion that residents are better suited to teach medical students than they are, and that may explain the large standard deviation we observed.

The results of prior research have indicated the reasons why residents thought attending doctors were better suited to teaching medical students, namely:

- teaching is a major responsibility of attending doctors;

- attending doctors have a broader theoretical knowledge base, and

- attending doctors have richer clinical and teaching experience than do residents'.

The results from this study show that attending doctors think residents' teaching skills can be improved by training. It is interesting to discover, however, that attending-staff say that they give more feedback on residents' attitudes than on their teaching ability. 
Despite the awareness of the need to improve residents' teaching abilities, these findings suggest that, so far, attending doctors' contribution to the quality of the teaching carried out by residents has been less than might be expected.

In this study we explored the attending doctors' perceived teaching characteristics. Clinical skills and ability as a tutor were the best predictors of perceived good teacher characteristics. An earlier study found that residents' perceived teacher characteristics were best predicted by knowledge related to the clinical domain and ability as a clinician ${ }^{2}$. The attending doctors rated themselves highly as teachers and slightly better as clinicians. A comparison of these ratings with those of the residents in our previous study showed that attending doctors rated themselves more highly both as teachers and as clinicians ${ }^{2,4}$.

The recommendations provided by attending doctors reflect the importance of and need for improvement in the areas of teaching skills, clinical skills, communication and attitude. The suggestions they provided corroborate the recommendations of residents on how to effectively transfer knowledge and give feedback to students'. Their recommendations also included skills that, although not directly related to teaching, may facilitate the teaching process, such as time management, professional responsibility, self-assessment and evaluation of peers and students.

A weakness of the present study lies in the relatively small number of participants from the other departments compared with those from the Paediatric Department of the University of Amsterdam, which contributed more than half of the respondents. The explanation for this is that the University of Amsterdam has a separate children's hospital and consequently employs a larger number of attending doctors in this department. The other respondents came from departments in academic hospitals. ANOVA and chi-squared analysis did not reveal any significant differences between the departments. Nevertheless, we should be cautious in making comparisons across departments and between institutions as the findings may still have been biased by the disparity in the number of respondents from each department in the study.

About a third of the potential respondents did not return the questionnaire. W/e had expected a larger response from attending doctors in academic hospitals, who can be expected to be familiar with clinical teaching and better informed of its importance. The results showed no obvious reasons why this group did not respond and we can only speculate on the causes of the moderate response. The respondents may have lacked motivation and stimulation. For example, the meagre response from the Paediatric Department of the University of Maastricht (six attending doctors, representing $30 \%$ of the department) might be explained by the attending doctors' poor motivation to participate.

The medical school at this university is renowned for its emphasis on undergraduate medical education and we would therefore have expected greater participation from staff members. Still, we are unable to pinpoint the exact source of the poor motivation. The highest response rates were found at the Department of Obstetrics \& Gynaecology in Maastricht, where all nine attending doctors participated, and the Department of Paediatrics in Amsterdam, where 51 attending doctors $(77 \%)$ participated. These high response rates may be related to the fact 
that these departments had highly motivated co-ordinators with an interest in teaching, who stimulated participation by their fellow attending doctors.

In conclusion, we can say that this study sheds light on the issue of teaching by residents from the perspective of an important stakeholder in clinical education. The results confirm earlier findings that teaching by residents is generally considered to be of great importance. All three stakeholders in the clinical educational process, students, residents and attending doctors, agree that teaching by residents is important and beneficial. By teaching medical students, residents improve not only their teaching skills, but also their theoretical knowledge and clinical competence. Undergraduate students, as the recipients of clinical teaching by residents, should be taught well and be provided with good role models to emulate. The focus on the role of residents in clinical medical education has now shifted from the question of whether it is necessary for residents to teach to the issue of how their teaching might be improved, and the benefits involved therein. The results of this study suggest that the teaching ability of residents can be improved by developing a formal teacher training programme for residents, improving staff commitment and creating a system of generating structured guidance from faculty. There is also evidence from this study and from a previous study that, if properly carried out, training on how to teach and a formal teaching curriculum for residents could be incorporated into residency programmes.

\section{Key Learning Points}

- Attending physicians think that students and residents benefit from teaching by residents.

- Attending physicians think that training can enhance residents' teaching skills.

- Attending physicians think that teaching by residents should be regarded as an integral part of residency training. 


\section{REFERENCES}

1. APTER, A., METZGER, R. \& GLASSROTH. J (1988). Residents' perceptions of their role as teachers. Journal of Medical Education, 3:900-5.

2. BUSARI, J.O., SCHERPBIER A.J.J.A., VAN DER VLEUTEN, C.P.M. \& ESSED G.G.M. Residents' perception of their role in teaching undergraduate students in the clinical setting. Medioal Teacher, 22(4): $34^{8}-53$.

3. BARROW, M.V. (1966) Medical student opinion of the house officer as a medical educator, Journal of Medical Education, 41:807-10,

4. BUSARI, J.O., PRINCE. J.A.H., SCHERPBIER, A.J.J.A., VAN DER VLEUTEN, C.P.M. \& ESSED, G.G.M. (2001) How residents perceive their teaching role in the clinical setting - a qualitative study. Medical Teacher, $24(1): 57-61$.

5. GREENBERG, L.W., GOLDBERG, L.W. GOLDBERG, R.M. \& JEWETT, L.S. (1984). Teaching in the clinical setting: factors influencing residents' perceptions, confidence and behaviour. Medical Education. 18:360-5.

6. TONESK, X. (1979) The house officer as a teacher: what schools expect and measure. Journal of Medical Education, 54:619-6.

7. DUNNINGTON, G.L. \& Da ROSA, D. (1998) A prospective randomised trial of a residents-as-teachers training program. Actdemic Medicine, 73:696-700.

8. ANDERSON, K., ANDERSON, W. \& SCHOLTEN, D. (r990) Surgical residents as teachers. Current Surgery, 47(3): 185-8.

9. BING-YOU, R.G. \& HARVEY, B.J. (1991) Factors related to residents' desire and ability to teach in the clinical setting. Traching and Learning in Medicine, 2:95-100. 


\section{Chapter 6}

HOW MEDICAL RESIDENTS PERCEIVE THE QUALITY OF SUPERVISION PROVIDED BY ATTENDING DOCTORS IN THE CLINICAL SETTING

Jamiu O. Busari, Nielske M. Weggelaar, Andrieke C. Knottnerus, Petra-Marije Greidanus, Albert J.J.A. Scherpbier

Medical Education (Accepted) 


\section{SUMMARY}

Introduction The supervision of medical residents is a key responsibility of attending-doctors in the clinical setting. Most attending-doctors however, are unfamiliar with the principles of effective supervision. Although inconsistent, supervision has been shown to be both important and effective for the professional development of medical residents.

Objective To examine how medical residents perceive the supervisory roles of attending-doctors, that is, what they perceive as poor supervision and what they characterize as good supervisory practice.

Method A questionnaire survey of 38 medical residents from the Department of Paediatrics of the teaching hospital of the University of Amsterdam, the Netherlands. Attending-doctors directly involved with the supervision of medical residents participated in the study. The clinical settings where supervision occurred included the neonatal and paediatric intensive care units and the general paediatric wards.

Results Medical residents rated the quality of supervision they received in all departments positively. Majority of the attending-doctors were rated highly in "overall supervision". Creating pleasant learning environments, and being stimulated to learn and function independently were aspects of supervision characterized positively. Coaching in clinical skills and procedures, effective communication skills and clinical decision-making using principles of cost-appropriate care were aspects of supervision found to be deficient.

Discussion This study shows that medical residents enjoy supervision from collaborative, understanding and patient attending-doctors. Medical residents prefer to be treated as adult learners and enjoy feedback that is constructive, measured and adapted to their professional needs.

\section{INTRODUCTION}

In most medical institutions teaching is the primary responsibility of specialist-physicians or attending-doctors. Unfortunately, majority of attending-doctors (AD) are unfamiliar with the principles of medical education and are short of the didactic skills that are involved in the process. "Also, many of them who teach and supervise medical residents and students in the clinical setting, do so without having had any formal training in teaching. Most of their didactic skills have been acquired through observation, trial and error, and reflection on personal experience. ${ }^{4}$ Consequently, achieving and maintaining the required high standard of clinical teaching and/ or supervision in medical education becomes a difficult objective to guarantee.

Kilminster and Jolly described supervision within the clinical setting as a complex activity that occurs in a variety of contexts and has various functions as well as different modes of delivery.5 This complexity probably explains why it is difficult to define good supervisory practice in the clinical setting, and why more research is required to improve the quality of supervision. The 
current literature shows that clear guidance in supervision and the establishment of appropriate mechanisms to resolve difficulties relating to inadequate supervision are indispensable in cinical practice. ${ }^{67}$ While medical residents have expressed dissatisfaction with the quality of supervision they receive, their supervision, although inconsistent, has been shown to be both important and effective for their professional development.". The presumption that only the proper understanding of one's clinical discipline is enough to teach medical students/residents is no longer tenable in medical education. Teaching and/or clinical supervision is presently an explicit professional responsibility for specialist physicians and the need for (more) teachertraining programmes for $\mathrm{ADs}$ to help them improve their teaching skills is increasing. ${ }^{10.19}$ While many institutions in North America and Europe have already established programmes to address this need, other educational bodies are developing strategies to promote and encourage teaching as an inherent part of professional development. ${ }^{14-19}$

Most authors agree that the function of supervision should be educative, supportive and administrative/managerial. They also agree on how, where and when supervision should occur, and on the features that constitute effective supervision. Furthermore, there is agreement on the aim of supervision in clinical practice, which is to promote professional development and ensure patient safery. ${ }^{70}$ Despite the information that is available on this subject, however, the current supervisory practice in medicine still lacks a well-founded theoretical basis. Indistinct theoretical links and research design problems have been identified as some of the flaws in several studies that have investigated various aspects of clinical supervision. ${ }^{5}$ Unfortunately, the findings from these studies were undermined by these inconsistencies, and have resulted in the need for more structured and methodologically sound investigations that can provide answers to the many facets of clinical supervision requiring improvement. ${ }^{5}$ In this paper, the main objective of our study was to investigate the quality of supervision by ADs in the Department of Paediatrics at the Emma Childrens Hospital, AMC, Netherlands. Our secondary objective was to identify the aspects of poor supervision that needed improvement as well as the characteristics of supervision that strongly correlated with overall good supervisory practice.

\section{MeTHOD}

The study, which lasted 3 months, was conducted as two separate and parallel investigations. The settings were respectively, the intensive care (the paediatric intensive care unit (PICU) and neonatal intensive care unit (NICU)) and general paediatric wards. The reason for conducting the investigations separately was because medical residents' claimed that the supervision in the general paediatric ward was inadequate and poorly structured compared to that in the intensive care wards, and not because we intended to compare the quality of supervision between the respective wards. We were therefore interested in identifying the (specific) deficiencies in supervision in the general paediatric ward that could account for the assertions. 


\section{Subjects}

There were 99 medical staff members in the hospital at the time the study was conducted. The 48 ADs who participated in the study were those who were directly involved with the supervision of medical residents on the wards and/or outpatient clinics during both day and night shift periods. Of the ADs, 28 were from the general paediatric ward, $n$ from the NICU and 9 from the PICU. The study was incorporated in a nomination for the best supervisor award. The aim was to enrol the participation of ADs and reduce any opposition they may have towards the evaluation of supervisory abilities. All participants were informed that the evaluations would occur confidentially. Information on the structure and objective of the study was provided to them directly and/or via email before commencement. The researchers (3 medical residents, 1 paediatrician) did not participate in the study, because they were not blinded to the participants. We approached all medical residents $(n=38)$, who were in different stages of their training, to rate the quality of the supervision they received from the ADs. Each medical resident could rate as many $A D s$ as possible provided that: 1) they had been under the direct supervision of the $A D$ within the last 6 weeks before the study and 2) they were (or had been) under the supervision of the AD for a significant period of time - designated as 8 weeks. The medical residents could not rate the same person twice, and we strove to have each $A D$ rated by an average of 5 different medical residents in order to guarantee reliable assessments. All the evaluations were conducted anonymously in order to allay the medical residents' fears of negative repercussions if unfavourable ratings were traced back to them. Furthermore, the ADs were unaware of when exactly they were evaluated during the period of the study.

\section{Instruments}

We used two different questionnaires because the clinical settings where supervision of medical residents took place were different. In the intensive care units, we used a questionnaire that was developed from the Wisconsin Inventory of Clinical Teaching. ${ }^{21}$ This instrument involves rating of supervisory qualities on a ten-point scale $(\mathrm{I}=$ very poor; $10=$ excellent $)$ in the following areas: Clinical role models, Professional mentors, Instructors, Evaluators and Supervisors.

For the assessment of supervision in the general paediatric wards we used the Cleveland Clinic's Teaching Effectiveness Instrument ${ }^{22}$. This instrument consists of 15 items teflecting good teaching ability, which are rated on a five-point Likert scale ( $\mathrm{I}=$ never/very poor; $5=$ always/very good). An important point was that before this study was conducted the instrument's reliability in measuring teaching effectiveness at individual and group teaching levels had been investigated in a different study by Van der Hem-Stokroos and co-workers (unpublished). That study re-confirmed the instrument's reliability and showed that 7 ratings were sufficient for a reliable assessment of quality of supervision at the individual level (compared to 5 ratings by Copeland and Hewson ${ }^{22}$ ), whereas at the group level, single ratings of a minimum of is educators would yield a reliable result. 
Lastly, the medical residents could provide general remarks in both questionnaires to elaborate their views on the quality of supervision.

\section{Data analysis}

Descriptive statistics were used to interpret the responses of the medical residents. Means and standard deviations were calculated for the perceived teaching abilities of the ADs. We did not investigate for any effect of residency level on the ratings. This had already been found to be insignificant when using these questionnaires. ${ }^{2}$ Spearman rho-rank order correlations were used to investigate any significant correlations between the medical residents' perceptions of the different supervisory characteristics and perceived overall quality of supervision. Multiple regression analysis was used to identify the item(s) that best reflected the overall quality of supervision. Finally, the general comments were analysed and summarized by the first author.

\section{Results}

Thirty-eight medical residents in different stages of their training rated 48 ADs. Twenty ADs were intensive care specialists $(\mathrm{NICU}=11, \mathrm{PICU}=9)$ and 28 were specialists in general paediat-

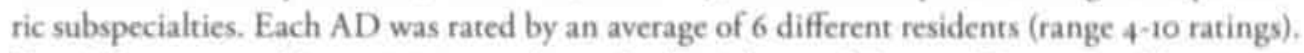
Two ADs were rated by a minimum of 4 medical residents, while one $A D$ was rated by a maximum of to medical residents. Two hundred and eighty-four $(284)$ rating forms were returned; 130 from the intensive care wards and 154 from the general paediatric ward.

\section{The perceived quality of supervision provided by attending-doctors in the ICUs}

The $\mathrm{AD}$ s in the PICU were rated highest as good clinical role models ( $m e a n=7.71, \mathrm{SD}=0.80$, range $=2.40$ ) while the $\mathrm{ADs}$ in the NICU were perceived best as professional mentors (mean $=7.48, \mathrm{SD}$ $=0.69$, range $=2.50$ ). The ADs in both ICUs scored lowest as evaluators (table $\mathrm{t}$ ). The overall mean rating (i.e. norm for the group) of supervision in the intensive care wards was 7.39 ( $\mathrm{SD}=0.61$, range $=2.13)$ and the mean rating in the PICU and NICU were $7.36(\mathrm{SD}=0.69$, range $=2.10)$ and 7.41 $(S D=0.58$, range $=2.04)$, respectively. Fifty-six per cent of ADs in the PICU scored 7.36 or higher and $64 \%$ of the ADs in the NICU scored 7.41 or higher. Spearman's rank order showed positive correlations between supervisory roles and overall supervision. Multiple linear regression analysis showed that the roles as professional mentor and instructor best predicted good supervision $(\mathrm{F}=285.2, \mathrm{P}=0.00)$. Both items accounted for $97 \%$ of the total variance $\left(\mathrm{R}^{2}=0.968\right)$. There were no significant differences relating to gender or department. 
Table I. MEDICAL RESIDENTS PERCEPTION OF THE SUPERVISION PROVIDED BY ATTENDING-DOCTORS IN THE INTENSIVE CARE WARDS

Scale: $\mathrm{I}=$ Very poor, $10=$ Very good

\begin{tabular}{|l|c|c|c|c|c|c|c|c|c|}
\hline \multirow{2}{*}{ Supervisory role } & \multicolumn{3}{|c|}{$\begin{array}{c}\text { NICU } \\
\text { (N=11) }\end{array}$} & \multicolumn{3}{c|}{$\begin{array}{c}\text { PICU } \\
\text { (N=9) }\end{array}$} & \multicolumn{3}{c|}{$\begin{array}{c}\text { Intensive care wards } \\
\text { (TOTAL) }\end{array}$} \\
\cline { 2 - 11 } & Mean & SD & Range & Mean & SD & Range & Mean & SD & $95 \%$ CI \\
\hline Clinical role model & 7.44 & 0.92 & 3.43 & 7.71 & 0.80 & 2.40 & 7.56 & 0.86 & $7.16-7.96$ \\
\hline $\begin{array}{l}\text { Professional } \\
\text { mentor* }\end{array}$ & 7.48 & 0.69 & 2.50 & 7.36 & 0.78 & 2.20 & 7.43 & 0.72 & $7.09-7.75$ \\
\hline Instructor* & 7.35 & 0.57 & 1.70 & 7.31 & 0.68 & 1.90 & 7.33 & 0.60 & $7.00-7.44$ \\
\hline Evaluator & 7.30 & 0.48 & 1.67 & 7.12 & 0.51 & 1.60 & 7.22 & 0.49 & $7.09-7.68$ \\
\hline Supervisor & 7.46 & 0.53 & 1.60 & 7.30 & 0.75 & 2.50 & 7.39 & 0.63 & $7.09-7.68$ \\
\hline $\begin{array}{l}\text { Overall } \\
\text { Supervision }\end{array}$ & 7.41 & 0.58 & 2.10 & 7.36 & 0.69 & 2.10 & 7.39 & 0.61 & $7.10-7.67$ \\
\hline
\end{tabular}

The differences in the means of supervisory roles (between and within groups) were not significant.

Correlations were calculated using Spearman tho rank correlation. All correlations between perceived supervisory role and overall supervision were significant $(\mathrm{p}=<.0 \mathrm{r})$.

- - Best predictors of perceived overall teaching ability using multiple linear regression $\left(R^{2}=0.97\right)$

\section{The perceived quality of supervision by attending-doctors in the general paediatric wards}

The medical residents rated the overall supervision in the general paediatric wards positively $($ mean $=3.58, \mathrm{SD}=0.44$, range $=1.77)$. Examination of individual averages showed that $57 \%$ of the ADs scored 3.58 or higher. The medical residents perceived that establishing a good learning environment was the most outstanding feature in the supervision provided by the ADs (mean $=4.10, \mathrm{SD}=0.50$, range $=\mathrm{t} .60$ ), while teaching the principles of cost-appropriate care was the poorest feature $($ mean $=2.85, \mathrm{SD}=0.49$, range $=1.80$ ). Spearman's rank order showed positive correlations among the is features used to evaluate the quality of supervision ranging from 0.44 to 0.87 . Multiple linear regression analysis, however, showed that "adjusting the teaching to the needs of medical residents" and "stimulating them to learn independently" were the features that best predicted good supervision $(F=124.0, P=0.00)$. Both items accounted for $90 \%$ of the total variance $\left(R^{2}=0.90 r\right)$. There were no significant differences relating to gender. 


\section{Table 2. MEDICAL RESIDENTS' PERCEPTION OF THE SUPERVISION PROVIDED BY ATTENDING-DOCTORS IN THE GENERAL. PAEDIATRIC WARDS}

\begin{tabular}{|c|c|c|c|c|}
\hline Supervisory role & Mean & SD & Range & $95 \% \mathrm{Cl}$ \\
\hline $\begin{array}{l}\text { 1. Establishes a good learning environment } \\
\text { (approachable, non-threatening, enthusiastic, etc.) }\end{array}$ & 4.10 & 0.50 & 1.60 & $3.90-4.29$ \\
\hline $\begin{array}{l}\text { 2. Allows me autonomy approptiate to my level/ } \\
\text { experience/competence }\end{array}$ & 403 & 0.39 & 1.40 & $3.88+4.18$ \\
\hline 3. Stimulates me to learn independently* & 3.93 & 0.45 & 2.80 & $3.76 \cdot 4.11$ \\
\hline $\begin{array}{l}\text { 4- Gives clear explanations/reasons for opinions. } \\
\text { advice actions, etc }\end{array}$ & 3.88 & 0.56 & 2.50 & $3.64 \cdot 4.07$ \\
\hline $\begin{array}{l}\text { 5. Incorporates research data and/or practice } \\
\text { guidelines into teaching }\end{array}$ & 3.84 & 0.51 & 1.80 & $3.64 \cdot 4.03$ \\
\hline $\begin{array}{l}\text { 6. Asks questions that promote learning } \\
\text { (clarifications, probes, reflective questions, etc.) }\end{array}$ & 3.76 & 0.57 & 2.00 & $3.54 \cdot 3.98$ \\
\hline $\begin{array}{l}\text { 7. Adjusts teaching to my needs (experience. } \\
\text { competence, interest, etc.) }\end{array}$ & 3.58 & 0.56 & 2.20 & $3.36 \cdot 3.79$ \\
\hline $\begin{array}{l}\text { 8. Offers regular feedback (both positive and } \\
\text { negative) }\end{array}$ & 3.53 & 0.56 & 2.20 & $3.31-3.74$ \\
\hline $\begin{array}{l}\text { 9. Clearly specifies what I am expected to know } \\
\text { and do during the training period }\end{array}$ & 3.50 & 0.56 & 2.00 & $3.28-3.71$ \\
\hline $\begin{array}{l}\text { 10.Teaches diagnostic skills (clinical reasoning, } \\
\text { selection/interpretation of tests, etc.) }\end{array}$ & 3.50 & 0.58 & 2.00 & $3.28 \cdot 3.72$ \\
\hline $\begin{array}{l}\text { 11. Organizes time to allow for both teaching and } \\
\text { care giving }\end{array}$ & 3.47 & 0.70 & 2.60 & $3.20-3.74$ \\
\hline $\begin{array}{l}\text { I2. Adjusts teaching to diverse settings (bedside, } \\
\text { view box, OR, consultation room, etc.) }\end{array}$ & 3.44 & 0.55 & 2.20 & $3.22-3.65$ \\
\hline $\begin{array}{l}\text { 13. Coaches me on my clinical/technical skills } \\
\text { (interview, diagnostic, examination, procedural, } \\
\text { lab, etc.) }\end{array}$ & 3.30 & 0.69 & 2.60 & $3.03-3.57$ \\
\hline $\begin{array}{l}\text { 14. Teaches effective patient and/or family } \\
\text { communication skills }\end{array}$ & 3.09 & 0.63 & 2,80 & $2.84 \cdot 3.33$ \\
\hline $\begin{array}{l}\text { 15. Teaches principles of cost-appropriate care } \\
\text { (resource utilization, etc) }\end{array}$ & 2.85 & 0.49 & 1.80 & $2.66-3.04$ \\
\hline Overall supervision & 3.58 & 0.44 & 1.77 & $3.41-3.75$ \\
\hline
\end{tabular}

Scale: $\mathrm{I}=$ Very poor $/$ never, $2=$ Poor/seldom, $3=$ Fair/sometimes, $4=$ Good/Often, $5=$ Very good $/$ Always. $(\mathrm{N}=28)$

All correlations between overall supervision and perceived supervisory role were significant $(p<, 01)$.

- = Best predictors of good supervision using multiple linear regression $\left(\mathbf{R}^{2}=0.91\right)$ 


\section{General comments on the quality of supervision of attending-doctors in the general paediatric wards}

The comments of the medical residents were found to reflect the following different supervisory roles: "direct supervision", "instruction", and "clinical role model" (table 3). The comments reflected both positive and negative aspects of the supervision perceived by the residents. In the category "direct supervision", the medical residents preferred ADs who showed genuine interest in supervising residents, were easily approachable and were prepared to assist them in performing practical procedures on the wards. In addition, they preferred ADs who allowed them to run the wards alone (autonomy), but who were readily available for consultation and guidance. Some of the comments in this category were "The supervisor was genuinely interested, easily accessible and gave practical assistance on the wards" and "he (the supervisor) allows me autonomy in performing my duties on the wards". In the category "instruction", the medical residents appreciated $A D$ s who stimulated them to learn by explaining difficult concepts and those who stimulated them to reflect on their clinical knowledge in a non-threatening manner. They used comments like "The supervisor explains a lot, which is very stimulating" and "The way the supervisor stimulated me to reflect on my knowledge was pleasant". Most of the negative comments were in the category of "direct supervision" and included not being treated as adult learners, insufficient supervision for junior residents and not being given more autonomy in their duties on the wards. An illustrative comment was: "The supervisor criticizes my work too much, he does not treat residents as adult learners".

\section{Table 3. Medical RESIDENTS COMMENTS}

ON THE SUPERVISION ATTENDING-DOCTORS PROVIDED

Positive comments

Direct supervision $(\mathrm{n}=10)$

- Genuinely interested, easily accessible, helps practically on the wards ( $\left.\mathrm{x}_{4}\right)$

- Allows me autonomy in performing my ward duties, helpful $\left(x_{4}\right)$

- Provides me with additional supervision in communication skills.

- Coaches me in deciding appropriate ancillary investigations to perform.

Clinical role model $(\mathrm{n}=3$ )

- Enthusiastic $\left(\mathrm{x}_{2}\right)$

- Creates a relaxed atmosphere that is pleasant and encouraging for learning.

Instruction ( $\mathrm{n}=6$ )

- Explains a lor, which is very stimulating ( $\left.x_{2}\right)$

- Asks (many) questions that stimulate me and encourage me to reflect on my knowledge.

- The way 1 was stimulated to reflect was pleasant $\left(x_{2}\right)$

- Stimulates and encourages residents to conduct (medline) literature searches 
Negative comments

Supervision $(\mathrm{n}=8)$

- Reacts impulsively sometimes and especially when expectations are not met. Appears bossy, is rather impatient

- Has no idea of the time available for residents to perform their dinical duties, handly helps in times of need

- The available supervision is insufficient for junior residents $\left(x_{2}\right)$

- Provides too much criticism, does not acknowledge residents as adule learners ( $\left.x_{2}\right)$

- Does not encourage autonomy on the ward $\left(\mathrm{x}_{2}\right)$

Instruction ( $\mathrm{n}-1)$

- Lacks optimal didactic skills but has good social skills that adequately compensate the deficiency

\section{Discussion}

In general, the medical residents rated the quality of supervision they received in all departments positively. The ADs in the NICU received higher ratings than their counterparts in the PICU, except for their performance as clinical role models. The observed differences were not statistically significant, and there were no suitable findings to explain them. We assume that the differences in perceived supervision was influenced by the professional style of the ADs, which was determined for example, by the sort of care they provided to their patients. The area in which most supervisors in the intensive care departments were rated lowly was as evaluator. It was also the area with the lowest average rating in both units. Unfortunately, the comments provided by the residents did not offer a good explanation for this finding.

In the general paediatric wards, the medical residents regarded the supervision as moderately good. What medical residents perceived as outstanding features in the quality of supervision included, 1) ADs being able to create a pleasant learning environment, 2) being stimulated to learn independently (directive learning) and 3 ) being allowed to function independently at a level appropriate to years of experience and competence (professional autonomy). The general comments corroborated these findings demonstrating the importance of treating medical residents as adult learners. The qualities that best predicted good supervision were adjusting teaching to the needs of medical residents and stimulating them to learn independently. Coaching in clinical skills and procedures, in effective communication skills and in making clinical decisions using principles of cost-appropriate care, were features of supervision perceived to be infrequent or poor.

The $A D s$ in the intensive care units were rated lowest in their role as evaluators, and were also found to be deficient in their "direct supervision" and "instruction" roles. The comments of the medical residents reflected their dissatisfaction with these aspects of supervision as they 
favoured ADs who showed understanding and were patient with them. They preferred ADs who treated them as adult learners and provided them with a reasonable amount of feedback that they could apply in practice. They disapproved of supervisors who were bossy, who lacked basic didactic skills, and who were not prepared or available to help when needed. Some of the characteristics we discovered as depicting poor supervision in our study reflected those qualities that differentiated good teachers from bad teachers. ${ }^{20}$ These included:

- Encouraging communication between student and teacher e.g. "creating a pleasant learning environment"

- Appearing to enjoy teaching e.g. "being patient and understanding"

- Being well organized e.g. "adjusting teaching to the needs of the medical resident"

- Being positive role models

- Facilitating learning i.e. "treating trainees as adult learners"

- Being available e.g. "being prepared and/or available to help when needed".

One comment provided by the medical residents in this study that is worth elaborating on is the preference for autonomy when performing their clinical duties. The feature "Allows me autonomy appropriate to my level/experience/competence" was one in which ADs were rated highly (mean = 4.03. SD = 0.39). Some of the general remarks, however, contradicted the desire for professional autonomy, such as: "The available supervision is insufficient for junior residents", "the AD has no idea of the available time residents have for performing their duties", "he hardly helps in times of need". What we found in practice was that in many cases ADs were not readily available to supervise medical residents and that medical residents were often left unsupervised without any back-up in the wards. Interestingly, the more experienced senior residents preferred this situation as it provided them with the independence they required in performing their duties. The junior residents with little professional experience on the other hand viewed this negatively as they felt they needed more supervision. This finding suggests that more supervision should be available for the less experienced trainee, considering also that good supervision is of immense benefit to those trainees.' In addition, it echoes the suggestion that because the needs of trainees vary with level of training, their supervision should be structured, supportive and directive, transforming into a collaborative style as the trainees become increasingly independent and versatile. ${ }^{22}$

One of the strengths of this study was the Cleveland Clinic's Teaching Effectiveness Instrument. In our study, ${ }^{28} \mathrm{ADs}$ in the general paediatric wards were rated by at least five different medical residents using this instrument. Therefore, we can assume that the findings in this group reflect a reliable picture of the quality of supervision both at the individual and group level.

Our inability to investigate how the setting and the time when supervision took place influenced the medical residents' perceptions was a weakness of this study. Although we requested the medical residents to indicate when and where supervision took place, the responses received 
were insufficient to perform reliable analysis. Therefore, we are unaware of whether the highly rated $A D s$ were those whom the medical residents encountered during their normal ward rotations (day-shifts), during the night call duties or a combination of both. We are of the opinion that knowing the effect of when and where supervision takes place could be helpful in developing a strategy to improve the quality of supervision. Other limitations of this study include the few general comments the medical residents provided on the quality of supervision of the ADs. The fact that we conducted two parallel investigations that used two different rating scales could also have caused a reduction in the statistical power of this study. Furthermore, one should not ignore the inherent weaknesses in the rating scales that we used, which could have blurred some of our findings e.g. the tendency to choose the middle score (3) in a five-point scale.

\section{Conclusions}

This study focused primarily on how medical residents perceived the quality of supervision provided by ADs. What we found corroborated reports from earlier studies." "We also attempted to identify what constitutes poor supervision and highlight aspects of supervision that (may) require improvement. What we discovered showed that:

- Improvement is possible in "direct supervision", "instruction", and "evaluation" of medical residents on the wards.

- Medical residents enjoy supervision by ADs who are collaborative, understanding and patient with them.

- Medical residents want to be treated as adult learners

- Medical residents prefer measured and constructive feedback.

The findings in this study emphasise the importance and need for good and effective supervision. We suggest therefore that the focus of effective supervision in medical education should be on improving existent training courses for clinical supervisors.

- What is already known on this subject

Supervision is a complex activity with different modes of delivery that occurs in a variety of contexts. Clear guidance and appropriate mechanisms to resolve difficulties that arise due to inadequate supervision are therefore necessary. Supervision is important for the professional development of medical residents.

- What this study adds

Medical residents prefer to be treated as adult learners. They enjoy supervision by attending-doctors who are collaborative, understanding and patient. They prefer measured and constructive feedback that is adapted to their level of experience and competence.

- Suggestions for further research

"Direct supervision", "instruction", and "evaluation" are areas of supervision where more research is needed for improvement 


\section{REFERENCES}

1. MCL.EOD, P.J. \& HARDEN, R.M. (1985) Clinical teaching strategies for physicians. Medical Teacher, 7: 173-89.

2. LOWRY, S. (1993) Teaching the teachers. British Medical Journal, 306:9.

3. MCLEOD, P.J., STEINERT, Y, MEAGHER, T. \& MCLEOD, A. (2003) The ABCs of pedagogy for clinical teachers. Medical Education, 37:638-44.

4. WIL.KERSON, L. \& IRBY, D.M. (1998) Strategies for improving teaching practices: a comprehensive approach to faculty development. Academic Medicine, 73: 387-96.

5. KILMINSTER S.M. \& JOLLY, B.C.(2000) Effective supervision in clinical practice settings: a literature review. Medical Education, 34:827*40.

6. CONN, J.J. (2002) What can clinical teachers learn from Harry Potter and the Philosopher's Stone? Medical Education, 36:1176-81.

7. COTTRELI., D., KII.MINSTER. S.M., JOL.LY, B.C. \& GRANT, J. (2002) What is effective supervision and how does it happen? A critical incident study. Medical Education, 36:1042-9.

8. BUSARI, J.O, PRINCE., K.A.H., SCHERPBIER, A.J.J.A., VAN DER VLEUTEN, C.P.M. \& ESSED, G.G.M. (2002) How residents perceive their teaching role in the clinical setting - a qualitative study, Medical Teacher, 24(1); 57-6t.

9. GRANT, J., KILMINSTER, S.M., JOLLY, B.C. \& COTTREL.L. D. (2003) Clinical supervision of SpRs: Where does it happen. when does it happen and is it effective? Medical Education, 37:140-8.

10. GENERAL MEDICAL COUNCIL. (1999) The Doctor as Teacher. London: General Medical Council

II. FINUCANE, P., ALLERY, L.A.\& HAYES, T.M. (1992) Teachers at a British medical school. Medical Teacber, 14:275-82.

12. WAL.L, D. \& MCALEER, S. (2000) Teaching the consultant teachers: identifying the core content. Medical Education, 34: 131-8.

13. GIBSON, D.R. \& CAMPBEL.L. R.M.(2000) Promoting effective teaching and learning: hospital consultants identify their needs. Medical Education, 34:126-30.

14. COLES, C.R. \& TOMLINSON, J.M. (1994) Teaching student-centred educational approaches to general practice teachers. Medical Edacation, 28:234-8.

15. DENNICK, R.G. (1996) The Teaching Improvement Project system (TIPS): servicing the need for teacher training in higher education. New Academic, 5:12-3.

16. DENNICK, R, (2003) Long-term retention of teaching skills after attending the Teaching Improvement Project: a longitudinal, self evaluation study. Medical Teacher, 25(3): 314-8.

17. NATIONAL COMMITTEE OF INQUIRY INTO HIGHER EDUCATION. (1997) Dearing Repert Higher Education in the Learning Society. London: HMSO

18. BENNOR D.E.(2000) Faculty development, teacher training and teacher accreditation in medical education: twenty years from now. Mrdical Teacher, 22:503-12.

19. CHALLIS, M. (2001) Building an effective programme for clinical teachers: the role of the staff developer. Medical Teacher, 23:270-6.

20. KILMINSTER. S.M., JOLLY. B.C., \& VAN DER VLEUTEN, C.P.M.(2002) A framework for effective training of supervisors. Medical Teacher $24(4): 385-9$.

21. HEWSON, M.G. \& JENSEN, N.M.(1990) An inventory to improve clinical teaching in the general internal medicine clinic. Medical Edwoation, 24:518-27.

22. COPELAND, L.H. \& HEWSON, M.G. (2000) Developing and testing an instrument to measure the effectiveness of clinical teaching in an academic medical center. Academic Medicine, 75:161-6. 


\section{Chapter 7}

Why Medical Residents should Teach: A Literature Review

Jamiu O. Busari, Albert J.J.A. Scherpbier

Journal of Postgraduate Medicine, 2004; 50: 205-10 


\section{Abstract}

Residents contribute significantly to the quality of undergraduate medical training and it is assumed that they improve their own professional competency in the process. We decided to investigate whether there is evidence to support this assumption. Our hypothesis, the physician as teacher rule, stated that "A skilled teacher has an increased likelihood of becoming a competent clinician, than a skilled clinician has of becoming a competent teacher".

We conducted a literature review to search for evidence to confirm or refute this assumption. Twenty-four articles written after 1990 were identified as relevant from 132 references we generated by searching Medline. The identified articles were qualitatively reviewed to identify key research conclusions and/or main discussion points. The findings from the review were collated and discussed. None of the studies showed specific evidence of how teaching results in improved professional competence. However, there was evidence that teaching ability correlated positively with the perception of clinical competency. There was also need for improved supervision and training programs for residents in teaching skills.

The review provided evidence that teaching influenced the perceived professional competency of physicians positively. Physicians who were perceived as competent were those who taught effectively, and who had a basic understanding of teaching and learning. The review shows that training in teaching is essential for physicians, and that further research is still needed to demonstrate the effect of good teaching on professional competency.

\section{INTRODUCTION}

One of the notable changes in medical education in the past twenty years has been the training of clinical teachers to teach effectively. This development has also witnessed medical residents being increasingly involved in teaching medical students. Plenty of information is available in medical literature on the teaching roles of medical residents and how they and the students they teach can maximally benefit from the process. ${ }^{1,2}$ These include studies that have examined the residents' role in teaching at different levels of the educational process, the effect of teaching by residents in undergraduate education' and the effect of good supervision by attending staff on the quality of residents' teaching skills. ${ }^{45}$ Other studies have focused on the qualitative aspects of the teaching process, on how to improve and evaluate the impact of teacher training programs, ${ }^{6.7 .8 .9}$ and on the extent of the residents' participation in undergraduate medical education. ${ }^{5,10}$ Such studies have shown that residents contribute substantially to the education of medical students ${ }^{11.12}$ and that medical students perceive them as the most important clinical trainers. ${ }^{3}$ In addition, residents revealed the need for supervision from superiors in order to improve their teaching skills. ${ }^{3.6}$ Presently, there is enough proof in the literature explaining why medical residents should teach.' $, 4,10,11,12,13,14$ There is also evidence that the knowledge and professional competency of residents correlates positively with their perceived teaching abilities." " However, in many of 
these studies, it is (implicitly) suggested that residents who can teach effectively are more likely to become competent physicians. Although this seems logical, ${ }^{12}$ there are a few (if any) of these studies that have thoroughly examined the claim. We therefore decided to review the medical literature for evidence that could shed more light on this subject. Our hypothesis, which we called the physician as teacher rule, was that "A skilled teacher has an increased likelihood of becoming a competent clinician, than a skilled clinician has of becoming a competent teacher."

\section{Physician-AS-TeACHER RULE}

The literature in medical education show that despite their lack of good didactic skills, attending doctors (and medical residents) are delegated the task of teaching undergraduate students in the clinical setting. The majority of the physicians who teach, possess little or no formal training in teaching, and employ the skills they acquired from their own experiences as students or residents when teaching. ${ }^{15}$ Some cultivate their teaching styles in practice, through trial and error and by reflecting on personal experience. ${ }^{16,17}$ Others develop a working knowledge of the principles of teaching and learning through observation, adopting positive and rejecting negative examples of clinical instruction. ${ }^{1 /}$ So far, possessing good clinical skills alone is not enough for the physician to teach effectively. This is because the skills of diagnosing illnesses or performing clinical procedures are different from those used in teaching. Teaching is a component of education, and education by itself is a vocation. The assumption that the physician is synonymous with a teacher is therefore wrong.

There is evidence in medical literature suggesting that in addition to being competent, analytical, and up to date in ones area of expertise, a basic understanding of educational theory and training in teaching is required to teach effectively. ${ }^{16,19}$ Knowledge of the subject matter as well as the process of knowledge transfer and receipt is therefore pertinent in teaching. This mechanism and the dynamics involved, however, are concepts that standard medical curricula do not teach. It is therefore a misconception to assume, that without a (prior) training in teaching, a good physician would make a good teacher,. Figure $\mathrm{I}$, illustrates how the components of effective teaching contribute to the cognitive skills, clinical proficiency and teaching ability of the physician.

On the one hand, we can see how the different responsibilities of the physician interact with each other, and on the other how they interact with the physician's cognitive skills, clinical proficiency and teaching ability. Expert medical knowledge and good clinical skills form the cornerstones of teaching in this context, because teaching is taking place in the clinical setting. These in turn, facilitate the development of relevant cognitive skills and clinical proficiency that the learner requires as a medical professional. The knowledge of educational principles and teaching skills also contribute to the development of cognitive skills as seen in this illustration. 
Fig. 1. The Physician-as-Teacher rule

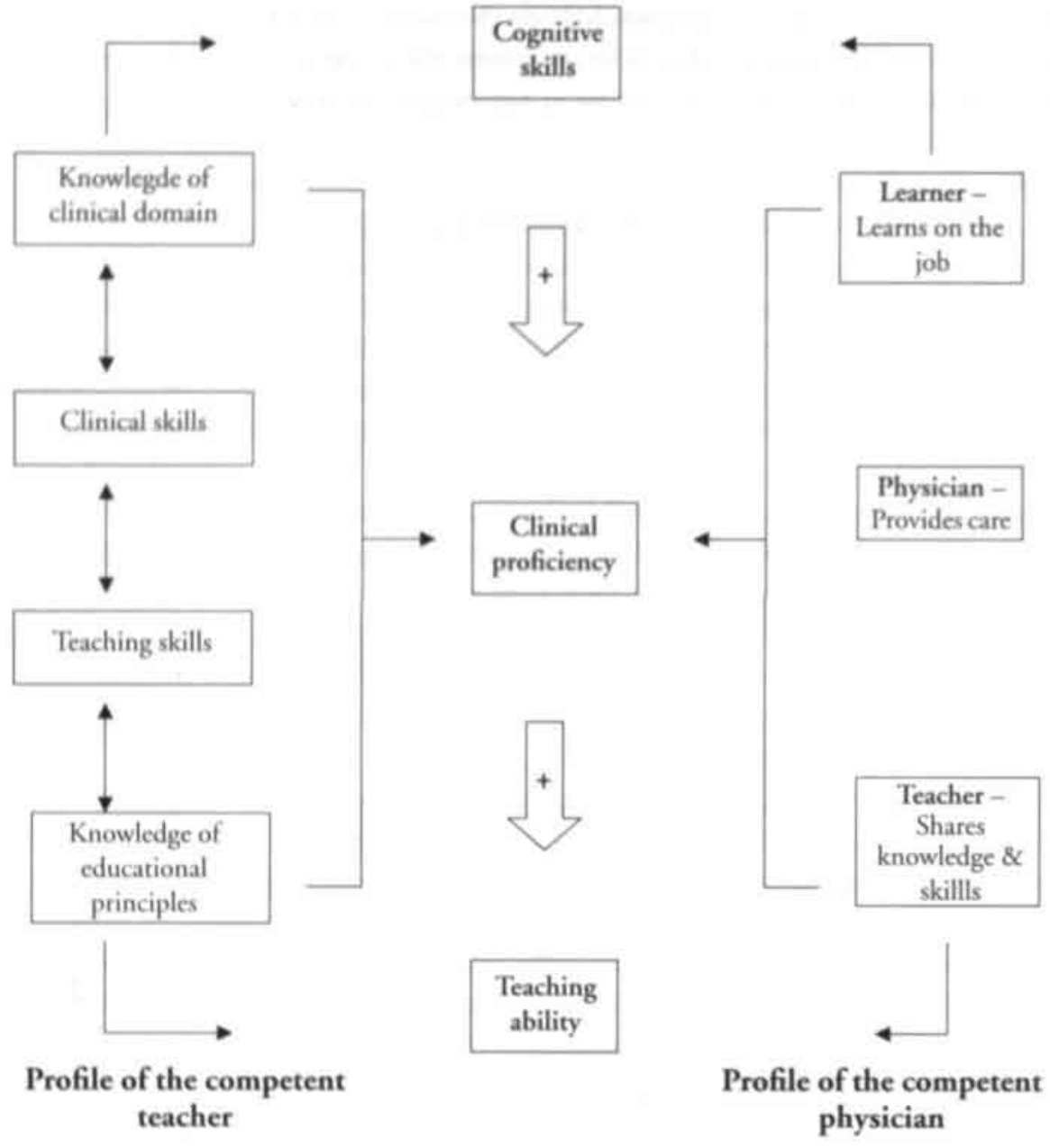


This illustration can also explain why many physicians lack effective teaching skills on completing their professional training, because most residency programs focus only on the right half of the process in the diagram. When we look at the illustration as a whole process, we may understand why physicians who can teach effectively, are regarded as good clinicians. The combined benefits of the components of effective teaching and the effects of the responsibilities as physicians are additive and augment each other. The input from both processes therefore add up and lead to improved cognitive skills, clinical proficiency and teaching ability. With this theoretical background, it is logical to assume that teaching and/or the ability to teach are important requirements for becoming a competent physician. Conversely, we cannot say that the knowledge of medicine or proficiency in clinical skills are requirements that would make one a skilled teacher. Our hypothesis, the physician as teacher rule, is therefore based on the premise, that if physicians are schooled in the principles of good teaching, their teaching skills should improve their clinical competence.

\section{Method}

We chose to examine all relevant literature that investigated the supervisory and teaching roles of medical residents, and the perceptions of any one (or more) of the stakeholders on the subject. The stakeholders referred to were medical students, medical residents, and attending staff. All medical disciplines in which the supervision of medical students took place were included. We did a database search on Medline (National Library of Medicine) using the following key words: "medical residents OR junior doctors", "teaching", "training" "medical students" "supervision" and "perceptions". We selected relevant review and research papers published on the subject after 1990 because we were interested in the latest developments in the area. The initial search resulted in 132 articles, which we scaled down to 49 based on the closeness of title to the subject of interest. Both authors conducted a second screening procedure separately, by analyzing the abstracts of the selected papers. Articles whose study objectives did not address any of the review's two central questions or whose results reported very low response rates (i.e. < $50 \%$ ) were excluded. Twenty four articles were eventually selected. The approach we adopted in the analysis was to examine the selected literature based on two central questions namely,

- Does teaching improve professional competence?

- Is training or supervision in teaching skills necessary for physicians?

The findings from the analysis were then used to evaluate if our hypothesis could be accepted or rejected. After the first session of reading, another six articles were dropped because the teaching roles of medical residents did not form their central objective. Most of the articles finally included in the review ( $n=14$ ) were quantitative research surveys that investigated the perceptions of the stakeholders on various aspects of medical residents' teaching and supervisory responsibilities. ${ }^{3,7,8,13,14,15,20,21,22,23,24,25,26,27}$ The medical disciplines that were involved 
included surgery, paediatrics, internal medicine, family medicine, and radiology. The articles were explorative studies that varied between smalf, 22 and large ${ }^{13,28,29}$ scale surveys, and whose research designs involved at least 4 different methodological approaches. ${ }^{20.24 .28 .26}$ The remaining four articles included one cross sectional survey of medical students perceptions of the subject, two qualitative studies, and one literature review. $6.19,29,30$ The heterogeneity of the studies and the observed variability in research designs made meta-analysis inappropriate for the review.

Another problem we encountered in preparing the review was how to properly define the competent clinical teacher and physician. Since there were several ways of defining a competent clinical teacher, we decided to use Irby's definition partly because of his renowned expertise on the subject and importantly, because his description suited the objective of our review. ${ }^{19}$ The competent clinical teacher was defined as being in possession of the clinical knowledge of medicine, patients, and the context of practice, as well as educational knowledge of learners, general principles of teaching and case based teaching scripts. Like the competent clinical teacher, it was also difficult to properly define the competent physician. The complexity and constant changes in the needs and expectations of medical science, societal norms and patient care on physicians, made this difficult. We defined the competent physician as one who is professionally competent, respectful, honest, caring and one who upholds patient confidentiality."

\section{DOES TEACHING IMPROVE PROFESSIONAL COMPETENCE?}

During their professional training, medical residents perform administrative, managerial, and technical related duties. They also teach medical students and peers, and it this last activity that we paid attention to in this review. The duties medical residents perform in clinical practice reflect their professional profile namely the "physician", "learner" and "teacher". These roles are determined by the context in which they are expected to function, and can be represented as a triangle shown in figure 2 , whose ends are continuously interchanging with each other. It reflects how residents are randomly and haphazardly changing their roles. 


\section{Physician}

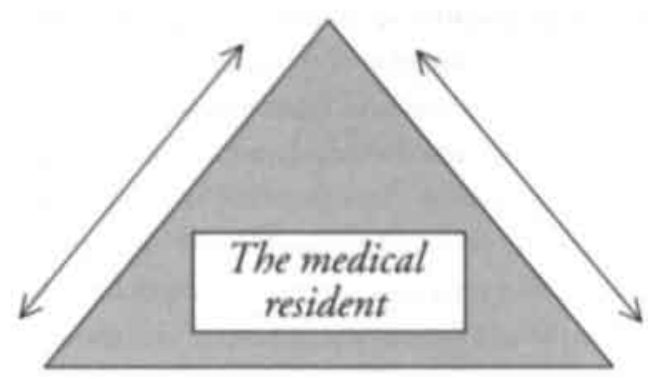

\section{Learner}

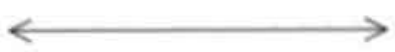

Teacher

As is known in the medical profession, the primary professional responsibility of the medical resident is as a physician, who in the hospital setting, is required to provide care and good health service to the patients. As aspiring specialists in their chosen fields, they are learners or apprentices i.e. "learning on the job", and a proportionate amount of their learning is acquired in the process of performing their professional duties. Lastly, the "resident as teacher", performs the didactic function of sharing his/her knowledge with medical students in the wards, during grand rounds and in the outpatient clinics. In practice, medical residents often combine two or more of these roles simultaneously. For example, during grand rounds with consultants/specialist physicians they can be seen as "physicians and learners", likewise during ward rounds with the medical students they function as "physicians and teachers".

As to whether teaching results in an improvement in the professional competence of medical residents however, we could not find sufficient direct evidence to support this in the literature. Scheiner et al. demonstrated that when radiology residents and attending radiologists underwent a similar standardized training program to teach medical students, the performance of the latter were just as effective as that of the attending-radiologists ${ }^{20}$. In a qualitative study that investigated how medical residents perceived their teaching role in the clinical setting, residents supported the notion that teaching medical students helped them in being better clinicians ${ }^{6}$. They supported their views with comments reflecting the theory that teaching stimulated critical thinking and reflection on knowledge. They noted that being stimulated to reflect served as a motivator to constantly keep their clinical knowledge abreast which enhanced self-learning. In an attempt to prepare surgery house officers for their teaching role, Sheets et al. conducted a detailed review of the medical literature for information on the subject ${ }^{21}$. They investigated studies on the teaching role of residents (house officers), how different stakeholders perceived 
teaching by residents, and how if necessary, teaching could be improved. This review provided valuable information on the role of residents as teachers of medical students. It showed that suitable teaching conditions, training in teaching, frequent and constructive feedback in teaching, and supervision by attending staff, were some of the aspects that were lacking in most educational settings. The review demonstrated that medical residents contributed significantly to the education of medical students, and that they (residents) enjoyed and were willing to teach to medical students. It also included studies in which medical residents reported that teaching medical students improved their individual clinical and intellectual skills. In their internal audit study of the role of surgical housestaff in the education of clinical clerks, Minor and Poenaru showed that teaching was beneficial for residents and that they could be taught to teach better. ${ }^{22}$ Pelletier and Belliveau showed that formal teaching by surgical residents enhanced knowledge acquisition, relative to self study and lecture attendance. ${ }^{23}$ In another large-scale comparative study, the perceptions of residents and faculty were investigated for the definition of the good and effective teacher. ${ }^{24}$ This study showed that the good clinical teacher was not only enthusiastic about teaching, but also able to stimulate intellectual curiosity and motivate self-directed learning in their students. Effective teachers were further described in the study, as good, competent and credible physicians who served as good role models in dealing sensitively with patients and families. Most of the studies described above showed a positive causal relationship between teaching and the medical residents' perception of improved professional competence. Unfortunately, none of them provided specific evidence that could explain or confirm this relationship.

\section{IS TRAINING (OR SUPERVISION) IN TEACHING SKILLS NECESSARY?}

Providing learners with the necessary materials and experiences that can facilitate individual learning is an important function of the educational process. As learning is not an automatic process, it is necessary to know how the process works. The literature on educational theory provides different descriptions of the process of learning. These descriptions underlie our ability to analyse and diagnose educational problems and guide applied research. They also share a similarity in the way they describe the concept of acquisition and compilation of knowledge for example, the theory that knowledge has to be bundled and systematically packed in such a way, that it is easily transferable and retrievable for application by the learner when solving problems. ${ }^{32.13}$ The concept of approach to learning is also described in the literature, but unlike educational theory, it highlights the "qualitative" aspect of education that is concerned with how learners organize and apply information. ${ }^{4}$ The background that learning involves a process, that if well understood, can improve teaching is clear. This is particularly relevant since the teaching responsibilities delegated to medical residents in many medical institutions have increased substantially. ${ }^{21,22}$ Training teaching skills in residency training programmes is therefore essential and should be encouraged. ${ }^{21,22,25,28}$ 
In a survey that investigated the qualities of good and effective teachers among paediatric residents and faculty. ${ }^{24}$ the style and content of what teachers taught were found to be important. Recommendations were made on why and how training in teaching skills should be encouraged. These included physicians spending more time on learning both the content of what to teach and how to teach. Irby also showed why it was important for clinical teachers to understand the (medical) educational process, and how it reinforces and improves their own didactic, cognitive and clinical skills". In 1996, Blount and Jolissaint investigated how primary care and non-primary care US army residents perceived the teaching behaviours of their faculty staff $^{2}$. Their responses indicated that (certain) teaching behaviours of the faculty staff needed to be improved. In another study, Bing-You and Greenberg ${ }^{26}$ investigated the perceptions of twenty-six residents in internal medicine who participated in a series of teaching workshops over a six-month period. The rationale for the conducting the study was that formal instruction improves the teaching skills of residents. $35,36,37$ There was a high level of participation by the residents in the study, reflecting their desire and appreciation for formal instruction in teaching. The residents considered teaching to be an important part of their role and were willing to teach medical students. Other studies corroborated these findings ${ }^{6,9.27}$ and showed that residents were willing to be evaluated for their teaching, provided the assessment methods were clear, formal and structured. ${ }^{6}$ Sheets et al. provided comprehensive proof on the importance of teaching by residents and why it should be encouraged ${ }^{21}$. They argued that faculty administrators should formally and widely acknowledge the teaching role of residents and that appropriate teaching skill improvement activities should be provided. Two different qualitative studies also provided explanations for why such training programs in teaching were necessary as well as why the supervision by attending staff was important for this..$^{6,30}$

The information we have so far shows that training physicians to teach effectively is important. Adequate guidance and supervision for junior doctors is also mandatory. Our assumption that the process of knowledge acquisition would be better understood if (and when) physicians are aware of the fundamental theories of learning is also supported. There are many advantages in this for clinical teachers for example, they would be more conscious of how they compile their own knowledge as well as how this process occurs in the students they teach. By understanding how the information they transfer is processed, physicians can anticipate and relate better with the learning difficulties medical students encounter. Finally, the significance of different educational concepts in teaching and the individual approaches to learning can be appreciated better. The illustration in figure 3 shows how these concepts constitute and facilitate the process of learning and the interrelationship between them. 
Fig. 3. Teaching in the clinical, setting

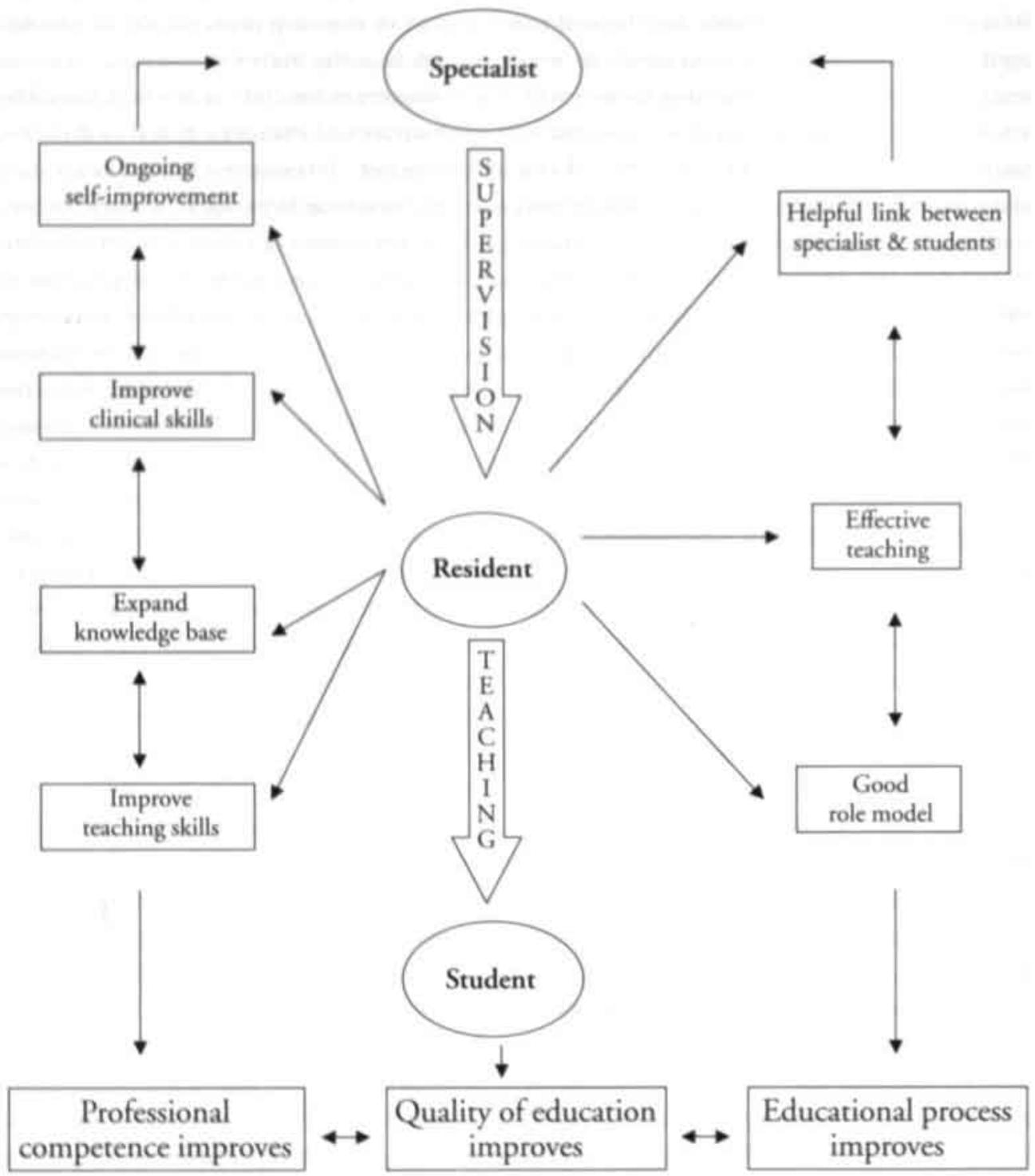


The illustration shows the way teaching contributes to both the educational process of students and to the professional development of medical residents (physicians). It stimulates self-improvement, expands knowledge base and improves both the teaching and clinical skills of the medical resident. Conversely, it contributes to the educational process of medical students through the direct didactic activities residents provide, the good role models they form for the latter to emulate and the important link they provide between attending staff and medical students. The figure also shows how the supervision by attending staff physicians is important and how effective supervision results in a better quality of education for both residents and students.

\section{Discussion}

The purpose for conducting this review was to identify if there was evidence that possessing good teaching skills would result in professionally competent physicians. The hypothesis, which we called the physician as teacher rule, was that "A skilled teacher has an increased likelihood of becoming a competent clinician, than a skilled clinician has of becoming a competent teacher." We approached this investigation by answering two central questions, whether teaching improves the professional competence of physicians and whether training or supervision in teaching skills was necessary for physicians. The information generated from this review provided some answers to the central questions, which we summarized and discussed in each section. In summary, teaching by physicians, particularly medical residents, improves their (perceived) professional competency, although studies to objectively demonstrate this were lacking. Training in teaching skills was found to be very important and was strongly recommended. Furthermore, the importance of good and sufficient supervision by attending staff was an important additional finding.

Regarding the legitimacy of our hypothesis, we found evidence that teaching improves the perceived professional competency of physicians. The evidence however was subjective and lacked validation. Furthermore, we found no studies that disproved the assumption. The review also showed that (perceived) competent physicians were those who taught effectively, and also possessed the basic understanding of teaching and learning. Presently, the hypothesis discussed in this review still needs to be validated. We also acknowledge that additional research is needed to assess the legitimacy of the relations that have been generated in this review. Nonetheless, we emphasize the importance of teaching skills (training) in the professional development of physicians and recommend its inclusion in the curricula of postgraduate medical training. 


\section{Key Messages:}

- Physicians (medical residents) should have an idea of the concepts that constitute and facilitate the process of learning in order to improve their teaching effectiveness

- Teaching stimulates self-improvement, expands knowledge-base and improves the teaching and clinical skills of physicians

- The development of cognitive skills in physicians is augmented by knowledge of educational principles and good teaching skills

- It is a misconception to assume that without a prioer training in teaching, a competent physician is als a good teacher

\section{REFERENCES}

1. TONESK, X. (1979). The house officer as a teacher: what schools expect and measure. Journal of Medical Education, 54: 613-616.

1. BORLEFFS, J.C.C., CATE, Th. J, ten, BRUIJNZEEL-KOOMEN, C.A.F.M. \& ERKELENS, D.W. (2002) (Dutch with summary in English). A proposal for the introduction of an internship in clinical didactics into residency training. Dutch Journal of Medical Education, 2t( $(x): 25-32.2$.

3. THOMAS, P.S., HARRIS, P., RENDINA, N. \& KEOGH, G. (2002). Residents as Teachers: Outcomes of a brief training programme. Education for Health: Change in Learning of Practice, 15(1):71-78.

1. KATES, N.S, \& LESSER, A.L. (1985). The resident as a teacher: a neglected role. Canadian Journal of Prychiatry, $30(6): 418-21.4$.

5. APTER, A. METZGER, R. \& GLASSROTH, J. (1988). Residents' perception of their role as teachers. Journal of Medical Education. 63, 185 -188.

6. BUSARI, J.O, PRINCE, K.A.H., SCHERPBIER, A.J.J.A., VAN DER VL.EUTEN, C.P.M. \& ESSED, G.G.M.(2002). How residents perceive their teaching role in the clinical setting - a qualitative study. Medical Tracher, 24(1): 57-6t.

7. BING-YOU, R.G. \& SPROUL, M.S. (1992). Medical students' perceptions of themselves and residents as teachers. Medical Teacber, 14 (2-3): 133-38.

8. PARLE. J., WALL, D., HOLDER, R. \& TEMPLE, J. (1995). Senior registrars' communication skills: attitudes to and need for training. British Journal of Hospital Medicine, 53(6): $257-60$.

9. BUSARI. I.O., SCHERPBIER, A.JJ.A., VL.EUTEN, C.P.M.. VAN DER \& ESSED, G.G.M. (2000). Residents perception of their role in teaching undergraduate students in the clinical setting. Medical Teacher, 22(4):348-53

10. GREENBERG, 1.W., GOLDBERG, R.M. \& JEWETT, L.S, (1984). Teaching in the clinical setting: factors influencing residents' perceptions, confidence and behavior. Medical Edacation, 18: 360-65

u. BARROW. M.V. (1966). Medical students' opinions of the house officer as a medical educator. Journal of Medical Eduottion, +1: 807-10. 
12. STEWARD, D.E. \& FELTOVICH, P.J. (1988). Why residents should teach: the parallel processes teaching and learning. In J.C. EDWARDS \& R.L. MARIER (Eds.) Clinical Teaching for Melioal Residenes: Roles, Techniques and Programs, 3-14, New York: Springer Verlag.

13. REMMEN, R., DENEKENS, J., SCHERPBIER, A.J.J.A., HERMANN, I., VAN DER VIEUTEN, C.P.M., VAN ROYEN. P. \& BOSSAERT, L..(2000), An evaluation study of the didactic quality of clerkships. Modical Education, 34: 460-464.

14. STENCHEVER, M.A., IRBY, D.M. \& O'TOOLE, B.(1990), A national survey of undergraduate teaching in Obstetrics and Gynaccology. Journal of Medical Education, 54: 467-470.

15. GIBSON, D.R. \& CAMPBELL. R.M. (2000). Promoting effective teaching and learning: hospital consultants identify their needs. Medical education, 34: 126-130.

16. Mc LEOD, P.J. \& HARDEN, R.M. (1985) Clinical teaching strategies for physicians. Medical Thucher, 7 . 173-89.

17. LOWRY, S. (1993). Teaching the teachers, British Medioal Journal, yo6: 127-130.

18. WIL.KERSON, L. \& IRBY, D.M. (1998). Strategies for improving teaching practices: a comprehensive approach to faculty development. Academic Medicine, 73:387-96.

19. IRBY. D.M. (1994). What Clinical Teachers in Medicine Need to Know. Academic Medicine, 6ro: 333342.

20. SCHEINER, J.D. \& MAINERO, M.B. (2003). Effectiveness and Student Perceptions of Standardized Radiology Clerkship Lectures. A Comparison between Residents and Attendant Radiologist Performances. Academic Radiology, 10: 87-90.

2. SHEETS, K.J., HANKIN, F.M. \& SCHWENK, T.L. (1991), Preparing Surgery House Officers for Their Teaching Role. The American Journal of Surgery,16r: 443-449.

22. MINOR, S. \& POENARU, D. (2002). The in-house education of clinical clerks in surgery and the role of housestaff. The American Journal of Surgery, 184: 471-475.

23. PELLETIER, M. \& BELLIVEAU, P. (1999). Role of surgical residents in undergraduate surgical education. Canadian Journal of Surgery, 42:451-456.

24. HILLIARD, R.I. (1990). The good and effective teacher as perceived by paediatric residents and faculty. American Journal of Diseases of Children, 144:1106-no

25. BUSARI, J.O. SCHERPBIER, A.J.J.A. VAN DER VLEUTEN, C.P.M \& ESSED, G.G.M. (2003). The perceptions of attending-doctors on the role of residents as teachers of undergraduate medical students. Medical education, 37: 241-47

26. BING-YOU, R.G. \& GREENBERG, L.W. (1990). Training residents in clinical teaching skills: a resident-managed program, Medical Teacher, 12:305-308.

27. SEELY, A.J., PELL.ETIER, M.P., SNELL. L.S. \& Trudy, J.L.(1999). Do surgical residents rated as better teachers perform better on in-training examinations? American Journal of Surgery, 177:33-7.

28. XU, G., WOL.FSON, P., ROBESON, M., VELOSKI, J.J. \& BRIGHAM, T.P. (1998). Students' satisfaction and perceptions of attending physicians' and residents' teaching role. American Journal of Surgery, 176(r): $46-48$.

29. BLOUNT, W.B. \& JOLISSANT, G. (1996). Perceptions of Teaching Behaviours by Primary Care and Non-primary care Residents, Academic Medicine, 71: 1247-49

30. KHERA, N., STROOBANT, J., PRIMHAK, R.A., GUPTA, R.\& DAVIES, H. (2001). Training the ideal hospital doctor: the specialist registrars' perspective, Medical Education, 35: 957-966.

31. RHODES, R. (1998). Ethical considerations for Residents, Academic Medicine, 73: 854-64. 


\section{Chapter 7}

32. THORNDIKE, E.L.. (1932), The fundamentals of Learning. New York: Teachers college, Columbia University

33. NEVES, D.M. \& ANDERSON, J.R. (1981). Knowiedge compilation: Mechanisms for the automatization of cognitive skills. In J.R.ANDERSON (Ed.) Cognitive skills and their acquisition, 86-102, Hillsdale, NJ: Eribaum

34. RAMSDEN, P. (1992). Chapter 4: Approaches to learning. In: Learning To Teach In Higher Education, 38-62, London: Routledge

35. LAWSON, B.K. \& HARVILL, L.M. (1980) The evaluation of a training program for improving residents' teaching skills. Journal of Mrdical Education, 55:1000-05.

36. CAMP M.G. \& HOBAN J. D. (1988) Teaching medicine Residents to Teach. In J.C. EDWARDS \& R.L. MARIER (Eds.) Clinical Teaching for Medical Residents: Roles, Techniques and Programs, 201-213, New York: Springer Veriag.

37. EDWARDS, J.C., KISSLING, E.G., PL.AUCHE, C.W. \& MARIER L.R. (1988) Developing and evaluating a teaching improvement program for residents. In J.C. EDWARDS \& R.L. MARIER (Eds.) Clinical Traching for Medical Revident: Roles. Techniquer and Programi, 157-174, New York: Springer Verlag. 


\section{Chapter 8}

Designing the Training Program: A Guideline for Course Developers 


\section{INTRODUCTION}

The process of teaching, irrespective of approach, revolves around the transfer of knowledge (or information) from one source to the other. The effective transfer of such knowledge is dependent upon identical elements present within the learning setting where the concept is taught, and the wards or clinics where the concept would be applied. It means that in practice, the extent to which two tasks share common methods, procedures or associations that would result in similar artitudes within the desired environment, should determine the way knowledge is transferred. There are however, two known dilemmas that many course developers encounter when developing educational interventions. The first dilemma is how to satisfactorily determine the content of what should be taught by the tutor and/or learnt by the pupil. The second dilemma is how to develop a method of instruction that would enhance the effective transfer of the knowledge (or information) that should be learnt. In this chapter, a description is provided of how these two dilemmas were addressed in this thesis. The first part describes how the content of an educational program can be determined using learning needs assessment and which methods we used in this study', while the second part describes the design of the workshop.

\section{IDENTIFYING THE LEARNERS NEEDS}

It is not unusual, that experts in medical education are faced with difficult decisions when developing training (or educational) programs that are aimed at adequately addressing the leaning needs of medical residents. As has been shown in the literature, these difficult decisions may be related to the discrepancies that exist between what medical residents perceive as their needs, and what professional or continuing medical education bodies identify as priority educational needs ${ }^{2}$. It is not surprising therefore if/when the intended objective of an educational intervention is not achieved. Basically, what should be borne in mind when developing an educational intervention is that its aim should be to effectuate (a) change in the conduct of medical residents (or students). The intervention should focus on ways of achieving good standards of professional practice as well as possess educational strategies that are individual, supportive and objective.

Needs assessment is an example of such an intervention that possesses these strategies. It is a systematic process of collecting and analyzing information on what a target group needs to learn'. It can be used to identify the deficiencies in a learners knowledge, skill, behavior or attitude in current teaching practices, as well as anticipate deficiencies in the quality of education based on expected changes in health care needs ${ }^{3}$. It is recommended that needs assessments should be conducted before developing any educational activity for adult learners, so that maximum use of the available information can be made for the benefit of the learnerst. Finally, the learning needs of postgraduate learners can be classified into two groups based on I) Who is determining the needs i.e. learners, educators, or others and 2) What standards are being used as the ideal. 


\section{TYPES OF LEARNING NEEDS}

Normative needs are described as the measured gap or difference between the set educational standards and the individual's (or group's) current knowledget. These needs encompass the knowledge skills and attitudes of the residents, which are determined by professional certifying bodies e.g. the Dutch association of paediatrics and American board of paediatrics. The standards that are set are based on professional judgment, expert opinion, or research information and the opinion of the learners are not taken into account. Prescribed needs are those areas that the educators or program planners determine as inadequate and that need educational intervention. Felt or Perceived needs are what the learner(s) identify as what they want to learn. Their knowledge, experience and environment they work in influence most of these needs and they are the needs as perceived by the learners themselves. Expressed needs are what an individual or group express as their needs. They are characterized by sentences such as "I know what I don't know". A pitfall of this method is that not all the needs of the learner(s) may be expressed, for example, due to the learner's embarrassment of being identified as lacking in knowledge. This may eventually result in educational interventions that are incomplete. Unperceived needs however are those needs not perceived by the learners as a learning need, but are identified by teachers, professional bodies, clients or patients, national and international organisations. Such needs are identified through epidemiological reviews of health care or educational problems within institutions or communities 5 . Finally, Comparative needs are those learning needs identified by comparing two similar groups or individuals rather than against normative standards e.g. medical residents from university $\mathrm{X}$ are less skilled in communicative skills compared to their counterparts in university Y. (see Table I).

\section{Table I. Types of LeARning Needs \\ (Adapted from Ratnapalan \& Hilliard, 2002)}

\begin{tabular}{|l|l|l|l|}
\hline $\begin{array}{l}\text { Learners' Needs \& } \\
\text { Wants }\end{array}$ & Focuses on & Who Decides & Good for \\
\hline Normative & $\begin{array}{l}\text { The set standards for } \\
\text { Learners' knowledge }\end{array}$ & $\begin{array}{l}\text { Professional bodies, } \\
\text { institutions e.g. Dutch } \\
\text { association of paediatrics }\end{array}$ & Board certification, licensing \\
\hline Prescribed & $\begin{array}{l}\text { Deficiencies in current } \\
\text { educational program }\end{array}$ & $\begin{array}{l}\text { Program directors } \\
\text { Educarors }\end{array}$ & $\begin{array}{l}\text { Training residents in a par- } \\
\text { ticular program }\end{array}$ \\
\hline Perceived & $\begin{array}{l}\text { What the students may } \\
\text { think they want to learn }\end{array}$ & Learners & $\begin{array}{l}\text { For planning educational } \\
\text { activities }\end{array}$ \\
\hline Expressed & $\begin{array}{l}\text { What the students say } \\
\text { they want to learn }\end{array}$ & Learners & $\begin{array}{l}\text { For planning educational } \\
\text { activities }\end{array}$ \\
\hline Comparative & $\begin{array}{l}\text { Needs of } 2 \text { groups com- } \\
\text { pared to one another }\end{array}$ & $\begin{array}{l}\text { Program directors } \\
\text { Educators }\end{array}$ & $\begin{array}{l}\text { For improving a cohort of } \\
\text { residents }\end{array}$ \\
\hline Unperceived & $\begin{array}{l}\text { What learners don't know } \\
\text { that they need to know }\end{array}$ & $\begin{array}{l}\text { Educators } \\
\text { Institutions } \\
\text { Allied health professional }\end{array}$ & $\begin{array}{l}\text { For identifying some impor- } \\
\text { tant educational objectives }\end{array}$ \\
\hline
\end{tabular}




\section{TYPES OF NEEDS ASSESSMENTS}

With respect to the different methods of needs assessment, the published literature demonstrates that medical educators often use more than one method of needs assessment to plan educational activities $^{6}$. These methods are used either in isolation or in combination with other needs assessment methods. In the latter case, the strategy is referred to as "triangulation", when the data from different needs assessments methods are combined to identify the learning needs of the target group. This concept is important in postgraduate medical education because the combination of different needs assessment methods can be very beneficial in planning educational activities. Examples of methods used in conducting needs assessment in medical education include questionnaires, interviews, focus groups, chart audits, chart simulated recall, standardized patients and environmental scans.

Questionnaires elicit written responses to specific questions in order to gather information from the responders. They are considered quantitative forms of needs assessment because the frequency of responses can be counted and answers to questions can be weighted with a numerical value. The responses however depend on the design and quality of the questions asked5. Questionnaires are a popular form of needs assessment and can be used alone or in combination with other methods. They are cheap, easy to administer, can sample large numbers of respondents and can be returned anonymously. The limitations of this method however are that they tend to have poor response rates and the effectiveness is dependent on the content and context of the questionnaire?

Interviews can be viewed as conversations with the aim of gaining a thorough insight into someone's perspective of a subject. The advantages of this method are that it is personal and gives the researcher and in-depth understanding of the learner's perspectives. Qualitative interviewing unveils a broader range of learning needs and opportunities for program development than quantitative methods $s^{8}$. Unfortunately, they take a lot of time and effort and are not feasible for assessing the needs of a large number of learners.

Focus groups are usually seven to ten randomly selected participants that meet the criteria of consumers of a particular service, and are interviewed by a skilled facilitator who whilst encouraging a sense of synergy explores the differences in opinions. Focus group interviews differ from individual interviews, because members of the group draw strength from one another to express opinions that they may otherwise view as unpopular. This is particularly important in eliciting negative views or constructive criticism from learners. The use of focus groups for needs assessments in postgraduate medical education is increasing and they are useful in areas of health care where physician attitudes or behaviour modifications are the subject of interest.

Chart audits are reviews and assessments of patients' medical records that use current criteria and standards. They are used as needs assessment tools in a variety of postgraduate and con- 
tinuing professional educational situations. They are used to determine learning needs prior to education, to assess change after education, and to assess variations in professional practice 9

Chart-Stimulated recall are case-based interviews that provide the rationale for management decisions and for other options that my have been considered and ruled out. Interviewers are often trained health professionals and the lengths of the interviews are between $15-20$ minutes. Usually, three to six chart-stimulated recalls are enough to provide reliable and valid assessmentsio and the interviews give medical residents the chance to explain the rationale behind particular management decisions. ${ }^{10}$ Chart stimulated recalls are more expensive than chart audits and are unlikely to be feasible if the needs of a large number of physicians have to be assessed.

Standardized patients are either healthy patients trained to present a particular medical case accurately or an actual patient who is trained to present his/her illness in a standardized manner. Standardized patients can be used for assessing needs for medical education and also to assess the impact of an educational activity. They can also be used to assess both the competency in simulated settings and performance in actual practice. It is particularly helpful in situations where it is unethical or impractical to assess certain skills, attitudes or behaviours in the real setting. Needs assessment in postgraduate education of counselling skills or ethical management issues can be accomplished using this method.

Environmental scans are non-threatening and unobtrusive research methods that check existing sources of information. They refer to methods and resources that professional educators use to assess their surrounding to help them identify current and potential learning needs. They can be internal (within the institution) involving the evaluation of resources like previous oral or written recommendations, attendance data or budget information for example. They can be external (outside the institution) involving the evaluation of resources like guidelines of literature searches, published reports and recommendations from professional organizations or medical core curricula". Environmental scans are very economic sources of data collection, and the data are usually regularly upgraded. They can also be used without inconveniencing the target population. Unfortunately, they may provide too much information that results in data analysis that is time consuming and expensive. Furthermore, interpretation of data may be limited by the interpreters' perspective. An overview of the needs assessment methods is provided in table 2. 


\section{Table 2. Types of NeEds Assessments \\ (Adapted from Ratnapalan \& Hilliard, 2002)}

\begin{tabular}{|l|l|l|l|l|}
\hline $\begin{array}{l}\text { Types of Needs } \\
\text { Assessments }\end{array}$ & $\begin{array}{l}\text { Type of data } \\
\text { collected }\end{array}$ & $\begin{array}{l}\text { Good for deter- } \\
\text { mining }\end{array}$ & $\begin{array}{l}\text { Advantages for } \\
\text { postgraduate medical } \\
\text { training }\end{array}$ & Can be used to \\
\hline Questionnaires & Quantitative & $\begin{array}{l}\text { Perceived needs } \\
\text { Expressed needs }\end{array}$ & $\begin{array}{l}\text { Can sample large } \\
\text { groups }\end{array}$ & $\begin{array}{l}\text { Identify seminar } \\
\text { topics }\end{array}$ \\
\hline Interviews & Qualitative & $\begin{array}{l}\text { Perceived needs } \\
\text { Expressed needs }\end{array}$ & $\begin{array}{l}\text { Identify individual } \\
\text { learning needs }\end{array}$ & $\begin{array}{l}\text { Plan remedial train- } \\
\text { ing }\end{array}$ \\
\hline Focus groups & Qualitative & $\begin{array}{l}\text { Perceived needs } \\
\text { Expressed needs }\end{array}$ & $\begin{array}{l}\text { Evaluate program } \\
\text { and identify areas of } \\
\text { discrepancy }\end{array}$ & $\begin{array}{l}\text { Improving or modify- } \\
\text { ing existing teaching } \\
\text { strategies }\end{array}$ \\
\hline Chart audits & $\begin{array}{l}\text { Quantitative \& } \\
\text { Qualitative }\end{array}$ & $\begin{array}{l}\text { Prescribed needs } \\
\text { Unperceived needs }\end{array}$ & $\begin{array}{l}\text { Identify areas of weak- } \\
\text { ness in a cohort of } \\
\text { residents }\end{array}$ & $\begin{array}{l}\text { Identify common } \\
\text { medical errors }\end{array}$ \\
\hline $\begin{array}{l}\text { Chart-stimulated } \\
\text { recall }\end{array}$ & $\begin{array}{l}\text { Qualitative \& } \\
\text { Quantitative }\end{array}$ & $\begin{array}{l}\text { Prescribed needs } \\
\text { Unperceived needs }\end{array}$ & $\begin{array}{l}\text { Identify individual } \\
\text { learning needs }\end{array}$ & $\begin{array}{l}\text { Evaluate problem } \\
\text { solving skills }\end{array}$ \\
\hline $\begin{array}{l}\text { Standardized } \\
\text { patients }\end{array}$ & $\begin{array}{l}\text { Qualitative \& } \\
\text { Quantitative }\end{array}$ & $\begin{array}{l}\text { Normative needs } \\
\text { Unperceived needs }\end{array}$ & $\begin{array}{l}\text { Identify learning } \\
\text { needs in attitude, or } \\
\text { behaviour }\end{array}$ & $\begin{array}{l}\text { Identify learning ob- } \\
\text { jective for topics like } \\
\text { ethics or counselling }\end{array}$ \\
\hline $\begin{array}{l}\text { Environmental } \\
\text { scans }\end{array}$ & $\begin{array}{l}\text { Quantitative \& } \\
\text { Qualitative }\end{array}$ & $\begin{array}{l}\text { Prescribed needs } \\
\text { Unperceived needs } \\
\text { Prescribed needs }\end{array}$ & $\begin{array}{l}\text { Identify educational } \\
\text { objectives. Evaluate } \\
\text { previous cducational } \\
\text { activities }\end{array}$ & $\begin{array}{l}\text { Plan educational } \\
\text { activities that are } \\
\text { relevant }\end{array}$ \\
\hline
\end{tabular}

As can be seen, the objective of an educational activity can easily guide the choice of a needs assessment method. For example, if the goal of education is to prepare learners for a test that is scheduled to take place within a short period of time, it would make sense to use a teaching strategy that is developed based on normative needs. On the other hand, if the learners are fully aware of the normative needs of the educational program as in the case of medical residents in the final year of their specialist training, then it would be appropriate for the educator to focus on the learners perceived or expressed needs. Studies in the literature have shown situations whereby needs assessment has been used to develop medical educational programs. Such examples include the study in Dublin, where questionnaires and semi-structured interviews were used to conduct a national educational needs' assessment of interns with the aim of developing training programs for them ${ }^{12}$. Also, another study in Canada showed how surveys and environmental scans were used to develop a successful core curriculum initiative for postgraduate medical education's. 


\section{DEVELOPING THE TWO-DAY WORKSHOP FOR TRAINING TEACHING SKILLS}

\section{BUILDING THE FRAMEWORK}

There were five contributors involved in designing this training program. Three of them were experienced educational researchers and teachers, two of them being physicians as well. One author was a medical resident and $\mathrm{PhD}$ student in medical education, while the last contributor was a medical student who was actively involved in medical education. To begin with, the development of this workshop involved conducting a learning needs assessment of the teaching duties of the medical residents. The type of needs assessment methods that were used in developing this workshop included questionnaire surveys (chapters 3, 5, 6), interview (chapter 4) and environmental scans (chapters 7$)^{1,2}$. The questionnaire surveys (Chapters $3 \& 5$ ) and interviews (chapter 4 ) were used to investigate the perceived needs of the medical residents on the subject, while the views of attending physicians were examined using a questionnaire survey alone (chapter 5). The environmental scan involved reviewing information from relevant educational research, medical educational theories and principles (Chapter 7), as well as, examining the opinion of educational experts i.e. the five contributors mentioned above. Their opinions were made use of in planning, implementing and developing program's course content.

The investigations that were conducted revealed that there was general agreement between the stakeholders; that medical residents needed to be trained to teach better. The (potential) benefits of teaching for both residents and students were also highlighted. The review of educational theories also revealed a couple of concepts that if well understood, could improve the teaching skills of medical residents. We pooled the information we gathered from the different sources together and analysed them. The aim of the analysis was to identify $t$ ) the cognitions that were considered essential for residents to improve their teaching abilities and 2) the skills (cognitive, affective and psychomotor-perceptual) that could easily be incorporated in a teaching training program for residents.

By cognitions, we meant the ideas and concepts that the residents were expected to learn. Cognitive skills referred to the residents' ability to utilize the learnt ideas or concepts when faced with a problem. Affective skills referred to their ability to exhibit the behaviours that reflect certain desired behaviours e.g. treating students with respect, while psychomotor-perceptual skills were the physical or perceptual competencies the residents were expected to possess after the training. From the analysis, fourteen recommendations were isolated. After clustering based on similarity eleven different recommendations were identified. These eleven recommendations i.e. desired learning outcomes, were regarded as the skills and cognitions the residents should possess on completion of a teacher-training program (see table 3.) 


\section{Table 3. Desired learning OUtcomes}

OF THE TRAINING PROGRAM FOR MEDICAL RESIDENTS

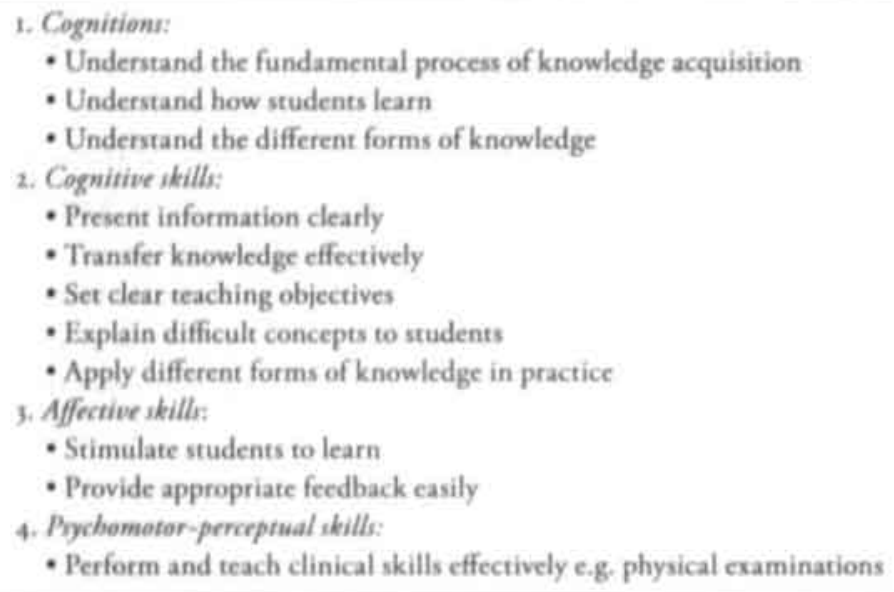

\section{Planning the training program}

In the planning phase, there were a number of issues with the design of the program that we had to deal with. These included the selection of an appropriate training format for the program, selection of instructors, selection of participating departments and residents and lastly logistical considerations. We dealt with these issues as follows:

- Selection of training format: Choosing an appropriate format for conducting the training program was dealt with, by examining experiences of other medical institurions that had implemented such training programs before ${ }^{14-18}$. Also, the medical literature was examined for information on the subject of choosing effective methods of instruction. In a review of studies that examined the various methods of instruction in teaching, Skeff et al ${ }^{19}$ concluded that multi-component methods i.e. seminars and workshops, were methods of instruction that showed the most evidence of effectiveness. The workshop as a training format was also found to be advantageous because: 1) they allowed the active participations of medical residents, 2) they were cost-effective, 3) residents were familiar with them, and 4) they provided a different learning environment for the resident and therefore reduced any interference that may arise from the residents' work during the training ${ }^{18}$.

- Selection of instructors: Staff members from the offices of educational research and development and from the medical faculty were eligible to provide instruction. It is known that such a combination of expertise provides a mix of educational expertise and credibility. Furthermore, the combination of faculty with differing areas of expertise has been shown to approximate the 
ideal situation of a physician, who is also a teacher with appropriate training and experience and residents perceive such personnel as good teachers ${ }^{17}$.

- Selection of Departments: The training program was intended for all residents (irrespective of clinical specialty) who were involved in teaching medical students.

- Selection of Residents: The residents for whom this training program is intended are those in the first three years of their training. The decision to focus this training program on junior residents was based on the residents' recommendation that training in teaching provided in the early stages of their residency program would be beneficial for themi9. Also, it was based on the recommendation that the instruction of residents on teaching should be timed to coincide with the first two years of residency ${ }^{18}$. They argued that in this period, it would be possible to exploit the learning vector in young residents. Stritter et al. ${ }^{20}$ explain that the learning vector in residents shows that there is a linear relationship between clinical instruction and professional development. The effect of this relationship reflects how learning evolves through the stage of exposure to knowledge to the stage of acquisition of skills, and later to the stage of integration where the development of a professional identity occurs. Based on the above information, our opinion was that junior residents would be the one to benefit most from such a training program.

- Logistical considerations: Although there is an increased awareness of the potential benefits of training medical residents to teach ${ }^{21-24}$, many residency programs still provide little room for this activity in their curricula. In institutions where such programs have been implemented, choice of venue, time schedule and duration of such programs have been and still remain some of the logistical considerations. Therefore, based on the positive experiences from comparable exercises that involved such training programs $s^{15,25,26}$, we chose to set up the training program as a two-day workshop, with 8 hours instruction time per day.

\section{IMPLEMENTING THE WORKSHOP}

As earlier mentioned, the workshop was set up as a two-day session with each session comprising of 8 hours instruction time. The course content was made up six instructional blocks that were based on the findings from the needs assessment. The themes of the instructional blocks included i) Effective teaching, 2) Self-knowledge of teaching ability, 3) Feedback, 4) Assessing prior knowledge, 5) Trouble shooting, and 6) Time management.

We clustered the blocks into two groups of three based on their relevance to the objectives of the workshop. Each group subsequently formed the course content for each day of the twoday workshop. The objectives of the workshop; based on the desired learning outcomes of the training program, were:

I. To acquaint the residents with the theory of learning, the forms of knowledge, and the process of knowledge acquisition and transfer 
2. To highlight the profile of the resident and the importance of their position in the educational process

3. To provide residents with basic educational skills that can improve their teaching and learning

4. To demonstrate how the residents can employ these skills

5. To demonstrate to the residents how these skills (can) facilitate learning.

Finally, prior to implementation of the workshop, the medical residents would be provided with a brief description of the structure and outline of the program. They would also be provided with information on the content of the workshop and the schedule of the learning activities during the two-day period. Supplementary handouts and references for additional reading on the workshop's blocks would also be provided. A comprehensive description and course details of the two-day workshop is provided in the addendum at the end of this thesis.

\section{REFERENCES}

1. RATNAPALAN, S. \& HILlitarD R. (2002) Needs Assessment in Postgraduate Medical Education: A Review, Medical Education Online, $7(8)$.

2. NORMAN, G.R., SHANNON, S.I. \& MARRIN, M.L. (2004). The need for needs assessment in continuing medical education. British Medical Journal, 328: 999-1001

3. DONALD, E.M.J. \& DONALD L.C. (1992) Needs assessment. In; Continuing Medical Education: A Primer. Westport, CT: Praeger

4. LAWTON, L (1999) Approaches to needs assessment. In E.R. PERKINS, L. WRIGHT \& I. SINNET (Eds.) Evidence-Based Health Promotion, 325-32, Chichester, England: Wiley.

5. MANN, K.V. (1998) Not another survey! Using questionnaire effectively in needs assessment. Journal of Contimuing Education in the Health Profosions, 18:142-49

6. LOCKYER, J. (1998) Lessons learned. Journal of Continuing Education in the Health Professions, 18:190192

7. LOCKYER, J. (rig98a) Getting started with needs assessment: Part 1 - the questionnaire. Journal of Contimuing Edwation in the Health Professions, 18:58-61

8. CRANDAL.L, S.J.S. (1998) Using interviews as a needs assessment tool. Journal of Continuing Education in the Health Profexsions, 18:155-162

9. DENTON, G.D., SMITH, J., FAUST, J. \& HOLBOME, E. (200t) comparing the efficacy of staff versus housestaff instruction in an intervention to improve hypertension management. Academic Medicine, 76 , (12): $1257-60$

10. FRANCKE, A.L., GARSSEN, B., ABU-SAAD, H.H. \& GRYPDONCK, M. (1996) Qualitative needs assessment priot to continuing education program. Journal of Continuing Education in Nursing, 27: 155162 
11. HATCH, T.F. \& PEARSON, T.G. (1998) Using environmental scans in educational needs assessment. Journal of Continuing Education in the Healtb Professions, 18:179-84

12. HANNON, F.B. (2000) A national medical education needs' assessment of interns and the development of an intern education and training program. Medical Education, 34: 275-84

13. TAYLOR, K.L. \& C CHUDLEY, A. (2001) Meeting the needs of future physicians: a core curriculum initiative for postgraduate medical education at a Canadian university. Medical Education, 35: 973-982

14. LAWSON, B.K. \& HARVIL.L, L.M. (1980) The evaluation of a training program for improving residents' teaching skills. Journal of Medical Education, 55:1000-05.

15. JEWETT, L.S., GREENBERG, L.W. \& GOLDBERG, R.M. (1982b) Teaching residents how to teach: a one-year study. Journal of Medical Education, 57:361-366.

16. MELECA, C.B., PEARSOL., J.A. (1988). Teaching surgery residents to teach. In J.C. EDWARDS 8 R.L. MARIER (Eds.) Clinical Teaching for Medical Residents: Roles, Techniques and Prognams, 187-200, New York: Springer Verlag

17. CAMP, M.G. \& HOBAN. J. D. (1988) Teaching medicine Residents to Teach. In J.C. EDWARDS \& R.I. MARIER (Eds.) Clinical Teaching for Medical Residents: Roles, Techniques and Programs, 201-213, New York: Springer Verlag.

18. EDWARDS, J.C., KISSLING, E.G., PLAUCHE, C.W. \& MARIER L.R. (1988) Developing and evaluating a teaching improvement program for residents. In J.C. EDWARDS \& R.L. MARIER (Eds.) Clinical Teaching for Medical Residents: Roles, Techniques and Programs, 157-174, New York: Springer Verlag.

19. BUSARI, J.O., PRINCE, K.A.H., SCHERPBIER, A.J.J.A., VAN DER VI.EUTEN, C.P.M. \& ESSED, G.G.M (2002). How residents perceive their teaching role in the clinical setting - a qualitative study. Medical Teacher, 24(1): 57-61.

20. STRITTER, F.T., SHAHADY, E.J. \& MATTERN, W.D. (1988) The resident as professional and teacher: a developmental perspective in J.C. EDWARDS \& R.L. MARIER (Eds.) Clinical Teaching for Medical Residents: Roles, Techniques and Programs, 15-31, New York: Springer Verlag.

21. ANDERSON, K., ANDERSON, W. \& SCHOLTEN, D. (1990) Surgical residents as Teachers. Current Surgery, 47(3): $185-88$

22. LOWRY, S. (1993). Teaching the teachers, British Medical Journal, 306: 127-130.

23. SCHWENK, T.L. \& WHITMAN, N. (1993). Residents as Teachers: A Guide to Educational Practice. 84, Salt Lake City: Department of Family and Preventive Medicine, University of Utah School of Medicine.

24. WIPF, J.E. (2000). The role of the Senior Resident: Team Manager, Leader and Teacher. Seattle: University of Washington.

25. GREENBERG, L.W., JEWETT, L.S. \& GOLDBERG R.M. (1988). The children's hospital experience, In J.C. EDWARDS \& R.L. MARIER (Eds.). Clinical Teaching for Medical Residents: Roles, Techniques and Programs, 175-186, New York: Springer Verlag.

26. STRITTER, F.T \& HAIN, J.D. (1977) A Workshop in Clinical Teaching. Journal of Medical Education, 52:155-57 



\section{Chapter 9}

A TWO-DAY WORKSHOP ON TEACHING SKILLS FOR MEDICAL. RESIDENTS: A DESCRIPTION

Jamiu O. Busari, Albert J.J.A. Scherpbier, Cees P.M. van der Vleuten, Gerard G.M. Essed, Robert Rojer

Submitted 


\section{SUMMARY}

Introduction: Studies have shown that teacher-training programs for residents could improve the educational quality of undergraduate clinical training.

Development of the training program: A teacher-training program for residents was designed and piloted in the St Elisabeth Hospital in Curaçao, Dutch Antilles. Six modules were developed based on recommendations concerning cognitions and skills (cognitive, affective and psycho-motor) that were considered essential for effective teaching. The themes of the modules were: effective teaching, self-knowledge and teaching ability, feedback, assessing prior knowledge, trouble shooting and time management.

Implementation of the training program: A two-day workshop with 8 hours of instruction per day was open to all residents in the first three years of training. The instructors were educational and clinical experts. The workshops consisted of lectures, discussions and case simulations, video presentations and role-plays.

Evaluation of the training program: Participants filled out two questionnaires about the quality of the workshop immediately after the workshop and three months later.

Results: The participants rated the quality of the workshop highly both immediately after the workshop and 3 months later. The length of the workshop received the lowest ratings. Participants supported inclusion of such a workshop in their residency training.

Discussion: Although attendance was not very high and the evaluation based on self-perception the workshop seems to be an appropriate and feasible tool for providing teacher training to residents. Further studies of the effects of the workshop should seek evidence of its effectiveness by examining changes in participants' teaching abilities as evaluated by objective measurements or students' evaluations.

\section{INTRODUCTION}

There is an ongoing campaign to improve the didactic skills of teachers of undergraduate medical students. Specialist physicians are essentially responsible for undergraduate clinical teaching although residents have also been found to contribute significantly to this process ${ }^{1.4}$. Furthermore, the teaching skills of clinical teachers have been shown to benefit from training ${ }^{3-11}$. The readiness of medical residents to teach medical students has been demonstrated in the literature -15 and it has been argued that they themselves benefit from teaching 4 . The way students, residents and attending physicians perceive the teaching roles of medical residents have also been investigated ${ }^{t}$ 16-21. It has been shown that there is a need to improve residents' teaching skills ${ }^{22.24}$ and programs to do so have been advocated ${ }^{17 \cdot 21,25 \cdot 27}$, as has the incorporation of teaching skills in residency training 22.28 .29 . Encouraging results have been reported of teacher training for residents, 12,30.12. Not only do teaching skills improve their professional competence ${ }^{14,20,21.39}$, but such skills may also enhance the effectiveness of undergraduate clini- 
cal training. Based on these points we developed, piloted and evaluated a program to improve residents' teaching abilities.

\section{DEVELOPMENT OF THE TRAINING PROGRAM}

\section{Design}

Four experienced educational researchers and teachers (of whom three were also physicians), and one medical student constructed the program. The design was founded on medical educational research, experts' opinions and a review of educational theory 32. We pooled information from theories on knowledge acquisition and transfer and identified cognitions and skills (cognitive, affective and psychomotor-perceptual) that we considered essential for improving residents' teaching abilities (table 1). Six modules were developed, whose themes represented the desired learning outcomes of the program: 1) Effective teaching, 2) Self-knowledge $\&$ teaching ability, 3) Feedback skills, 4) Assessing prior knowledge, 5) Trouble shooting, and 6) Time management.

\section{Table I. LIST OF SKILLS AND COGNITIONS MEDICAL RESIDENTS SHOULD POSSESS IN ORDER TO TEACH EFFECTIVELY}

\begin{tabular}{|l|l|l|}
\hline $\begin{array}{l}\text { Residents' suggestions } \\
\text { (Busari et al., 2002) }\end{array}$ & $\begin{array}{l}\text { Specialists' suggestions } \\
\text { (Busari et al., 2003) }\end{array}$ & Review of literature \\
\hline $\begin{array}{l}\text { Be able to present information } \\
\text { clearly (cognitive skill) }\end{array}$ & $\begin{array}{l}\text { Set clear teaching objectives and } \\
\text { develop problem-solving skills } \\
\text { (cognitive skill) }\end{array}$ & $\begin{array}{l}\text { Understand the fundamental } \\
\text { process of knowledge acquisition } \\
\text { (cognition) }\end{array}$ \\
\hline $\begin{array}{l}\text { Be able to transfer knowledge } \\
\text { effectively (cognitive skill) }\end{array}$ & $\begin{array}{l}\text { Be able to transfer knowledge } \\
\text { effectively (cognitive skill) }\end{array}$ & $\begin{array}{l}\text { Be able to transfer knowledge } \\
\text { effectively (cognitive skill) }\end{array}$ \\
\hline $\begin{array}{l}\text { Be able to explain difficult } \\
\text { concepts to students (cognitive } \\
\text { skill) }\end{array}$ & $\begin{array}{l}\text { Stimulate students to learn e.g. } \\
\text { by interacting better with them } \\
\text { (affective skill) }\end{array}$ & $\begin{array}{l}\text { Understand how students learn } \\
\text { (cognition) }\end{array}$ \\
\hline $\begin{array}{l}\text { Be able to provide feedback } \\
\text { to students (cognitive skill) + } \\
\text { (affective skill) }\end{array}$ & $\begin{array}{l}\text { Be able to provide appropriate } \\
\text { feedback easily (cognitive skill) } \\
\text { +(affective skill) }\end{array}$ & $\begin{array}{l}\text { Understand the different forms of } \\
\text { knowledge (cognition) }\end{array}$ \\
\hline & $\begin{array}{l}\text { Perform and teach clinical skills } \\
\text { effectively e.g. history taking and } \\
\text { physical examination (psycho- } \\
\text { motor skill) }\end{array}$ & $\begin{array}{l}\text { Know how to apply different forms } \\
\text { of knowledge (cognitive skill) }\end{array}$ \\
\hline
\end{tabular}




\section{Planning}

Planning involved the selection of an appropriate training format, instructors, participating departments and residents, and logistical considerations.

Training format: The literature provided the strongest evidence of effectiveness for multicomponent instruction methods, such as seminars and workshops ${ }^{3,12,30,31,32,34}$. We favored a workshop because it: 1) would allow the active participation of the residents, 2) is cost-effective, 3) is a familiar format for residents, and 4) could be held outside the wards, thereby reducing interference from the residents' work $^{32}$.

Instructors: Educational experts and clinical staff were considered to offer a desirable mix of educational expertise and credibility, which would also approximate residents' idea of a good teacher: a physician who is also a teacher with appropriate training and experience".

Departments: All residents involved in undergraduate teaching, that is residents in the major clinical disciplines, were eligible for participation.

Residents: We focused on residents in the first three years of residency, because teacher training early in residency has been recommended by residents ${ }^{20}$ as well as others ${ }^{2}$.

Logistical considerations: The choice of a two-day workshop with 8 hours instruction time per day was based on positive experiences from similar workshops ${ }^{12,13,35}$.

\section{Implementation of the training program}

In 2002, a pilot study funded by the Netherlands Antilles Foundation for Higher Clinical Education was conducted at the University of the Netherlands Antilles, Curaçao. Its aim was to assess the suitability and feasibility of a teacher-training workshop for residents. The participants were graduates from Dutch medical schools who were undergoing (pre-)residency training in the major specialties (internal medicine, surgery, pediatrics, obstetrics and gynecology) at the St. Elisabeth Hospital, Curaçao ${ }^{36}$. The five workshop instructors were physicians and teachers in the departments of pediatrics (2), neurology $(\mathrm{l})$ and internal medicine $(\mathrm{t})$, and a pediatric resident, who is an educationalist and one of the workshop developers. The workshop was expected to achieve the desired learning outcomes through:

- acquainting the residents with the relevant theory of learning, forms of knowledge, and the process of knowledge acquisition and transfer;

- highlighting the profile and position of residents in the educational process;

- providing residents with basic educational skills;

- training the residents how to employ those skills;

- demonstrating how those skills (can) facilitate learning.

The program and study material were sent out two weeks before the workshop. On day one of the program a brief orientation on the structure and objectives was provided.

On each day of the workshop 3 modules were run. The program started at $8.30 \mathrm{a} . \mathrm{m}$. and finished at 15.00 p.m. It consisted of lectures, discussions, case simulations, video presentations and role-plays. We will now describe the rationale and teaching strategies for each module. 


\section{Effective teaching}

Rationale: The residents were acquainted with the concept of teaching and learning, which was illustrated by the educational theory of Neves \& Anderson ${ }^{37}$, and with the principles of effective teaching ${ }^{36}$, the concept of learning within a context, and how to facilitate student learning and participarion within the leaning context ${ }^{32} 40$.

Teaching strategies:

- A 20-minute lecture illuminated the concepts of teaching and the importance of the educational setting (classroom, ward, consultation room).

- The concept of patient-based teaching was used to illustrate "teaching in context", for instance how bedside teaching can facilitate student-learning".

- Skills that might improve teaching were addressed. The residents reflected on skills (and prior knowledge) that facilitate teaching in an interactive manner. They then formulated new skills they considered essential for effective teaching.

- The importance of student autonomy was shown, for example, how acknowledging students as adult learners motivates them to learn ${ }^{40}$. The residents received instruction (to minutes) on how to identify and acknowledge their individual limitations. A 20-minute demonstration illustrated how honest and open rapport with students reflects goodwill and creates a favorable atmosphere.

\section{Self-knowledge and teaching ability}

Rationale: The module focused on ways to improve residents' teaching abilities and on factors that can facilitate student learning. It was illustrated how the "closeness" of students and residents, i.e. working together on the wards and residents' fairly recent experiences as students, could positively influence teaching and learning $4,35,41$.

Teaching strategies:

- A ro-minute lecture on how fundamental concepts of educational theory can improve teaching. The process of knowledge organization and compilation was illustrated by an explanation of Neves \& Anderson's theory ${ }^{37}$.

- The residents discussed (20 minutes) surface and deep learning following a 5 -minute video presentation. A ro-minute lecture presented different approaches to learning and their impact.

- A discussion (20 minutes) of factors, such as clinical ability, pedagogical ability, personal qualities (table 2), and how they can improve teaching ability. 
Table 2. Factors THAT CAN IMPROVE TEACHING ABILITY

\begin{tabular}{|l|l|l|}
\hline Clinical Abilities & Pedagogical abilities & Personal qualities \\
\hline - Good clinician & - Active participant in teaching & - Enthusiasm for work \\
- Up to date theoretical & - Individualises teaching ap- & - Able to assess own strengths \\
knowledge & proach & and weaknesses \\
- Up to date clinical knowledge & - Identifies strengths and weak- & - Self improvement \\
- Holistic approach & nesses & - Warm and respectful \\
- Flexible & & - Listens \\
- Integration of preventive and & & - Expresses own emotions ap- \\
curative aspects & & propriately \\
- Critical and analytical & & - Interacts with others \\
& & - Manages stressful situations \\
& & - Gets support when necessary \\
& & - Balances personal and profes- \\
& & sional life \\
\hline
\end{tabular}

Modified from Cote, 1993.

\section{Feedback}

Rationale: Feedback informs learners about their progress and affects the acquisition and transfer of knowledge. Both positive and negative feedback should be specific, frequent, formal and informal, and include explanations and remedies ${ }^{42,43}$.

Teaching strategies:

- A 20-minute lecture showed the importance of appropriate feedback and of the following concepts which can facilitate effective feedback:

* the balance between positive and negative feedback;

- why and how honesty in providing feedback can create an atmosphere for open communication and facilitate learning;

- clarity, i.e. formulating clear objectives at the onset of the discourse with students;

* the importance of a partnership with the students (constructivism).

- A to-minute video presentation showed positive and negative ways of providing feedback.

A 6o-minute session involving discussion and role play addressed ways of:

- identifying positive and negative forms of feedback;

" providing balanced feedback to one another;

" exploring and identifying students' expectations and agreeing upon common learning goals.

\section{Troubleshooting}

Rationale: Problems may arise during teaching, for instance due to discordance between what students are expected to do and what they actually do. Some problems can be anticipated, such 
as students arriving late for a clinical meeting, whereas others are unexpected, for instance a student losing motivation after negative feedback. Residents must be able to identify, acknowledge and recognize the cause of a problem, in order to select the appropriate intervention to resolve it.

Teaching strategies:

- The definition of terms (e.g. performance problems) and distinctions between measurable and observable problems were provided in a lecture and discussion session (Is minutes). Four steps in troubleshooting were discussed (20 minutes each):

- Problem identification - By reflecting on their own experiences, residents discussed ways of detecting problems in students' performance.

- Problem acknowledgement - Problems can be professional (clerkship-relared) or personal (not clerkship-related) and behavioral and/or educational in nature. Acknowledging a problem entails identifying the nature of the problem and accepting it with the aim of finding a solution.

- Identifying the cause - This can be done by answering the following questions: is the problem due to:

I an absent or incomplete professional behavior, or a skill or behavior that was incorrectly learnt or taught (professional + behavioral);

2 a skill or knowledge that has diminished with lack of use and time (professional + educational);

3 a non-educational cause affecting knowledge or skills, e.g. health or family issue (personal + educational);

4 a non-educational cause affecting professional conduct or behavior, e.g. religious or cultural beliefs (personal + behavioral).

- Finding the solution - It is essential to determine the nature of a problem and the appropriate intervention. Some problems are beyond a resident's responsibility and should be channeled to the appropriate quarters, e.g. counselor's office. Solutions for performance problems were categorized as:

- educational strategies, e.g. educational intervention, skill training ( $1 \& 2$ above);

- non educational strategies, e.g. feedback, counseling ( $3 \& 4$ above).

\section{Assessing prior knowledge}

Rationale: Fostering the acquisition of clinical skills and knowledge by activating existing knowledge $e^{44.45}$.

Teaching strategies:

- A I5-minute lecture explained the concept of prior knowledge, why it should be ascertained and how it influences feedback and stimulates learning.

- In a 45-minute discussion the residents generated methods for assessing students' prior knowledge, including formal enquiry, questioning of domain-related knowledge, and observation of students' performance. 


\section{Time management}

Rationale: The efficient use of what little time, if any, residents have available for teaching can be enhanced by adjusting the work schedule.

Teaching strategies:

-A 20-minute lecture on time management and how it influences teaching. In a 30-minute session the residents outlined the negative effects of time shortage, such as work pressure and poor teaching. They generated suggestions for effective use of the time for teaching, which were compared with the following practical tips:

- Define clear learning objectives and expectations at the outset.

- Limit the number of learning objectives per encounter (2 seems ideal).

- Establish a partnership with students, e.g. the teaching provided by residents in exchange for the students' assistance in carrying out routine clinical activities.

- Share the responsibility for finding answers to difficult topics with students. Students can be of immense help in finding information faster for residents.

- Delegate tasks and share patient responsibilities with students. Also give and request feedback. Students benefit from the experience, it motivates them and saves time that can be used for teaching.

- Establish an honest and open atmosphere. This ensures students' understanding and consideration for the residents' limited time for teaching.

\section{EVAlUATION OF THE TRAINING PROGRAM}

\section{Procedure}

After the workshop participants rated items of a 10-item questionnaire $(\mathrm{t}=$ totally disagree; $s=$ totally agree) to evaluate the workshop's effectiveness and the planning of sessions. A 17 -item questionnaire $(1=$ very poor; $s=$ very good $)$ asked participants to rate the quality of instruction in the sessions in the areas: Clarity and organization, Presentation style, Group interaction, and Content.

\section{Results}

Thirteen ( $87 \%$ ) out of fifteen eligible residents participated in the workshop, with three participants attending the full program. On both days an average of eight residents were in attendance. Twelve questionnaires were analyzed. Most residents had had no formal teaching instruction $(n=7)$. There was agreement among the participants that such instruction would have been beneficial. 


\section{Residents' perceptions of the workshop}

The residents regarded the workshop as a good learning experience (mean $=4.50 ; S D=0.53$ ) and agreed that such a workshop should be incorporated in their residency training (mean $=4.80$; $\mathrm{SD}=0.42$ ). They considered the workshop well-planned (mean $=4.10 ; S D=1.10$ ). Their opinion of the duration of the workshop was almost neutral (mean $=3.40 ;=$ SD L.08). (Table 3 )

\section{Residents' perceptions of the quality of instruction}

Clarity and organization, presentation style, group interaction and content were rated highly across modules (mean $=4.27 ; \mathrm{SD}=0.17$ ) and overall ratings for the modules were also high $($ mean $=4.26 ; \mathrm{SD}=0.20)$. (Table 4$)$

\section{Residents' perceptions of the workshop 3 months later}

Three months after participation the residents again gave positive ratings. They still felt that such a program should be incorporated in residency training (mean $=4.37 ; \mathrm{SD}=0.92$ ). They felt better prepared in their role as tutors for medical undergraduates (mean $=3.88 ; \mathrm{SD}=0.35$ ) and expressed their willingness to participate in such a program again (mean $=4.00 ; \mathrm{SD}=0.76$ ). (Table s)

\section{Table 3. General eVAlUation OF THE 2-DAY WORKSHOP}

in answer to the question: How would you rate the workshop in the following specific areas, using the scale: $1=$ totally disagree, 2 = disagree, $3=$ neutral, $4=$ agree, $5=$ totally agree.

\begin{tabular}{lccc}
\hline Aspect of the workshop & $\mathrm{N}$ & Mean & Std. Dev. \\
\hline Incorporate such a workshop in the specialist training program & 10 & 4.80 & 0.42 \\
The workshop was a good learning experience & 10 & 4.50 & 0.53 \\
I learnt new concepts that can improve my teaching & 10 & 4.50 & 0.53 \\
I feel better prepared in my role as tutor for medical undergraduates & 10 & 4.30 & 0.48 \\
Incorporate such a workshop in medical undergraduate program & 10 & 4.20 & 0.79 \\
Provided instruction is relevant for my clinical responsibilities & 10 & 4.10 & 0.88 \\
The workshop was well planned & 10 & 4.10 & 1.10 \\
The provided literature was appropriate & 10 & 3.80 & 0.79 \\
Length of individual sessions was appropriate & 10 & 3.80 & 1.23 \\
The duration of the workshop was appropriate & 10 & 3.40 & 1.08 \\
Valid N (listwise) & 10 & & \\
\hline
\end{tabular}




\section{Table 4. MeAn Ratings of THE Individual MOdUles AND QUALITY OF INSTRUCTION}

in answer to the question: How would you rate the workshop sessions in the following specific areas, using the scale: 1 = very poor, 5 - very good.

\begin{tabular}{|c|c|c|c|c|c|c|c|}
\hline $\begin{array}{l}\text { Aspect of } \\
\text { instruction }\end{array}$ & $\begin{array}{c}\text { Module } \\
\text { I }\end{array}$ & $\begin{array}{c}\text { Module } \\
2\end{array}$ & $\begin{array}{c}\text { Module } \\
3\end{array}$ & $\begin{array}{c}\text { Module } \\
4\end{array}$ & $\begin{array}{c}\text { Module } \\
5\end{array}$ & $\begin{array}{c}\text { Module } \\
6\end{array}$ & $\begin{array}{c}\text { Average } \\
\text { of means } \\
\text { (instruc- } \\
\text { tion) }\end{array}$ \\
\hline $\begin{array}{l}\text { Clarity \& organi- } \\
\text { zation }\end{array}$ & 4.39 & 4.25 & 4.61 & 3.69 & 4.39 & 4.54 & $4 \cdot 31$ \\
\hline Presentation style & $4 \cdot 36$ & 4.26 & 4.42 & $4 \cdot 38$ & $4 \cdot 36$ & $4 \cdot 33$ & 4.35 \\
\hline Group interaction & 4.40 & 4.39 & 4.57 & 3.77 & $4 \cdot 44$ & 3.78 & 4.23 \\
\hline Content & 4,30 & 4.24 & 4.24 & 3.78 & $4-37$ & 4.04 & 4.18 \\
\hline $\begin{array}{l}\text { Average of means } \\
\text { (modules) }\end{array}$ & 4.36 & 4.28 & 4.46 & 3.91 & 4.39 & 4.17 & \\
\hline
\end{tabular}

Overall evaluation of instruction: Mean $=4.27, \mathrm{SD}=0.17,95 \% \mathrm{Cl}$ of means $=4.15-4.39$

Overall evaluation of the modules: Mean $=4.26, \mathrm{SD}=0.20,95 \% \mathrm{Cl}$ of means $=4.05-4.47$

\section{Table 5. General evaluation of the 2-day workshop 3 MONTHS Later.}

Anwers to the question: How would you rate the workshop in the following specific areas, using the scale: $x$ = totally disagree, 2 = disagree, 3 = neutral, 4 = agree, 5 = totally agree.

\begin{tabular}{llll}
\hline Aspect of the workshop & $\mathrm{N}$ & Mean & Std. Dev \\
\hline Incorporate such a workshop in the specialist training program & 8 & 4.37 & 0.92 \\
The workshop was a good learning experience & 8 & 4.25 & 0.46 \\
Ilearnt new concepts that can improve my teaching & 8 & 4.25 & 0.70 \\
I would be willing to participate in a similar workshop again & 8 & 4.00 & 0.76 \\
I feel better prepared in my role as tutor for medical undergraduates & 8 & 3.88 & 0.35 \\
Provided instruction is relevant for my clinical responsibilities & 8 & 3.88 & 1.12 \\
The workshop has influenced my teaching skills & 8 & 3.75 & 0.46 \\
Incorporate such a workshop in medical undergraduate program & 8 & 3.50 & 0.93 \\
The workshop was well planned & 8 & 3.50 & $t .07$ \\
The duration of the workshop was appropriate & 8 & 3.12 & 0.99 \\
Valid $N$ (listwise) & 8 & & \\
\hline
\end{tabular}




\section{Discussion}

The workshop was highly appreciated. A notable finding, three months later, was that the residents still gave high ratings. They recommended that such a workshop should be incorporated into residency training and acknowledged some improvement in their teacher characteristics. In addition, they thought they had learnt new concepts that could improve their teaching. The residents indicated that the instruction was good and relevant to their needs. The lowest ratings were given for the duration of the workshop.

One might question the validity of the evaluation, because attendance was low and the evaluation based on self-perception. As for attendance, the best results from similar programs have been achieved with 10-20 participants ${ }^{35}$. In this study thirteen residents participated, with a minimum of 8 residents attending at any module. Although, the ratings of quality and content were uniformly favorable, the effectiveness of this workshop remains to be validated by investigating observable changes in participants' teaching abilities and medical students' evaluations of residents' teaching skills following participation in such a workshop. For now, the evaluation indicates that this workshop is an appropriate tool for training teaching skills to residents and a feasible program to implement.

\section{Funding}

Netherlands Antilles Foundation for Clinical Higher Education, Curacao, Netherlands Antilles and the institute for medical education, university of Maastricht, the Netherlands

\section{REFERENCES}

I. BARROW, M.V. (1966). Medical students' opinions of the house officer as a medical educator. Journal of Medical Education, 41: 807-10.

2. BROWN, R.S. (1970). House staff attitudes toward teaching. Journal of Medical Education, 45: 156-59.

3. MELECA, C.B. \& PEARSOL, J.A. (1988). Teaching surgery residents to teach. In J.C. EDWARDS \& R.L. MARIER (Eds.). Clinical Teaching for Medical Residents: Roles, Technigues and Programs, 187-200, New York: Springer Verlag.

4. STEWARD, D.E. \& FELTOVICH, P.J. (1988). Why residents should teach: the parallel processes teaching and learning. In J.C. EDWARDS \& R.L. MARIER (Eds.) Clinical Teaching for Medical Residents: Roles, Techniques and Programs, 3-14, New York: Springer Verlag.

5. ANDERSON, J., GALE, J. \& TOMLINSON, R.W. (1974). Training of medical teachers. Lancet 7. 2 (7880): $566-568$.

6. HARRISON, G.A. (1976). The role of formal courses in the vocational training of anaesthetists. Anaesthesist Intensive-Care, 4, 291-296. 


\section{Chapter 9}

7. WRIGHT, H.J. \& KNOX, J.D. (1977). Teaching teachers in medical practice. Medical Education iI: 4852.

8. CRAIG, J.L. (1988), Teachet-training for medical faculty and residents. Canadian Medical Awociation Journal, 15, 139(10): 949-52.

9. BIGGS, J.S.G., AGGER, S.K., DENT, T.H.S., AL.I.ERY, L.A. \& COLES, C. (1994). Training for medical teachers: a UK survey. Medical Education, 28: 99-106.

10. GIBSON, D.R. \& CAMPBELL. R.M. (2000), Promoting effective teaching and learning: hospital consultants identify their needs. Medical Education, 34: 126-30.

it. WALL., D. \& McALEER, S. (2000). Teaching the consultant teachers: identifying the core content. Medical Education, 34:131-38.

12. JEWETT, L.S., GREENBERG, L.W. \& GOLDBERG, R.M. (1982). Teaching residents how to teach: a one-year study, Journal of Medical Education, 57:36r-66.

13. GREENBERG, L.W.,JEWETT, L.S. \& GOL.DBERG R.M. (1988). The children's hospital experience. In J.C. EDWARDS \& R.L. MARIER (Eds.). Clinical Teaching for Medical Resident: Reles, Techniques and Programi, 175-186, New York: Springer Verlag.

14. APTER, A., METZGER, R. \& GLASSROTH, J. (1988), Residents' perception of their role as teachers. Journal of Medical Education, 63, $185-188$.

15. BING-YOU, R.G. \& HARVEY, B.J. (1991). Factors related to residents' desire and ability to teach in the clinical setring. Teaching and Learning in Medicine, 2:95-100.

16. BARROW, M.V. (1965). The house officer as a medical educator. Journal of Medical Education, 4o: 712-14.

17. BING-YOU, R.G. \& SPROUL, M.S. (1992). Medical students' perceptions of themselves and residents as teachers. Medical Teacher, $14(2-3) ; 133-38$.

18. NKANGINIEME, K.E.O. \& IHEKWABA, A.E. (1998). Students' perception of the house officer as a teacher. Medical Teacher, 20(2): 109-13.

19. BUSARI, J.O., SCHERPBIER, A.J.J.A., VI.EUTEN, C.P.M., VAN DER \& ESSED, G.G.M. (2000). Residents' perception of their role in teaching undergraduate students in the clinical setring. Medical Teacher, $22(4): 34^{8-53}$

20. BUSARI, J.O., PRINCE, K.A.H., SCHERPBIER, A.J.J.A., VLEUTEN, C.P.M., VAN DER \& ESSED, G.G.M. (2002). How residents perceive their teaching role in the clinical setting - a qualitative study. Medical Teacher, $24(\mathrm{x}): 57-61$.

21. BUSARI, J.O., SCHERPBIER, A.J.J.A., VL.EUTEN, C.P.M., VAN DER \& ESSED, G.G.M. (2003). The perceptions of attending doctors on the role of residents as teachers of undergraduate clinical students. Medical Edacation, 37: 241-47.

22. TONESK, X, (1979). The house officer as a teacher: what schools expect and measure, Journal of Medical Education, 54: 6r3-16.

23. COTE, L. (1993). Supervision of family medicine residents. Comperencies and qualities [French]. Canadian Family Physician, 39: 366-72.

24. CHAL.LIS, M., WILLIAMS. J. \& BATSTONE, G. (1998). Supporting pre-tegistration house officers: The needs of educational supervisors of the first phase of post-graduate medical education. Medical Educatien, 32: 177,80. 
25. GENERAL MEDICAL. COUNCIL. (1993), Tomorrow's docton: recommendations on wndengraduate medical education. London: General Medical Council.

26. PARLE, J., WALL, D., HOLDER, R. \& TEMPLE, J. (1995). Senior registrars' communication skills: attitudes to and need for training. British Journal of Hospital Medicine, 53(6): 257-60.

27. PORTER, N. (1997). Clinical supervision: the art of being supervised. Nursing Standard, 11: 44-45.

28. DUNNINGTON, G.L. \& DAROSA, D. (1998). A prospective randomized trial of a residents-as-teachers training program. Academic Medicine, 73: 696-700.

29. BORLEFFS, J.C.C., CATE, Th. J. ten, BRUIJNZEEL-KOOMEN, C.A.F.M. \& ERKEL.ENS, D.W. (2002) (Dutch with summary in English). A proposal for the introduction of an internship in clinical didactics into residency training. Dutch Journal of Medical Education, $21(\mathrm{t}): 25-32$.

30. LAWSON, B.K. \& HARVILL. L.M. (1980). The evaluation of a training program for improving residents' teaching skills. Journal of Medical Education, 55: 1000-1005.

31. CAMP, M.G. \& HOBAN, J. D. (1988), Teaching medicine residents to teach. In: J.C. EDWARDS \& R.L. MARIER (Eds.) Clinical Teaching for Medical Residents: Roles, Techniques and Prognams, 201-13. New York: Springer Verlag.

32. EDWARDS, J.C., KISSLING, E.G., PLAUCHE, C.W. \& MARIER L.R. (1988) Developing and evaluating a teaching improvement program for residents. In J.C. EDWARDS \& R.L. MARIER (Eds.) Clinical Teaching for Medical Residents: Roles. Techniques and Programs, 157-174. New York: Springer Verlag.

33. KATES, N.S. \& LESSER, A.L. (1985). The resident as a teacher: a neglected role, Canadian Journal of Psychiatry, 30(6): 418-21.

34. SKEFF, M.K., BERMAN, J. \& STRATOS, G. (1988). A review of clinical teaching improvement methods and a theoretical framework for their evaluation. In J.C. EDWARDS \& R.L. MARIER (Eds.) Clinical Teaching for Medical Residents: Roles, Techniques and Programs, 92-120, New York: Springer Verlag.

35. STRITTER, F.T., HAIN, J.D. \& GRIMES, D.A. (1975). Clinical teaching re-examined. Journal of Medical Education, 50, 876-882.

36. BUSARI, J.O., VERVOORT, M., HERMANS, S.M. \& BLOM, J.R. (2001). Medical education in the new millennium - a Caribbean perspective. Medical Education, 35(7): 703-706.

37. NEVES, D.M. \& ANDERSON, J.R. (1981). Knowledge compilation: mechanisms for the automatization of cognitive skills. In J.R. ANDERSON (Ed.) Cognitive Skills and their Acquisition, 86-102, Hillsdale, NJ: Erlbaum.

38. RAMSDEN, P. (1992). Chapter 4: Approaches to learning. In Learning to Teach in Higher Education, 3862, London: Routledge.

39. FRANSSON, A. (1977). On qualitative differences in learning, IV - Effects of motivation and test anxiery on process and outcome. British Journal of Psychology, 47:244-57.

40. DAVID, T.J. \& PATEL, L. (1995). Adult Learning theory, problem based learning and pediatrics. Archives of Disease in Childhood, 73: 357-63.

41. FOLEY, R.P. \& SMILANSKY, J. \& YONKE, A (1979). Teacher-student interaction in a medical clerkship. Journal of Medical Education, 54: 622-26.

42. DINHAM, S.M. \& STRITTER, F.T. (1986). Research on professional education. In M.C. WITTROCK (Ed.) Handbook of Research in Teaching, 952-70, New York: Macmillan. 
43. MEANS, J.H. (1988), Learning in the clinical setting. In K.C. DOUGLAS, M.C. HOSOKAWA \& F.H. LAWLER (Eds.) A Practical Guide to Clinical Teaching in Medicine, 7-18, New York: Springer Veriag.

44. ANDERSON, R.C. (1977). The notion of schemata and the educational enterprise: general discussion of the conference. In R.C. ANDERSON, R.J. SPIRO \& W.E. MONTAGUE (Eds.) Schooling and the acquisition of knowledge, Hillsdale: Erlbaum.

45. SCHMIDT, H.G. (1983). Problem-based learning: rationale and description. Medical Education, 17: [1-16. 


\section{Chapter io}

A TWO-DAY TEACHER-TRAINING PROGRAM FOR MEDICAL RESIDENTS:

INVESTIGATING THE IMPACT ON TEACHING ABILITY

Jamiu O. Busari, Albert J.J.A. Scherpbier,

Cees P.M. van der Vleuten, Gerard G.M. Essed

Submitted 
Introduction A lot of residents who supervise medical students in clinical practice are unfamiliar with the principles of effective supervision. Training in teaching skills is therefore seen as an effective strategy to improve the quality of clinical supervision.

Method Twenty-seven medical residents were matched and randomly assigned into two groups in this study. Fourteen ( $52 \%$ ) participants who were assigned to the experimental group took part in a two-day workshop in teaching skills. Using standardised questionnaires, medical students assessed the teaching abilities of all participants before, and after the workshop. The objective was to examine if the workshop had any effect on teaching ability.

Results A significant improvement in the teaching abilities of the medical residents in the experimental group was observed following the workshop $(t=-2.68, p=0.02)$. Effect size estimation within the experimental group was large $(d=1.17)$ indicating that the training in teaching skills caused a measurable positive change in the medical residents' teaching abilities. Compared to the control group, a moderate improvement $(d=0.57)$ in the teaching abilities of the residents in the experimental group was observed.

Discussion Medical students' perceived that the teaching abilities of the medical residents who underwent the training as better than their counterparts who did not. The ability to adjust teaching to the needs of the students and teach effective communication and diagnostic clinical skills were among the features that characterised effective teaching. Properly designed, teachertraining workshops could be effective and feasible methods for training medical residents to teach.

\section{INTRODUCTION}

The changes that are presently taking place in undergraduate medical education indicate, that the task of teaching in the clinical setting is no more the sole responsibility of specialist doctors. Over the years, medical residents have increasingly been seen to be participating in the education of medical students in the hospital wards ${ }^{1-4}$ and their contributions have been found to be quite significant ${ }^{1-3}$. The medical residents' perceptions of their teaching activities, and the problems involved with this responsibility have also been extensively investigated ${ }^{1.5-10}$, and recommendations have been made, aimed at improving the teaching and supervisory skills of medical residents ${ }^{11-13}$. Most of these recommendations have been made on the pretext that better teaching skills do not only improve the medical resident's professional competence. 14. 15, but would probably enhance the effectiveness of undergraduate clinical training as well. There are reports in the literature, that in institutions where such programs have been implemented, improvements in the didactic skills and perceived teaching qualities of medical residents have been achieved.16-21. However many of these studies do not reflect a standard method in the way the training programs were developed or in the way the effectiveness was evaluated. Regardless 
of this however, a lot of medical institutions are demanding for more of such initiatives in order to improve the quality of undergraduate and postgraduate medical education, as well as, the teaching skills of medical residents ${ }^{6-10,16,22.24}$.

In practice, the development of teacher-training programs for medical residents is a rather complicated issue. This is partly due to the current practice in medical education, where the structure and content of most educational programs are (still) largely determined by departmental or faculty course planners, and not by what medical residents themselves perceive as their needs ${ }^{25,26}$. Furthermore, in the few situations where such initiatives have been realised, logistic problems such as irregular working hours and/or clinical rotations have been found to hinder medical residents' (full) participation in such training programs ${ }^{18,27}$. Finally, the support of important stakeholders in medical education e.g. specialist training boards, medical faculties, and attending doctors is also important in this process, as their co-operation can influence the successful implementation of such training programs considerably, 16, 17, 18.

Earlier in a separate study, we provided a description of how a training program in teaching skills for medical residents was developed and how its appropriateness and feasibility as an educational intervention was tested (Busari 2004, unpublished). A needs-assessment strategy was used in developing the program ${ }^{28.29}$, as our objective was to address the perceived teaching needs of the medical residents' appropriately. ${ }^{9}$. The two-day workshop comprised of six educational modules whose themes represented the desired learning outcomes of the program i.e. 1) Effective teaching, 2) Self-knowledge \& teaching ability, 3) Feedback skills, 4) Assessing prior knowledge, 5) Trouble shooting, and 6) Time management. The pilot study we conducted showed that the workshop was appropriate and feasible for its purpose. However, the effectiveness of the program as an educational intervention was not investigated. We therefore decided to investigate whether the workshop we designed was effective in training teaching skills and if the participants perceived it as an appropriate educational intervention. Our research question was: could the two-day teacher-training workshop improve the (perceived) teaching abilities of medical residents?

\section{METHOD}

The design of this study involved selecting a group of medical residents that would be exposed to a teacher-training program, and a second group that would not take part in the training but serve as a control for comparison. The objective was to see, if any significant difference in the teaching skills between the residents could be identified, that could be attributed to the training. Medical students whom the residents supervised on the wards carried out the assessments at two separate periods (i.e. before and after the intervention). 


\section{Subjects}

This study was conducted in the teaching hospitals of the universities of Amsterdam and Leiden, the Netherlands. Two departments in the respective institutions were involved in the study namely, Paediatrics and Obstetrics and Gynaecology. The residency training in both institutions was comparable both in content and duration and medical residents in different stages of their specialist training programs were eligible to participate. The residents were also known to be actively involved with supervising medical students on the wards. To estimate a minimum feasible sample size a compromise power analysis was performed using $\mathrm{G}^{*}$ power analysis ${ }^{30,},{ }^{3}$. This showed that a total of 40 participants (i.e. 20 experimental and 20 controls) were needed in order to make a fairly accurate and reliable statistical judgement (Power $=0.70$ ), and to be able to detect any effect $(d=>.50)$ within or between the two study groups that may have arisen from the training program ${ }^{30}$. Randomisation was not perfectly adhered to, since each resident had a fixed and personal schedule of clinical postings that covered the whole length of their training. As a result, we could not randomly select our participants. The medical residents who were included in the study were those whose clinical rotations primarily took place in the teaching hospitals. Their assignment into test and control groups was determined by the schedule of their clinical rotations during the period of the study.

The 40 participants we needed in this study were recruited from the two teaching hospitals in Leiden and Amsterdam and both centres provided a group of 20 participants each. The participants in each group were then assigned to either the experimental, or control group of the study. Two dependent variables were investigated in this study. The first was the medical residents satisfaction with the workshop training. The medical residents judged the quality of the workshop using a questionnaire that assessed its content, and quality of instruction. The second dependent variable was the quality of teaching by the medical residents, which was judged by the medical students. Standardised questionnaires were used for the evaluation, which took place at two separate intervals during the period of the study. The first (pre-workshop) evaluation in the study occurred about a month prior to the workshop and the second (post-workshop) evaluation took place about three months after the workshop was conducted. Each medical student could rate as many medical residents as possible, provided he/she had been under the direct supervision of the resident for a period of at least 6 weeks before the evaluation. The medical students could not rate the same resident twice, and we strove to have each resident rated by an average of five different medical students in order to guarantee reliable assessments. Lastly, the rating by the medical students was anonymous and the medical residents were unaware of who their rater was.

\section{Instrument}

The questionnaire that was used by the students to assess the teaching abilities of the medical residents was the Cleveland Clinic's Teaching Effectiveness Instrument (CCTEI). This instrument has been found to be a valid and reliable instrument for assessing the quality of teaching 
provided by clinical teachers ${ }^{32}$ and comprises is different items that assess different components of teaching ability. Each item is rated on a Likert scale of $\mathrm{t}=$ never/very poor to $\mathrm{s}=$ always/very good.

\section{Table 1. ITEMS USED TO ASSESS THE MEDICAL RESIDENTS TEACHING ABILITY}

Scale: 1 = Very poor/never, 2 = Poor/seldom, 3 = Fair/sometimes, 4 = Good/Often, 5 = Very good/Always.

\begin{tabular}{|l|}
\hline 1. Establishes a good learning environment (approachable, non-threatening, enthusiastic, etc.) \\
\hline 2. Allows me autonomy appropriate to my level/experience/competence \\
\hline 3. Gives clear explanations/reasons for opinions, advice actions, etc \\
\hline 4. Stimulates me to learn independently \\
\hline 5. Adjusts teaching to my needs (experience, competence, interest, etc.) \\
\hline 6. Asks questions that promote learning (clarifications, probes, reflective questions, etc.) \\
\hline 7. Adjusts teaching to diverse setrings (bedside, view box, OR, consultation room, etc.) \\
\hline 8. Offers regular feedback (both positive and negative) \\
\hline 9. Coaches me on my clinical/technical skills (interview, diagnostic, examination, procedural, lab, etc.) \\
\hline ro. Teaches diagnostic skills (clinical reasoning, selection/interpretation of tests, etc,) \\
\hline 11. Clearly specifies what I am expected to know and do during the training period \\
\hline 12. Organizes time to allow for both teaching and care giving \\
\hline 13. Teaches effective patient and/or family communication skills \\
\hline 14. Incorporates research data and/or practice guidelines into teaching \\
\hline 15. Teaches principles of cost-appropriate care (resource utilization, etc) \\
\hline
\end{tabular}

Modified from The Cleveland Clinic's Clinical Teaching Effectiveness Instrument, Copeland L.H. \& Hewson, M.G. (2000) Academic Medicine, 75: 161-166.

The questionnaire that was used to evaluate medical residents' satisfaction with the workshop comprised of two sections. The first section contained ro-items ( Likert scale: $1=$ totally disagree to $s=$ totally agree) that reflected the medical residents satisfaction with the structure of the workshop. The second section was made up of 17 -items (Likert scale: $1=$ very poor; $5=$ very good) that was used to assess the quality of instruction and the content of the different modules in the following areas: Clarity and organisation, Presentation style, Group interaction, and Content. 


\section{Analysis}

Means and standard deviations were calculated for the perceived teaching abilities of the medical residents in the two different groups before and after the workshop. Paired sample t-tests were used to identify significant differences in overall teaching abilities between the group means that could be attributed to the effect of the workshop. Effect size estimates (Cohen's d) were calculated to measure the magnitude of the effect of the training on the medical residents teaching abilities. This was done because unlike significance tests, effect size estimates are independent of sample size. The estimates of effect size were defined as "small, $d=0.2$, " medium, $d=0.5$," and "large, $d=0.8$." 35 We did not investigate for any effect residency level might have on the medical residents ratings as this had already been found to be insignificant when using the CCTEI questionnaires" ${ }^{33}$. Finally, descriptive statistics were used to interpret the medical residents evaluations of the workshop.

\section{Results}

Out of the forty medical residents who initially volunteered to take part in this study, only 27 $(67.5 \%)$ of them ended up fully participating. The considerable fall-out of participants was due to a number of reasons, which included illness $(n=2)$, maternity leave $(n=1)$, graduation during the period of the study $(\mathrm{n}=3)$, incomplete participation in the workshop training $(\mathrm{n}=3)$. and posting to clinical departments outside the study environment $(n=4)$. Compromise power analysis, repeated post hoc to investigate the effect of this fall out on our findings, revealed an acceptable power of 0.66 and a Cohen's $d$ of 0.5 . The demographic distribution of the medical residents in this study was fairly balanced. 14 (51.9\%) of the participants were from the teaching hospital in Amsterdam and 13 (48.1\%) from Leiden. The 13 medical residents in the experimental group comprised of 7 from Leiden and 6 from Amsterdam, while the 14 in the control group was made up of 8 medical residents from Amsterdam and 6 from Leiden. Furthermore, 17 (63\%) of the participants were residents in paediatrics and most of the participants were female i.e. $18(66.7 \%)$. Each medical resident was rated by an average of 4 different medical students (range 1-6 ratings). In total, we obtained two hundred and one (2OI) rating forms from the students; ninety eight $(98)$ from the pre-workshop evaluation and one hundred and three (103) from the post-workshop evaluations.

\section{Medical residents' satisfaction ratings of the workshop}

As shown in table 2, the residents who participated in the workshop regarded it as a good learning experience (mean $=4.25 ; \mathrm{SD}=0.34$ ) on a scale of $\mathrm{t}=$ very poor to $\mathrm{s}=$ very good. They agreed that such a workshop should be incorporated in their residency training (mean $=4.88 ; \mathrm{SD}=$ 0.33 ). They also felt that the workshop was well planned (mean $=4.24 ; \mathrm{SD}=0.56$ ) and expressed their satisfaction with the duration of the program (mean $=4.12 ; \mathrm{SD}=0.70$ ). Their opinion on the appropriateness of the provided literature was neutral $($ mean $=3.00 ; S D=0.82)$. 
Table 2. General eVAluation OF THE wORKShOP IN ANSWER TO THE QUESTION: HOW WOULD YOU RATE THE WORKSHOP IN THE FOLLOWING SPECIFIC AREAS,

using the scale: $x=$ totally disagree, 2 = disagree, 3 = neutral, 4 = agree, 5 - totally agree.

\begin{tabular}{|l|c|c|c|}
\hline Aspect of the Workshop & $\mathrm{N}^{*}$ & Mean & Std. Dev. \\
\hline $\begin{array}{l}\text { Incorporate such a workshop in the specialist training } \\
\text { program }\end{array}$ & 17 & 4.88 & 0.33 \\
\hline I learnt new concepts that can improve my teaching & 17 & 4.59 & $0.6 \mathrm{t}$ \\
\hline The workshop was a good learning experience & 17 & 4.53 & 0.51 \\
\hline $\begin{array}{l}\text { I feel better prepared in my role as tutor for medical } \\
\text { undergraduates }\end{array}$ & 17 & 4.47 & 0.62 \\
\hline $\begin{array}{l}\text { The Provided instruction was relevant for my clinical } \\
\text { responsibilities }\end{array}$ & 17 & 4.29 & 0.59 \\
\hline The workshop was well planned & 17 & 4.24 & 0.56 \\
\hline $\begin{array}{l}\text { Incorporate such a workshop in medical undergraduate } \\
\text { program }\end{array}$ & 17 & 4.18 & 1.24 \\
\hline The duration of the workshop was appropriate & 17 & 4.12 & 0.70 \\
\hline The length of individual sessions were appropriate & 17 & 3.88 & 0.60 \\
\hline The provided literature was appropriate & 13 & 3.00 & 0.82 \\
\hline Overall rating of the workshop & 17 & 4.25 & 0.34 \\
\hline
\end{tabular}

- 17 out of the initial 20 medical residents completed the full two-day workshop. An additional 4 fell out during the course of the study. Results have been adjusted for missing values.

The medical residents rated the content of the six educational modules positively (mean $=4.11$; $\mathrm{SD}=0.28,95 \% \mathrm{CI}=3.99-4.21$ ) and the quality of instruction i.e. Clarity and organisation, presentation style, group interaction and content, in the six modules was perceived as good (mean = 4.10; $\mathrm{SD}=0.22,95 \% \mathrm{CI}=3.97-4.25$. 


\section{Students ratings of the medical residents teaching abilities}

In general, the medical students rated the teaching abilities of the medical residents positively. The results showed that improvements were observed in the teaching abilities of the residents who participated in the training program; the post-workshop rating of their teaching abilities was higher $($ mean $=3.88, \mathrm{SD}=0.28)$ compared to their pre-workshop ratings (mean $=3.51, \mathrm{SD}=$ 0.34 ). The difference between the two means was also significant $(t=-2.68, p=0.02)$. A similar analysis of the teaching abilities in the control group did not yield any significant difference. Further analysis of individual teaching characteristics of the medical residents showed, that their post workshop ratings were significantly higher in the following areas i.e. "stimulating medical students to learn independently", "asking questions that promote learning" and "incorporating research data and/or practice guidelines into teaching". The post workshop rating of the medical residents overall teaching abilities was slightly higher (mean $=3.88, \mathrm{SD}=0.28$ ) in the experimental group compared to the ratings (mean $=3.68, \mathrm{SD}=0.41$ ) of their colleagues in the control group. The difference however, was not significant. Estimation of effect size in the medical residents' teaching abilities after the training revealed a value of 0.57 (i.e. moderate effect size) between the experimental and control group (See table 3). The estimation of effect size was also performed on the means of the experimental group i.e. before and after the training, and revealed a larger value ( $E S=1.17$ ), compared to that of the control group ( $E S=0.04)$.

\section{Table 3. EFFECT SIZE ESTIMATIONS (ES) OF THE IMPACT OF THE WORKSHOP TRAINING BETWEEN AND WITHIN THE STUDY GROUPS.}

Cohen's $d$ defined as "small" $=>0.2$, "medium" $=>0.5$, "large" $=>0.8$.

\begin{tabular}{|c|c|c|c|c|c|c|c|}
\hline \multirow[t]{2}{*}{ Measurement } & \multicolumn{3}{|c|}{ Control group } & \multicolumn{3}{|c|}{ Experimental group } & \multirow{2}{*}{$\begin{array}{c}\text { Effect size } \\
\text { (Between } \\
\text { groups) }\end{array}$} \\
\hline & $\mathbf{N}$ & Mean & SD & $\mathrm{N}$ & Mean & SD & \\
\hline Pre Workshop & 14 & 3.66 & 0.49 & 13 & 3.52 & 0.34 & -0.33 \\
\hline Post Workshop & 14 & 3.68 & 0.42 & 13 & $3.88^{*}$ & 0.28 & 0.57 \\
\hline $\begin{array}{l}\text { Effect size } \\
\text { (Within groups) }\end{array}$ & \multicolumn{3}{|c|}{0.04} & \multicolumn{3}{|c|}{1.17} & $d$ \\
\hline
\end{tabular}

$* \mathrm{p}=0.02$ 


\section{Discussion}

In this study, the effectiveness of a teacher-training program developed to improve medical residents teaching abilities was investigated. The question we intended to answer was whether a two-day teacher-training workshop could improve the (perceived) teaching abilities of medical residents? In general, the medical residents who took part in the workshop regarded it as a good learning experience. They felt that it was well planned and that the duration of the individual sessions and the workshop was suitable as a whole. Their approval of the workshop correlated with the views of the residents who participated in our initial pilot study (Busari et al. 2004, unpublished).

The positive overall rating of the workshop reflected that it was a good instructional tool for training teaching skills of medical residents. The students' perceptions of the teaching abilities of medical residents showed that the residents who underwent the training were better in teaching than their counterparts who did not. Analysis of means however revealed that the perceived difference was not significant between the control and experimental groups. Possible explanations for this finding could be the considerable fall out we had in the number of participants in the study (fall out rate 32.5\%) that eventually affected the study's statistical power. Alternatively it could be due to the "ceiling effect" that may have been caused by the 5 -point rating scale we used to evaluate the medical residents teaching abilities.

As earlier mentioned in this paper, the small size of the target population in this study was associated with ill health, maternity leave, graduation, external clinical rotations and incomplete participation in the workshop among the participants. Since we were aware that the dropouts could blur the results from conventional tests of significance, we decided to use effect size estimations to investigate the magnitude of the treatment effect between and within the two groups $^{29}$.31.33. The effect size estimation of the impact of the workshop showed that the training in teaching skills caused large positive changes $(d=1.17)$ in the teaching abilities of the medical residents in the experimental group. The effect on the teaching abilities of the medical residents in the control group was negligible $(d=0.04)$. Furthermore, the estimation of the effect size when both groups were compared showed that compared to the control group, a moderate improvement $(d=0.57)$ in the teaching abilities of the medical residents in the experimental group was realised after the training.

This study demonstrates that that if well designed, workshops in teaching skills can be effective methods for training medical residents to teach. Despite the methodological limitations and the problems that we encountered in implementing the workshop, measurable positive changes in teaching ability of the medical residents were observed. Although the findings of this study appear promising, it is important to acknowledge some organisational and logistic problems we encountered and the potential effect they may have had on the results. For example, securing the full support and co-operation of the heads of department and attending doctors for the educational intervention proved to be more difficult than we expected. This problem was 
dealt with by providing the above-mentioned stakeholders with comprehensive information on the aim and potential benefits of the project in the initial and later stages of the study. A peer approach strategy was used whereby a fellow medical resident approached medical residents. A peer consultant on the other hand approached attending doctors. This helped to lower the threshold of resistance to the idea of an educational intervention that involved the evaluation of the individual performances of the participants. Another difficulty we encountered was the logistics of getting as many residents as possible to participate in the full two-day workshop. This was a problem because the work-shifts of many residents were irregular and this made their full participation in the two-day workshop difficult to guarantee. We made efforts to bypass this obstacle by scheduling the workshop on a Friday and Saturday. We had the department approve the workshop participants' exemption from clinical duties on the Friday, while the medical residents on their part pledged to attend the workshop on a free Saturday. Although approval and commitment of both stakeholders were secured in this way, 17 out of the 20 medical residents $(85 \%)$ in the experimental group eventually completed the full two-day workshop.

The problems we encountered in this study, although not unfamiliar, reflect that a lot still needs to be done to enhance the smooth and effective implementation of such programs. In retrospect, we probably could have reduced the difficulties we faced by recruiting more faculty and/or departmental support, and engaging them more actively in the idea. Nonetheless, we still consider that this study stresses the importance of educational interventions in improving medical residents' teaching abilities. We assume that in better and more controllable circumstances, improved and more significant changes in the teaching behaviour of medical residents can be achieved. We therefore recommend that more initiatives like this should be encouraged to improve the teaching abilities of medical residents.

\section{REFERENCES}

1. BARROW, M.V. (1966) Medical students' opinions of the house officer as a medical educator. Journal of Medical Education, 41: 807-10.

2. BROWN R.S. ( 1970 ) House Staff Attitudes toward Teaching. Journal of Medical Education, 45: 156-59.

3. MELECA C.B.\& PEARSOL. J.A. (1988). Teaching surgery residents to teach. In J.C. EDWARDS \& R.L. MARIER (Eds.) Clinical Teaching for Medical Residents: Roles, Techniques and Programs, 87-200, New York: Springer Verlag

4. STEWARD, D.E. \& FELTOVICH, P.J. (t988). Why residents should teach: the parallel processes teaching and learning. In J.C. EDWARDS \& R.L. MARIER (Eds.) Clinical Teaching for Medical Residents: Roles. Techniques and Programes, 3-14. New York: Springer Verlag

5. BARROW, M.V. (1965). The house officer as a medical educator. Journal of Mrdical Education, 40: 712 14.

6. BING-YOU, R.G. \& SPROUL. M.S. (1992). Medical students' perceptions of themselves and residents as teachers. Medical Teacher, 14:133-138. 
7. NKANGINIEME, K.E.O. \& IHEKWABA, A.E. (1998). Students' perception of the house officer as a teacher. Medical Teacher, 20 (2): 109-113.

8. BUSARI, J.O. SCHERPBIER, A.J.J.A. VAN DER VLEUTEN, C.P.M \& ESSED, G.G.M. (200o). Residents' Perception of their role in Teaching Undergraduate Students in the Clinical Setting, Medical Teatber, 22(4): 348-353.

9. BUSARI, J.O., PRINCE, K.A.H., SCHERPBIER, A.J.J.A., VAN DER VLEUTEN, C.P.M $\&$ ESSED, G.G.M. (2002). How residents perceive their teaching role in the clinical setting - a qualitative study Medical Teacher, 24(1): 57-61.

10. BUSARI, J.O. SCHERPBIER, A.J.J.A. VAN DER VLEUTEN, C.P.M \& ESSED, G.G.M. (2003). The perceptions of attending-doctors on the role of residents as teachers of undergraduate medical students, Medical Education, 37: 241-247.

in. TONESK, X. (1979). The house officer as a teacher: what schools expect and measure. Journal of Medical Education, 54: 613-616.

12. COTE, L. (1993). Supervision of family medicine residents. Competencies and qualities [French], Canadian Family Physician. 39: 366-372.

13. CHALliS, M., WILLIAMS, J. \& BATSTONE, G. (1998). Supporting pre-registration house officers: The needs of educational supervisors of the first phase of post-graduate medical education. Medical Education, 32: $177-180$.

14. APTER, A., METZGER, R. \& GLASSROTH, J. (1988). Residents' perception of their role as teachers. Journal of Medical Education, 63: 185-88.

15. KATES, N.S. \& LESSER, A.L. (1985). The resident as a teacher: a neglected role. Canadian Journal of Psychiatry, 30 (6): 418-21.

16. LAWSON, B.K. \& HARVILL, L.M. (1980). The evaluation of a Training program for Improving Residents' Teaching skills. Journal of Medical Education, 55: 1000-05

17. JEWETT, L.S., GREENBERG, L.W. \& GOLDBERG, R.M. (1982b) Teaching residents how to teach: a one-year study, Journal of Medical Education, 57:361-366.

18. CAMP M.G. \& HOBAN J. D. (1988) Teaching medicine Residents to Teach. In J.C. EDWARDS \& R.L. MARIER (Eds.) Clinical Teaching for Medical Residents: Roles, Techniques and Programs, 201-213, New York: Springer Verlag.

19. EDWARDS, J.C., KISSLING, E.G., PLAUCHE, C.W. \& MARIER L.R. (1988) Developing and evaluating a teaching improvement program for residents. In J.C. EDWARDS \& R.L. MARIER (Eds.) Clinical Teaching for Medical Residents: Roles, Techniques and Programs, 157-174, New York, Springer Verlag.

20. BING-YOU, R.G. \& GREENBERG, L.W. (1990) Training residents in clinical teaching skills: a residentmanaged program. Medical Teacher, 12: 305-308.

21. SHEETS, K.J., HANKIN, F.M. \& SCHWENCK T.L. (1991) Preparing Surgery House Officers for Their Teaching Role. American journal of Surgery 161:443-449

22. GENERAL MEDICAL. COUNCIL (1993). Tomorrow's doctors: recommendations on undergraduate medical education. London: General Medical Council.

23. PARLE, J., WALL, D., HOLDER, R. \& TEMPLE, J. (1995). Senior registrars' communication skills: attitudes to and need for training. British Journal of Hospital Medicine, 53 (6): 257-60. 
24. PORTER, N. (1997). Clinical supervision: the art of being supervised. Nurning Standard, 11: 44-45.

25. PAGE G.G., BATES, J. DYER, S.M. VINCENT, D.R., BORDAGE, G. \& JACQUES, A. et al. (1995) Physician-assessment and physician-enhancement programs in Canada. Canadian Medical Asociation Journal, 153:1723-8.

26. NORCINI, J.J. (1999) Recertification in the United States British Medical Journal, 319: n83-5.

27. GREENBERG. L.W.,JEWETT, L.S. \& GOLDBERG R.M. (1988). The children's hospital experience. In J.C. EDWARDS \& R.L.. MARIER (Eds.). Clinical Teaching for Medical Residents: Roles, Techniques and Programs, 175-86, New York: Springer Verlag.

28. RATNAPALAN, S. \& HIL.LIARD R. (2002). Needs Assessment in Postgraduate Medical Education: A Review. Medical Education Online $7(8)$.

29. NORMAN, R.G. SHANNON, S.I. \& MARRIN, M.L. (2004) The need for needs assessment in continuing medical education. British Medical Journal, 328: 999-1001.

90. BUCHNER, A., ERDFELDER, E., \& FAUL, F, (1997). How to Use G*Power [WWW document]. URL http://www.psycho.uni-desseldorf.de/aap/projects/gpower/how_to_use_gpower.html

31. FAUL., F. \& ERDFELDER, E. (1992). GPOWER: A priori-, post hoc-, and compromise power analyses for MS-DOS [computer program], Bonn, Germany: Bonn University.

32. COPELAND, L.H. \& HEWSON, M.G. (2000) Developing and testing an instrument to measure the effectiveness of clinical teaching in an academic medical center. Academic Medicine, 75: 161-166.

33. COHEN. J. (1988), Statistical power analysis for the behavional scienca (2nd ed.). Hillsdale, NJ: Lawrence Erlbaum Associates. 
Chapter II

General discussion 
It is not an issue of why anymore, but a matter of when, formal training programs in teaching would form an integral part of professional medical training - J. Busari

\section{INTRODUCTION}

One of the primary responsibilities of specialist physicians in clinical medicine is to guide and supervise medical residents in their clinical duties. Since, many specialists do not posses the basic skills required to teach or supervise medical residents, the quality of clinical supervision of medical residents in many clinical settings is thereby compromised. In addition to supervising medical residents, specialist physicians are also responsible for teaching medical students. However, in clinical practice, this latter task has (gradually) become a primary responsibility for medical residents as well. Unfortunately, the medical residents delegated with these didactic responsibilities are also learners, who are less experienced than the specialist physicians and also possess little or no supervisory or teaching skills. There is enough proof in the medical literature, that the quality of medical education needs to be improved. The required improvements are not limited to the content and form of curricula alone ${ }^{t-4}$, but extend to the methods of instruction that are applied in clinical practice. It is observed that many clinical instructors require additional training in their supervisory and teaching skills ${ }^{3-9}$, and that medical residents are (potentially) suitable clinical teachers for medical students provided however, that they are properly trained to do so and that adequate training and supervision is available to guide them ${ }^{9-14}$. By judging the contents of this dissertation in the context of the above-mentioned points, the reader might not be offered anything new, as the need for improving the quality of teaching by clinical teachers is again re-affirmed. However, what this dissertation contributes to the knowledge that is available is a careful analysis of the current situation as well as of the needs of medical residents as clinical teachers.

\section{OBjective(s) OF THE DISSERTATION}

The medical resident as a professional, was the focus of artention in this dissertation. Of particular interest was how effective they were in their pivotal roles as teachers in the clinical setting. We were interested in investigating the extent to which they were involved in teaching medical students, and how their roles could be improved in this respect. We wished to know the factors that influenced their contribution to teaching and how a valid and reliable intervention for improving their teaching abilities could be developed. In order to answer these enquiries the following research questions were formulated,

1. To what extent are medical residents involved in teaching undergraduate medical students? 
2. What are the factors that hinder medical residents effective contribution to teaching undergraduate medical students?

3. How can an effective educational program be designed as a form of intervention for improving medical residents' teaching skills?

4. How can the feasibility and appropriateness of such an educational program be assessed?

5. How can the impact of such a program on the teaching skills of medical residents be measured?

\section{WHAT ARE THE (NEW) THINGS THAT THIS DISSERTATION DISCOVERED?}

This dissertation started by re-visiting what is understood by the concept of a profession and how this understanding translates into the practice of medicine. The description provided in chapter one illustrates that the practice of medicine is based on a theoretical and scientific base that is integrated with the skills of history taking, physical examination, and performing procedural tasks. The illustration demonstrates that the practice of medicine qualifies as a profession because it incorporates the development of theory alongside an apprenticeship, and develops its own theories and actions by which it defines its responsibilities. The competent professional is seen as one who is expected to learn a high level of technical skills in order to be able to fulfil the responsibilities his/her profession demands ${ }^{15}$. The professional training itself is characterized by the cognitive and intellectual learning that ranges from the simplest levels of factual knowledge acquisition to the complexities of synthesis, evaluation, and reasoning. It also involves the assimilation of a rich fabric of socialization, interpersonal skills, moral reasoning and attitudes that characterizes the professions' and distinguishes the members of one profession from the other.

One of the assumptions of this dissertation was that clinical instructors had to understand the theory of education first, if improvements in the process of professional development were to be achieved. In this regard, it was practical to begin by re-examining the concept of a profession first; to see if, and how educational theory contributes to professional development. As we saw in chapter one, the theory of education is inherent in the process of professional development, and contributes largely to the development of the professional's gestalt. In addition, this theory of education is responsible for the process of acquiring scientific knowledge and the cognitive processes needed for synthesizing information. Chapter two elaborates more on this process by providing an explanation on the principles of educational theory and the mental processes of how knowledge is acquired and transferred. After knowledge is attained, it is usually categorized into different forms (Knowledge acquisition) and later collated and organized into subunits before application (Knowledge compilation). Learners then use different learning styles to operationalize and put the knowledge they have acquired into practice (Approach to learning). 
Summarily, these two chapters show that medicine is a profession because it involves on the one hand learning a craft and on the other, it contains a scientific and theoretical basis that explains how the craft is executed in practice. Inherent in this concept is the process of teaching and learning (i.e. education), which this dissertation was particularly investigating in medical residents.

\section{THE EXTENT TO WHICH MEDICAL RESIDENTS ARE INVOLVED IN TEACHING UNDERGRADUATE MEDICAL STUDENTS}

It is very well known in clinical medical education, that medical residents teach undergraduate medical students and as much as $70 \%$ of what the students learn is attributed to this effort ${ }^{10 .}$ 16. This dissertation revealed that medical residents considered teaching to be one of their primary responsibilities and were willing to teach students. Residents were also actively engaged in educational activities in the clinical setting and spent as much as 1.3 hours/day in teaching activities. The amount of time considered to be ideal for teaching was between 1.5-1.7 hours/day. Despite the general consensus that residents should teach, there is reason to assume that the benefits of this activity are not being appropriately exploited by medical institutions and faculty. For example, medical residents' contribution to teaching in many institutions is limited due to the lack of time allocated for teaching activities during their training. As clear departmental (or faculty) objectives outlining the roles of residents as supervisors are lacking, it makes it difficult for residents to know what they are expected to do as teacher. Also, formal training programs for medical residents on how to teach are sparse, which further complicates their tasks as teachers. Finally, structured supervisory and formative assessment mechanisms required to guide residents' teaching roles are deficient, and thereby hinders the process of objectively assessing their individual teaching performances ${ }^{17}$.

One would argue, that because of the (potential) benefits in teaching for medical residents, the students who they teach, and the medical profession as a whole, more efforts should be made to improve the quality of teaching in the clinical setting. Furthermore, that teaching by medical residents (and attending physicians) should be regarded as an important professional responsibility, and not as a second-ranked task. Bearing this in mind, the strategic position of medical residents could be of immense benefit in the medical educational process if handled appropriately. This is because, as we found in this dissertation, the large amount of teaching medical residents provide is ascribed to their being easily approachable for medical students, being readily available on the wards, and being able to explain problems easily from the medical student's perspective. Although at present, the extent of medical residents involvement in teaching in the clinical setting is considerable, it is as yet, not fully exploited. More can (and should) be done to address this situation, with the first step being, to acknowledge that teaching is an inherent part of the medical profession, and that it is a separate skill that should be formally learnt. 


\section{THE FACTORS THAT HINDER MEDICAL RESIDENTS EFFECTIVE CONTRIBUTION TO TEACHING UNDERGRADUATE MEDICAL STUDENTS}

The extent to which medical residents are involved in medical education is determined by the factors that influence their teaching. These factors could be intrinsic i.e. closely related to a resident's individual abilities or extrinsic being determined by external factors that are related to the context of teaching, pressure of work or departmental or faculty regulations. Chapters three and four describe some of these factors as including the lack of formal training in teaching and poor departmental acknowledgement and support for medical residents' teaching roles. As was described in these studies, many residents are presently engaged in teaching without having undergone any formal training in teaching. In extreme situations, freshly graduated medical residents are also expected to supervise medical students, as early as the first week after their graduation. It is obvious that a lot of residents, particularly those in the beginning years, could benefit from a formal instruction in teaching. Even senior residents can benefit from such courses by understanding the process of teaching and learning better, and modifying any wrong teaching behaviours they may have cultivated. The following section illustrates a few factors that were found to hinder the medical residents' effective contribution to teaching in this dissertation.

\section{Availability of teacher training programs}

A major recommendation to be derived from this dissertation is that formal teacher training programs and educational resources in teaching should be made available to medical residents. Medical residents and attending physicians unanimously agree that training in teaching should be a mandatory requirement during the professional training of medical residents. Unfortunately, in practice, the appeals that are being made to embrace teacher-training programs within the curricula of specialist training programs are not being optimally honoured. Why this is so is not entirely clear, although there are a number of possible reasons that could explain this. For example it could be due to specialist physicians' ignorance of the importance of training to teach better, or that they consider teaching to be a less important professional responsibility and an extra burden. It could also be due to the costs and time such activities demand from the specialist physicians or the inherent resistance to innovative change i.e. embracing teaching as a separate and new professional responsibility.

Regarding this last point, this innovative change entails that medical educators and specialist physicians should discard the misconception that qualified physicians are automatically competent teachers. The review article in chapter seven elaborates more on this, by taking a critical look at the profile of the medical resident as physician. In the paper, the medical residents' function as a physician and professional is characterized as comprising of three roles namely, that of a learner, caregiver and teacher. Of these three characteristics, their role as teachers receives the least attention during the professional training. This may explain why many specialist physi- 
cians lack the skills of effective teaching and the thorough understanding of educational theory. Since they have not been schooled in the basics of medical education, it is illogical to expect that physicians be able to do teach and supervise medical residents effectively.

\section{Knowledge of the teaching and learning process}

The fact that a handful of attending physicians can and do teach well, despite their lack of a formal training in teaching, does not justify that all physicians should and are qualified to teach. Furthermore, these physicians who are gifted with this ability to teach effectively, are more of the exception than is the rule. Currently, there is growing acknowledgement that instruction in teaching should be (made) mandatory for all physicians entrusted with the duty of teaching and supervising in the clinical setting. This is because there is more evidence showing that clinical instructors should be aware of the responsibilities involved in teaching and supervising medical residents and students $16 \cdot 21$. Not only should they understand why they are teaching, but they should also know what they intend to achieve i.e. objectives. They should also understand the mechanisms involved in the process of teaching and the effects they have on the cognitive processes of learners ${ }^{21}$.

The review in chapter seven provides a description of how this process occurs; showing how improved skills in teaching may contribute to the improvement of professional competency in medical residents. The connection made between effective teaching and professional competency in the description was referred to as the physician as teacher rule, which states that, "A skilled teacher has an increased likelihood of becoming a competent clinician, than a skilled clinician has of becoming a competent teacher". Basically, this connection illustrates how the knowledge of the concepts that constitutes and facilitates the process of learning are relevant for improving the quality of teaching. It describes how the knowledge of educational principles and good teaching skills augments the development of the physicians' cognitive skills and also how teaching enriches the knowledge of medical residents and stimulates self-improvement.

\section{Distinction between a physician and a teacher}

What the review also showed was the basic and fundamental understanding that the art of teaching is a separate vocation. Although there are specialist physicians who possess good teaching skills and other attributes of good teachers, this does not automatically make them expert teachers. For example, in the medical profession, the internist with an affinity for renal medicine would never be considered a nephrologist, neither would a paediatrician with an interest in endocrinological disorders be seen as a paediatric endocrinologist. The profession requires that these individuals first have to undertake additional and specific training in these fields of interest before they can qualify as experts in those areas.

In this same light, the specialist physician with a good affinity for teaching cannot be considered an expert teacher. This is because there are fundamental principles and theories that need to be learnt so that the expert understands what he/she is doing or is trying to achieve. With this fact in mind, it would be a misconception to assume that specialist physicians are qualified 
to teach when in reality, they have not undergone a training to teach, but of that to practice medicine! It is simply wrong to assume that the specialist physician is also an expert teacher. Nonetheless, it is noteworthy to mention that medicine is a profession that primarily involves teaching and learning and most doctors are exposed to this didactic process very early during their training. As a result, there is a good foundation from which any pre-existent teaching practices can be improved and/or refined.

\section{Definition of didactic responsibilities}

The study in chapter four showed that medical residents' participation in teaching was hindered by the insufficient and unclear information most clinical departments/faculties provided them, on what they were expected to do as "teachers". In reality, these findings were not far removed from the state of affairs in many medical institutions. In many clinical settings, the responsibility of the resident as teacher is (still) ill defined. By evaluating the impact of this problem and taking measures to address them, a change in the general attitude of medical residents may be facilitated that could eventually motivate a lot of them to teach. Essentially, this would mean, that detailed and comprehensible teaching objectives are set up that clearly define what medical residents are expected to do as teachers. Informing them beforehand, on what they would be assessed on, as well as on the purpose of the assessment i.e. formative or summative, would be of additional benefit. Supplemental to all these measures would be, the presence of supervisors who are prepared to offer assistance when needed, and provide prompt feedback on residents' teaching behaviours.

\section{Effective supervision and feedback}

The lack of formal supervision and feedback on their teaching activities was also found to be a factor that hindered medical residents in their contribution to teaching. This point was a major source of concern in the study described in chapter three, where medical residents gave this as a reason for refusing to participate in the formal evaluation of their teaching activities. Although medical residents regularly express their dissatisfaction with the quality of supervision they receive in clinical practice, their supervision, although inconsistent, is still considered to be important and effective for their professional development ${ }^{13,22}$. Most authors agree that while the function of supervision in clinical practice is educative, supportive and administrative, its ultimate aim is to promote professional development and ensure good patient care and safe$t^{23,24}$. Nonetheless, supervision in the clinical setting is still seen as a complex activity that occurs in a variety of contexts, has various functions and different modes of delivery ${ }^{25}$.

\section{Good supervisory qualities}

The medical residents perception of supervision was investigated in this dissertation and the findings were presented in chapter six. In general, medical residents consider collaboration, patience and showing understanding, as good supervisory qualities that attending physicians should possess. Attending physicians who are valued as effective supervisors are those who are 
readily available to help in the wards when needed, provide measured and constructive feedback regularly, and who also treat medical residents as adult learners. This dissertation revealed that extra supervision is necessary and should be made available to the less experienced trainees. This is because the needs of trainees (medical residents) vary according to their different levels of training, requiring that supervision should be structured, supportive and directive towards trainees' requirements. As the training process progresses however and more experience is acquired, the supervision automatically transforms into a collaborative style. This is because at such stages, most trainees become increasingly independent and versatile. It is important that the attending physician is aware of this because senior medical residents appreciate more autonomy when performing their duties than their younger counterparts. Acknowledging this for example illustrates being treated as adult learners and motivates residents to perform better. Furthermore, medical residents felt that attending physicians' supervisory skills in "direct supervision", "instruction", and "evaluation" were poor and cited these as areas where improvement is needed.

\section{How CAN AN EFFeCtive EdUCATIONAL PROGRAM BE DESIGNED AS A FORM OF INTERVENTION FOR IMPROVING MEDICAL RESIDENTS' TEACHING SKILLS?}

Like most professions, medicine enjoys a professional autonomy that is granted by society. This autonomy rests on the assumption that its members have fulfilled certain conditions that permit them to practice as (medical) professionals. Furthermore, it assumes that there is a system in place that ensures that the quality of service being provided is good and that a high standard of professional training is maintained. However, in practice, the continuously changing, evidencebased and consumer driven nature of the medical profession makes it difficult to guarantee these conditions.

In the preparation of the two-day workshop in teaching skills described in chapter 8, a needs assessment of medical residents teaching activities was conducted before prior to designing the educational program. Needs assessment is an educational strategy that is useful in identifying the contents, and the way an educational intervention can be implemented. This strategy enables the objective evaluation of deficiencies in the knowledge, skill, behaviour or atritude of the learner(s) and facilitates the anticipation of deficiencies in the quality of education, based on expected changes in health care needs ${ }^{26}$.

The needs assessment methods that were used in developing the two-day workshop in chapter 8 included questionnaire surveys, interviews and environmental scans ${ }^{27}{ }^{28}$. The perceived (Chapters $3 \& 6$ ) and unperceived (chapter s) learning needs of the medical residents were investigated with the aid of questionnaire surveys, while their expressed needs were obtained through interviews (chapter 4 ). The environmental scan involved the review of relevant research 
in medical education, medical educational theories and principles (chapter 7), and an appraisal of the opinion of educational experts. The investigations that were conducted revealed that there was general agreement between the two stakeholders; that medical residents needed to be trained to teach better. The (potential) benefits of teaching for both residents and students were also highlighted. Important cognitions and skills that were considered necessary for effective clinical teaching/supervision were also identified. The review of educational theories also revealed concepts that could improve the teaching skills of medical residents. We pooled the information we gathered from the different sources together and analyzed them. From the analysis, eleven recommendations were eventually identified as the skills and cognitions medical residents should possess on completion of a teacher-training program (see table 1, chapter 9) These recommendations, formed the desired learning outcomes of the program, and were used in designing the contents of the workshop.

\section{HoW THE FEASIBILITY AND APPROPRIATENESS OF SUCH AN EDUCATIONAL PROGRAM CAN BE ASSESSED}

Until recently, the use of needs assessment to diagnose aspects of education that required change was uncommon in postgraduate medical education. Since its introduction however, its value as an educational strategy has gradually been acknowledged and medical educators are increasingly using it to develop educational and/or training programs for medical residents. Furthermore, it has been shown that continuing medical education programmes that have been developed using well-conducted needs assessment methods have been effective in changing doctors' behaviours $^{29}$. Although there is proof in the literature to assume that interventions based on well conducted needs assessment should produce the desired learning outcome $e^{27,26,50}$, it is still important that the reliability, validity and feasibility of implementing these interventions be evaluated after they have been developed.

In Chapter nine, a description was provided of how the appropriateness and feasibility of the workshop was assessed as an educational intervention. A pilot study of the two-day workshop was conducted among medical residents in different disciplines and at different stages of their specialist training. The objective of the study was to assess whether the content of the workshop was reliable and if the workshop was an appropriate educational intervention. The findings showed that the content of the workshop was appropriate, which was demonstrated by the medical residents positive remarks and their strong recommendations that such a workshop should be incorporated in their residency training. The quality of the instruction that was provided was rated highly and its contents were considered relevant for their needs. The perception of having learnt new educational concepts as well as the perceived improvement in their teaching abilities also showed that the workshop was a reliable intervention. The positive findings in this chapter show needs assessment methods are useful in developing educational interventions in medical 
education and further support the pre-existent notion that workshops are feasible strategies for training teaching skills in medical residents31-33.

\section{HOW CAN THE IMPACT OF SUCH A PROGRAM ON THE TEACHING SKILLS OF MEDICAL RESIDENTS BE MEASURED?}

A research design is the plan and structure of investigation so conceived as to obtain answers to research questions and to control variance. The design helps the investigator obtain the answers to the research question and to control the experimental, extraneous and error variances of the particular research problem under study. There are certain conditions however, that should be fulfilled when research plans are being designed. First, the design of the research should be able to answer the research question or hypothesis. Secondly, the independent variables of the research study (and extraneous independent variables) should be adequately controlled. Thirdly, there is the question of whether the results of the study can be generalized to other subjects, groups and conditions ${ }^{4}$.

In the study described in chapter ten, a description was given of how these criteria were met. First, there was a clear research question, whether the workshop was a good instructional tool for improving the teaching abilities of medical residents. Secondly, measures were taken to control independent and extraneous variables in the research design. An experimental group that comprised of medical residents who participated in the workshop and a control group that did not were created. Secondly, subjects were randomly selected into the two groups. Pre- and posttest evaluations were also performed to limit the effect of variance of the participants individual differences. Medical students, who were the recipients of instruction, evaluated the medical residents. The results of the investigation showed that there was a significant improvement in the teaching skills of the residents in the experimental group when their ratings before and after the training were compared. Effect size estimations ${ }^{28,35}$ also showed that the training in teaching skills resulted in moderate positive changes in the teaching abilities of the medical residents in the experimental group when compared to their colleagues in the control group. The effect of the training in the experimental groups was even larger when the ratings of their teaching abilities before and after the training were compared. Based on these findings, one can cautiously conclude that the results in chapter ten support the internal validity of the educational intervention. We can also draw certain conclusions on the external validity of this workshop. So far, this workshop has been implemented in three different educational settings and the perceptions of the medical residents on the quality of the workshop and the perceived benefits have been consistently similar and positive (Busari, et al., submitted). In addition, the positive changes that were observed in the medical residents teaching abilities were comparable in effect and separately identified in different teaching hospitals suggesting, that this educational intervention had some external validity. 


\section{Overall Conclusion}

This dissertation has shown why the medical profession can be duly regarded as a profession as it is a craft that involves healing and caring for people and its practice is guided by rules and skills derived from logical and scientific reasoning. In addition, the importance of education in this concept has been drawn to the foreground. What has also been shown in this dissertation is that medical residents are prepared to teach medical students, and that both they and the medical students they teach benefit in the process. The role of medical faculties and attending physicians in this process should be more prominent than it is at present. Attending physicians and medical residents, who are actively involved in the teaching process should be encouraged more, and rewarded properly for their input. Mechanisms that would ensure that those involved in clinical teaching benefit from the privileges of promotion and recognition as is awarded excellence in scientific activities should be established in medical institutions. That is one way in which the much needed, and continued improvement in medical education can be guaranteed. What the dissertation has also demonstrated is the place of scientific and evidence based investigations in medical education. As described in the preceding chapters, an educational intervention was developed based on objective analysis of medical residents' perceived educational needs. The suitability of the intervention was confirmed in an initial pilot study and its effect was subsequently validated in a pre- and post-test, partially randomised, controlled study. The exercise in this dissertation demonstrates a process of innovation in medical education based on careful methodological and scientific reasoning.

The main message provided by this dissertation, is that the preconception that a specialist physician is also a (qualified) teacher, is wrong. This line of thought has been, and is still responsible for a lor of stumbling blocks in medical education today. It would be a major breakthrough, if and when, all (non-) medical professionals can totally discard this assumption; that specialist physicians are also teachers, and start focusing on strategies of training doctors to teach effectively and incorporate formal teacher training courses in the curricula of residency training programs.

\section{IMPLICATIONS OF THE FINDINGS FOR MEDICAL EDUCATION}

This dissertation provided a description of the practice of medicine as a profession. Inherent in this concept, was the theory of learning and how it occurred in practice. The role of medical residents was also examined; the ways in which they contributed to the profession (e.g. teaching), how their contributions can be improved and why their contributions were important for the profession. The result of this evaluation was the development of a workshop in teaching for medical residents. How this workshop was implemented and how its effectiveness as an educational tool was evaluated was also described. Below, a few recommendations derived from the 
conducted research work, that may be helpful for course developers and clinical instructors are discussed briefly. The recommendations are based on how some of the problems that were encountered in preparing this dissertation were dealt with, as some of these problems (may) have considerable influence on the ongoing innovation in medical education.

\section{Identify the important stakeholders in the educational process; secure their cooperation and support}

The first problem that was encountered in this study was securing the full support and cooperation of the medical faculty, department, attending physicians and the curriculum planners for the training program. The support and cooperation of these stakeholders was considered very important because,

1. The specialist training boards and medical faculties should be willing to fund and allow the implementation of such teaching courses as formal training programs.

2. Attending physicians should be prepared and willing to provide residents with more supervision in their teaching tasks, alongside their clinical work.

3. Structured evaluations and constructive feedback should also be provided on a regular basis.

4. Curriculum planners should be willing to create extra time for residents' teaching activi-

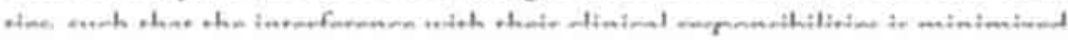

This problem was dealt with by providing the stakeholders with comprehensive information of the aim and potential benefits of the project, during the initial and later stages of the study. Presentations on the subject were held in which the objectives and the outline of the proposed program were explained. We approached and enrolled the heads of departments in the idea of the program first, and subsequently had them recruit the participation of faculty staff members. The support of the medical residents was also won by having a medical resident who was involved in developing the program explain its purpose to them. This method of peer approach helped to lower the threshold of resistance to the idea of an educational intervention that involved the evaluation of individual performances of the participants.

\section{Define the structure and content of the educational intervention based on the needs assessment of the learners}

A second obstacle was defining the content and structure of the teacher-training program for medical residents. The experience from previous training programs show that so far, workshop designs are very effective methods of training physicians to develop better teaching skills $^{31,32,36}$. However, the length and structure of such workshops are an issue of concern, because as is current practice, the decisions on these issues are based primarily on the views and preferences of individual course planners, faculty or institutions. In this dissertation, we gave these issues adequate consideration by first conducting an inventory of the views and recommendations of the stakeholders i.e. medical residents, attending physicians and educational experts. 
Through this needs assessment strategy, we were able to identify important recommendations that were subsequently used in designing the workshop. In addition, necessary modifications to the length and structure of the workshop were performed, based on the evaluation and recommendations medical residents provided in the pilot study that was conducted.

\section{Plan around potential logistical obstacles; be flexible and creative}

A third obstacle was the logistics involved in getting as many residents as possible, to participate in the full two-day workshop. This was a problem because the clinical working hours of most medical residents was irregular, as is illustrative of many hospital settings. It also made the full participation of the medical residents in the two-day workshop difficult to ensure. The effort we made to address this obstacle was scheduling the workshop on a Friday and Saturday. We had the department approve the workshop participants' exemption from clinical duties on the Friday, while they on their part pledged to attend the workshop on their free Saturday. In this way, we were able secure the approval and commitment of both stakeholders.

\section{Perform an initial implementation analysis; is there a clear plan of action, funding and infrastructure?}

A fourth obstacle we encountered involved the implementation of the training program. Experience has shown that planning, funding and implementing training programs of this nature is time consuming, and demanding in terms of the required manpower, infrastructure and financing. Some of the problems we had with the planning were related to enrolling medical residents in the study and having them participate in all of the workshop's sessions. This made it difficult to set up a clear program schedule as the choice of when and where to conduct the workshop was largely dependent on the research subjects. We were fortunate enough to have the program funded by the institute for medical education of the university of Maastricht. The medical residents' respective departments also provided sufficient support, although in retrospect more support would have been helpful. The venue of the workshops was located ourside the hospital setting and the decision to conduct the workshop outside the hospital setting was made at the onset of the study. This decision was based on the premise that educational activities conducted outside the normal working setting tend to yield more positive results ${ }^{37}$. Furthermore, the facilities and services that were provided were professional and suitable for the objective.

\section{Before implementing an educational intervention, obtain information about the structure of medical residents' training program}

Despite the obvious willingness and interest that was shown for the workshop, the overall participation of the medical residents in the study was disappointing. From the onset it was difficult to guarantec the full participation of all the participants during the entire period of the study, because of the nature of their clinical rotations. A number of residents left the study halfway because they had to continue their rotation elsewhere in a peripheral hospital setting. The training schedules of most of the medical residents was fixed and offered little room for flexibility. 
Subsequently, during the period of the study, it became difficult to have participating residents stay long enough at any one department for proper assessments. This contributed to the failure of achieving the required number of ratings per individual in all of those who fully participated in the study. It also resulted in the considerable number of fallouts that was witnessed among the participants. Rating of the medical residents was also dependent on the number of medical students they encountered during their rotarion and whether the department was one that allowed the placement of medical students or not. It is therefore possible, that before implementing the intervention, a prior and thorough assessment of the residency program could have reduced the effect of this problem. Furthermore, we probably should have had more faculty and departmental staff engaged in the idea than we had and that their assistance should have been more actively recruited than we did.

\section{IMPLICATIONS FOR FURTHER RESEARCH}

The findings in this dissertation emphasise the importance and need for good and effective supervision. They suggest that the teaching abilities of medical residents can be improved by developing formal training programs in teaching skills. The findings also demonstrate that increased commitment from medical saff in their supervision of medical residente wonld improve the latter's teaching ability. So also would standard, structured and clear objectives of what the teaching responsibilities of medical students should be in the clinical setting. Effective supervision in medical education should therefore be focused on developing new training programs in teaching and improving the already existent training courses for clinical instructors and medical residents.

Presently, the role of residents as teachers in clinical medical education has shifted from whether it is necessary for them to teach or not. The focus now is on how to improve the quality of their teaching and optimise the benefits involved. The goal of further research should therefore be on how to properly and objectively assess the learning needs of medical residents. It should address how educational interventions can be set up and effectively implemented within the constantchanging and dynamic process of clinical medical training. More investigations should be conducted to identify effective methodological approach(es) to assess medical residents' teaching abilities. Finally, it is essential that educational strategies be set up, that can continuously and objectively monitor the quality of teaching provided by medical residents (and supervisors). 


\section{MAIN RECOMMENDATIONS}

- More innovation in medical education is required for the medical profession to be fully operational as a profession.

- The development of more (effective) educational strategies should be encouraged in postgraduate medical education.

- More physicians should be involved as teachers in undergraduate and postgraduate medical education.

- Physicians involved in the educational process should be acknowledged professionally and/or financially for their contributions.

- Training programs in teaching should be compulsory and inherent in the professional development of physicians.

- The educational needs of physicians should be determined by conducting needs assessment.

\section{REFERENCES}

I. FRIEDMAN, C.P., De BLIECK, R., GREER, D.S., MENNIN, S.P., NORMAN, G.R., SHEPS, C.G., SWANSON, B.D, \& WOOLWARD, C.A. (1990). Charting the Winds of Change: Evaluating Innovative Medical Curricula. Academic Medicine, 65: 8-14.

2. PATEL, V.L., GROEN, G.J. \& NORMAN, G.R. (1991). Effects of Conventional and Problem-Based Medical Curricula on Problem solving. Academic Medicine, 66: 380-89

3. ALBANESE. M.A. \& MITCHELL, S. (1993). Problem Based Learning, a Review of Literature on Its Outcomes and Implementation Issues. Academic Medicine, 68:52-81

4. BUSARI, J.O., SCHERPBIER, AJ.J.A. \& BOSHUIZEN, H.P.A. (1997) A Comparative Study of Medical Education as Perceived by Students at Three Dutch Universities. Advances in Health Sciences Education, $1:$ $14 \mathrm{I}-51$

5. Mc LEOD, P.J., HARDEN, R.M. (1985) Clinical teaching strategies for physicians. Medical Teacher, 7: $173-189$.

6. LOWRY, S. (1993) Teaching the teachers, British Medical Journal, 306: 127-130.

7. WILKERSON, L. \& IRBY, D.M. (1998). Strategies for improving teaching practices: a comprehensive approach to faculty development. Academic Medicine, 73: 387-96.

8. GIBSON, D.R. \& CAMPBELL R.M. (2000) Promoting effective teaching and learning: hospital consultants identify their needs. Medical education, 34: 126-130.

9. BARROW, M.V. (1966). Medical students' opinions of the house officer as a medical educator. Journal of Medical Education, 41: 807-10.

10. BROWN, R.S. (1970). House staff attitudes toward teaching. Journal of Medical Education, 45: 156-59

II. MELECA, C.B. \& PEARSOL, J.A. (1988) Teaching surgery residents to teach. In J.C. EDWARDS \& R.L. MARIER (Eds) Clinical Teaching for Medical Residents: Roles, Techniques and Program, 187-200, New York: Springer Verlag. 
12. STEWARD, D.E. \& FELTOVICH, P.J. (t988). Why residents should teach: the parallel processes teaching and learning, In J.C. EDWARDS \& R.I. MARIER (Eds.) Clinical Traching for Medical Residents: Roles, Techniquer and Programs, 3-14, New York: Springer Verlag.

13. BUSARI, J.O., PRINCE, K.A.H., SCHERPBIER, A.J.J.A., VAN DER VLEUTEN, C.P.M. \& ESSED, G.G.M.(2002). How residents perceive their teaching role in the clinical setting - a qualitative study. Medical Teacher, 24(1): 57-61.

14. BUSARI, J.O. SCHERPBIER, A.J.J.A. VAN DER VL.EUTEN, C.P.M \& ESSED, G.G.M. (2003) The perceptions of attending-doctors on the role of residents as teachers of undergraduate medical students. Medical education, 37: 241-47

15. DINHAM, S.M. \& STRITTER, FT. (1986). Research on Professional Education. In M.C. WTTTROCK (Ed.) Handbook of Research in Traching, 952-70, New York: Macmillan.

16. STENCHEVER, M.A., IRBY, D.M. \& O'TOOLE, B. (1979). A national survey of undergraduate teaching in Obstetrics and Gynaecology, Journal of Medical Education, 54:467-70.

17. ANDERSON, K., ANDERSON, W. \& SCHOLTEN, D. (r99o) Surgical residents as teachers. Current Surgern, $47(3): 185-88$

18. BIGGS, J.S.G. AGGER, S.K., DENT, T.H.S., AL.L.ERY, L.A. \& COLES, C. (1994) Training for medical teachers: a UK survey. Medical Education, 28: 99-106.

19. ROBINSON, L.A.,SPENCER, J.A. \& NEAL, D.E. (1996) Teaching the teachers - a needs assessment of tutors for a new clinical skills course. Medical Education, 30: 208-14.

20. PRESTON-WHYTE, E.M., FRASER, R.C. \& McKINLEY, K.R. (1998) Teaching and assessment in the consultation: a hospital clinicians' preparatory workshop for integrated teaching of clinical method to undergraduate medical students. Medical Teacher, $20(3): 266-7$

21. BUSARI, J,O., SCHERPBIER, AJ.J.A. (2004) Why Medical Residents Should Teach: A literature review. Journal of Postgraduate Medicine, (in press)

22. GRANT, J., KILMINSTER, S.M., JOLLY, B.C. \& COTTRELL, D. (2003) Clinical supervision of SpRs: Where does it happen, when does it happen and is it effective? Medical Education, 37: 140-148.

23. CONN, J.J. (2002) What can clinical teachers learn from Harry Potter and the Philosopher's Stone? Medical Education, 36: 1176-81.

24. KIL.MINSTER, S.M. JOLIY, B.C. \& VAN DER VL.EUTEN, C.P.M.(2002) A framework for effective training of supervisors. Medical Teacher, $24(4): 385-89$

25. KIL.MINSTER, S.M. \& JOLLY, B.C. (2000) Effective supervision in clinical practice settings: a literature review. Medical Education, 34:827-40.

26. DONALD, E.M.J. \& DONALD L.C. (1992) Needs assessment. In Continuing Medical Education: A Primer. Westport CT: Pracger

27. RATNAPAL.AN, S. \& HILLIIARD R. (2002) Needs Assessment in Postgraduate Medical Education: A Review. Medical Education Online, $7(8)$.

28. NORMAN, G.R., SHANNON, S.I. \& MARRIN, M.L. (2004). The need for needs assessment in continuing medical education. British Medical Journal, 328: 999-1001.

29. FOX, R.D, \& BENNETT, N.L. (t998) Learning and change: implications for continuing medical education. Britisb Mrdinal Journal, 316: 466-69. 
30. TAYLOR, K.L. \& C CHUDLEY, A. (2001) Meeting the needs of future physicians: a core curriculum initiative for postgraduate medical education at a Canadian university Medioul Education, 35: 973-82.

31. GREENBERG, L.W., JEWETT, L.S. \& GOLDBERG (1988) The children's hospital experience, In J.C. EDWARDS \& R.L. MARIER (Eds.) Clinical Teaching for Medical Residents: Roles, Technigues and Pnsgrams, 175-186, New York: Springer Verlag.

32. JEWETT, L.S: GREENBERG, L.W. \& GOLDBERG, R.M. (1982b) Teaching residents how to teach: a one-year study, Journal of Medical Education, 57: 361-366.

33. STRITTER, F.T \& HAIN, J.D. (1977) A Workshop in Clinical Teaching, Journal of Medical Education, 52: 155-7.

34. KERLINGER, F.N. (1986) Designs of research. In Foundations of behavioural reseanch, 279-301, New York: Holt, Rinchart and Winston.

35. COHEN, J. (1988). Statistical power analysis for the behavional seiences (and ed.). Hillsdale, NJ: Lawrence Erlbaum Associates

36. STRITTER, F.T, HAIN, J.D. \& GRIMES, D.A. (1975) Clinical Teaching re-examined. Journal ef Medical Education, 50 : 876-82.

37. SKEFF, M.K., BERMAN, J. \& STRATOS, G. (1988) A review of Clinical Teaching Improvement Methods and a Theoretical Framework for their Evaluation. In J.C. EDWARDS \& R.L. MARIER (Eds.) Climical Teaching for Medical Residents: Roles, Techniques and Prognams, 92-120, New York: Springer Verlag 

Chapter 12

Summary 


\section{SUMMARY}

This thesis examined the teaching role of medical residents in the clinical setting and explored the extent to which they were involved in the educational process. It investigated the factors that influenced medical residents contributions to teaching as well as methods that could be used to improve their teaching skills. A summary of the findings in this dissertation is provided below.

In Chapter one, an outline of the background of this thesis was described including a reexamination of the concept of a "profession". Here, the concept of a profession was presented as a craft that incorporates the development of theory alongside an apprenticeship. The reliance on theory as well as the ability to develop its own theories and actions by which its responsibilities are defined, distinguished a profession from a trade. A description of the medical profession was provided using this context, and the aspiring professional (e.g. medical resident) was illustrated as one learning many facets of the profession from the master or expert (attending physician). The expectation that the competent professional should learn a high level of technical skills in order to be able to fulfil the responsibilities that a profession demands was also described. This was characterized by the cognitive and intellectual learning that the learner should acquire, ranging from the simplest levels of factual knowledge acquisition to the complexities of synthesis, evaluation, and reasoning indicative of most professional training. The assimilation of the rich fabric of socialization, interpersonal skills, moral reasoning and attitudes represented the features that distinguished the member of one profession from the other. A description of various stakeholders in the medical educational process was also provided in the first chapter. Lastly, why medical residents formed the focus of our investigation was discussed, which was mainly due to the pivotal role they played in the education of undergraduate medical students.

In Chapter two an introduction to the theoretical foundations of education was provided so that the non-educationalist could get acquainted with the basic and important theoretical concepts of education, and to acquaint him/her with the basic educational principles that constitutes and facilitates the process of learning. A detailed explanation of three educational processes were provided to illustrate this, namely:

1. How knowledge is attained and categorized into its different forms (Knowledge acquisition)

2. How knowledge is gathered and organized before it is applied. (Knowledge compilation) and,

3. How learners operationalise the knowledge they acquire (Approach to learning)

This chapter also provided an explanation on the approach to learning and its implications for teaching and learning in medical education. Two different aspects of the approach to learning were described namely deep and surface approaches i.e. whether or not the learners are engaged with the learning task and/or searching for meaning, and the atomistic and holistic approaches, 
i.e. how the learners organize information, and whether the framework of a task is distorted or segmented. How and why these concepts influence the medical educational process was also illustrated, and a description of how a better understanding of these concepts could improve the teaching process was provided. The educational concepts and principles described in this chapter provide an illustration of the theoretical background of the objective of this dissertation.

It is known that in the clinical setting, as much as $70 \%$ of medical students' education is attributable to the teaching medical residents provide. The nature and scope of the teaching medical residents provide as well as its implication in developing strategies for improvement, were explored in chapters three and four. Chapter three was a quantitative study that focused on investigating medical residents' perceptions of their teaching. The study revealed that the continued presence of medical residents on the wards, their being easily approachable for medical students and their ability to explain problems better and easily from the student's perspective, were factors that accounted for the significant contributions they made to undergraduate medical education. The content of what medical students learn from medical residents was described as clinical problem-solving skills that were useful primarily in the wards. Compared to the specialist physicians, medical residents lacked the wealth of domain related knowledge, and this limited the amount of what they could contribute as expert teachers. Factors that influenced their teaching activities included (prior) reaching experience, clinical experience as well as the time available for teaching. With respect to this last factor, medical residents felt that 1.5 hours/ day was the ideal amount of time that should be allocated to teaching activities alongside their daily clinical duties. They saw the need for improving their teaching skills, as well as, the need for better training and guidance in teaching. They were also of the opinion, that teaching medical students was beneficial for their own personal education and professional development.

The qualitative study described in Chapter four provided answers to some of the findings we could not explain in chapter three. Some of the factors that hindered medical residents' effective contribution to teaching were for example, due to the lack of formal training in teaching, poor departmental support and insufficient acknowledgement for (their) teaching activities. These reasons were responsible in part, for the declination they expressed in being assessed for their teaching, despite their willingness for, and participation in teaching activities. Only if additional time for teaching was allocated and attending staff and faculty were committed to offering proper supervision, would medical residents be willing to be evaluated for their teaching abilities. The recommendations of medical residents in this study reflected the strong need for guidance and coaching in how to effectively transfer knowledge and give feedback to students. Some of the specific recommendations included the need for:

- Formative and constructive assessment methods,

- Clearly defined and well structured objectives for teaching responsibilities,

- Additional commitment from faculty and staff, and lastly,

- Additional time allocated for teaching. 
The study in Chapter five showed how specialist physicians perceived the teaching roles of medical residents in the clinical setting. Specialist physicians felt that it was beneficial for medical residents to teach because they believed it would help them in becoming better clinicians. They corroborated the views of medical residents, by recommending that teacher-training programs were necessary to promote and improve the quality of teaching by the latter. The study also revealed that specialist physicians felt medical residents spent less time than was expected in teaching (Ideal teaching time: 1.7 hours/day). Some of the factors they cited as responsible, were the lack of additional time allocated for teaching, undefined teaching responsibilities by faculty, and the poor supervision provided by attending staff in teaching. The recommendations they provided to address these problems reflected the importance of, and the need for improvement in the areas of teaching skills, clinical skills communication and attitude. They also recommended skills that although were not related to teaching, could facilitate the teaching process, for example, time management, professional responsibility, self-assessment, peer and student evaluation.

The study reported in Chapter six describes how medical residents perceived the supervisory role of attending physicians. The aim was to identify the factors that constituted effective teaching and supervision from the perspective of the medical resident as recipient. The study showed that the teaching qualities that best predicted good supervision included adjusting teaching to the needs of medical residents and stimulating them to learn independently. Being available to help in the wards, providing measured and constructive feedback, and treating medical residents as adult learners, were some of the qualities medical residents claimed, that represented effective supervision by attending physicians. In addition, being collaborative, patient and understanding were characteristics attributed to good supervisors. The areas where the medical residents felt supervision was poor (or infrequent) included coaching in clinical skills and procedures, effective communication skills and in making clinical decisions using the principles of cost-appropriate care. Furthermore, they identified "Direct supervision", "instruction", and "evaluation" as areas of supervision that required improvement.

Chapter seven provides a review of the literature on medical residents teaching responsibilities. The review explored whether there was evidence to support the presumption that being in possession of good teaching skills would result in professionally competent physicians. A hypothesis was formed called the physician as teacher rule, stating that "A skilled teacher has an increased likelihood of becoming a competent clinician, than a skilled clinician has of becoming a competent teacher." Two central questions were used to explore this hypothesis; whether teaching improves the professional competence of physicians and whether training or supervision in teaching skills was necessary for physicians. The review revealed assertions suggesting that teaching undergraduate students contributed positively to the (perceived) professional competency of medical residents. None of these assertions however were objectively backed up in the literature. On the other hand, the review did not produce any study that denied the positive influence of teaching 
on professional competency. Regarding the legitimacy of our hypothesis, there was evidence that teaching improved the perceived professional competency of medical professionals. Although the evidence was largely subjective and lacked validation, there were no studies to refute the assumption. An additional finding in the review was that the physicians who were perceived as competent, were those who taught effectively and also demonstrated a basic understanding of teaching and learning. This finding supported one of the fundamental objectives of this dissertation, which was to demonstrate why medical residents' required the basic understanding of the concepts that constitute teaching and learning, Knowledge of these educational concepts is assumed to be a prerequisite for improving their own teaching skills.

Another objective of this thesis was to examine how the teaching skills of medical residents could be improved. A needs assessment strategy was used for this purpose and Chapter eight provides a comprehensive update of this educational strategy. A detailed description of the development of a two-day training workshop in teaching skills for medical residents is also provided in this chapter. It shows how the recommendations from medical residents and attending physicians were analysed and later synthesized with information from medical educational literature and opinion of educational experts, to develop an educational intervention.

Chapter nine describes how the appropriateness and feasibility of the two-day workshop developed in chapter eight was assessed. A pilot study of the workshop was conducted in which the content and quality of instruction of the workshop was evaluated. The medical residents who participated in the workshop rated it positively, and strongly recommended that such a workshop should be incorporated in specialist training programs. There was perceived improvement in some of the participants' teacher characteristics, and they acknowledged learning new educational concepts that could improve their teaching. The instruction provided in the workshop was considered good and relevant to the needs of medical residents and the ratings of the quality and content of the workshop were uniformly favorable. The workshop was considered to be an appropriate tool for training teaching skills in residents and it was feasible to implement.

In Chapter ten, the impact of the two-day workshop on the teaching skills of medical residents was investigated. The aim of the investigation was to identify any observable changes in the teaching behaviours of the medical residents that could be attributed to the intervention. Medical students assessments of the medical residents' teaching ability, prior to, and after participating in the teacher-training workshop were used to measure any significant effect(s). As expected, improvements were found in the group of residents who participated in the workshop compared to their counterparts who did not. The observed improvements were those we expected to find, and demonstrated that the intervention produced positive changes in the medical residents' teaching skills. Effect size estimation revealed that the change observed in the teaching skills of medical residents between the groups was moderate and positive in favour of the experimental 
group. Meanwhile, the change that was observed in the teaching skills of the residents within the experimental group was large when compared to their skills prior to participating in the training. We could therefore conclude that the workshop had a positive impact on the medical residents teaching behaviours. 
Chapter 13

Samenvatting 


\section{SAMENVATTING}

Dit proefschrift handelt over de rol van arts-assistenten in het klinisch onderwijs aan co-assistenten en de omvang van hun bijdrage aan dit onderwijs. Onderzocht is welke factoren een rol spelen ten aanzien van de bijdrage van arts-assistenten aan het onderwijsproces en hoe hun onderwijsvaardigheden verbeterd kunnen worden. In dit hoofdstuk wordt een samenvatting gegeven van de onderzoeken die in dit proefschrift beschreven worden.

In Hoofdstuk een wordt aandacht besteed aan de achtergronden van dit proefschrift, waarbij ingegaan wordt op het concept 'beroep'. In dit proefschrift wordt beroep gezien als een ambacht waarbij zowel theorie als leerlingschap een rol spelen. Een beroep verschilt van een ambacht doordat er bij een beroep sprake is van de ontwikkeling van specifieke theorieên en handelingen die bepalend zijn voor de beroepsuitoefening. Dit is de context waarbinnen het medisch beroep beschreven wordt. De arts in spe (de assistent-in-opleiding) wordt hierbij gezien als de leerling die de verschillende facetten van het beroep leert van de meester of expert. Ook wordt gesteld dat een afgestudeerd beroepsbeoefenaar de technische vaardigheden behorend bij het beroep op een hoog niveau moet beheersen om te kunnen voldoen aan de eisen die gesteld worden ten aanzien van de beroepsuitoefening. Deze eisen betekenen dat studenten zowel kennis als intellectuele vaardigheden moeten verwerven. Met andere woorden, de student dient zich niet alleen de voor het beroep vereiste feitenkennis eigen te maken maar ook de complexe vaardigheden die nodig zijn om te kunnen synthetiseren, evalueren en redeneren. De combinatie van socialisatie, verwerving van communicatievaardigheden, normen en attitudes is bepalend voor het onderscheid tussen verschillende beroepsgroepen.

In hoofdstuk een worden ook de voornaamste groepen die betrokken zijn bij het medisch onderwijs beschreven. Ten slotte wordt tocgelicht wat de aanleiding was om de rol van arts-assistenten in het medisch onderwijs te kiezen als onderwerp voor het promotieonderzoek dat beschreven wordt in dit proefschrift.

Hoofdstuk twee behandelt onderwijstheoretische achtergronden teneinde ook niet-onderwijsdeskundigen enig inzicht te geven in onderwijskundige basisprincipes die van belang zijn voor een geslaagd leerproces. De volgende drie onderwijsprocessen worden behandeld:

I. Hoe kennis wordt verworven en onderverdeeld in verschillende vormen van kennis (Kennisverwerving)

2. Hoe kennis wordt verzameld en geordend voordat deze toegepast kan worden (Compilatie van kennis)

3. Hoe studenten de kennis die zij verwerven operationaliseren (leerstrategie).

Er wordt aandacht besteed aan verschillende manieren waarop studenten kunnen leren en de implicaties hiervan voor het medisch onderwijs. 
Twee aspecten van leerbenaderingen worden besproken, namelijk 'diep' en 'oppervlakkig' leren en atomistische en holistische benadering van het leerproces. Bij 'diep' leren is de lerende zelf, al dan niet actief, betrokken bij het leerproces. Bij 'oppervlakkig' leren daarentegen heeft de leerling een passieve rol en wacht af welke 'hapklare' feiten worden aangeboden. De atomistische en holistische benaderingen hebben betrekking op de manier waarop lerenden informatie ordenen en op het kader waarbinnen de leertaak wordt aangeboden. met name of de leerstof op een kunstmatige en gefragmenteerde wijze wordt gepresenteerd. In dit hoofdstuk wordt beschreven hoe deze concepten het medisch onderwijs beïnvloeden en hoe meer inzicht hierin het onderwijsproces ten goede kan komen. De onderwijskundige concepten en grondbegrippen die in dit hoofdstuk beschreven worden, vormen de theoretische achtergrond van de hoofdvraagstelling van dit proefschrift.

Het is algemeen bekend dat arts-assistenten 70\% van het klinisch onderwijs aan co-assistenten voor hun rekening nemen. De bijdrage van arts-assistenten aan het klinisch onderwijs wordt beschreven in hoofdstuk drie en vier. In Hoofdstuk drie wordt een kwantitaticf onderzock beschreven waarin de mening van arts-assistenten gevraagd wordt over hun onderwijstaak. Uit de bevindingen van dit onderzoek komt naar voren dat er verschillende redenen zijn waarom de rol van arts-assistenten in het onderwijs aan co-assistenten een zo belangrijke is: arts-assistenten vormen een stabiele factor op de klinische afdeling; als docent zijn zij laagdrempelig voor studenten; zij zijn beter dan specialisten in staat om een probleem op het niveau van de student uit te leggen. Inhoudelijk brengen zij de studenten vooral vaardigheden bij om klinische problemen op te lossen. Dit betreft met name vaardigheden die direct toepasbaar zijn op een ziekenhuisafdeling. Arts-assistenten blijken minder goed in staat te zijn dan medisch specialisten om vakinhoudelijke kennis over te dragen aan co-assistenten. Dit komt vooral door hun (relatief) geringere subspecialistische kennis, waardoor zij minder goed in staat zijn om diepergaande aspecten te verduidelijken. Belangrijke factoren bij het overdragen van kennis zijn onderwijservaring, klinische ervaring en de hoeveelheid tijd die arts-assistenten kunnen besteden aan onderwijs. Arts-assistenten vinden dat zij idealiter ongeveer 1.5 uur per dag aan onderwijstaken moeten kunnen besteden. Ook zijn zij van mening dat hun onderwijsvaardigheden verbeterd kunnen worden en dat meer begeleiding daarbij wenselijk is. Ten slotte vinden zij dat hun taak in het onderwijs aan co-assistenten een belangrijke bijdrage kan leveren aan hun eigen professionele vorming en opleiding.

In Hoofdstuk vier wordt een kwalitatief onderzoek beschreven. De bevindingen van dit onderzoek vormen een aanvulling op de resultaten van het onderzoek dat beschreven wordt in hoofdstuk drie. Het onderzoek levert aanwijzingen dat een verklaring voor de niet altijd even effectieve invulling van de onderwijstaak door arts-assistenten gevonden kan worden in de volgende factoren: arts-assistenten hebben nooit geleerd hoe zij onderwijs moeten geven; zij krijgen weinig begeleiding van stafleden; en zij krijgen bovendien te weinig erkenning voor 
hun onderwijsinspanningen. Deze factoren dragen bij tot een afname van de inzet van artsassistenten voor onderwijstaken, hoewel zij in principe bereid zijn om deze taken te vervullen. De assistenten willen graag meer tijd voor onderwijstaken en betere supervisie. Pas als aan deze voorwaarden is voldaan, zijn zij bereid om onderwijsprestaties mee te laten wegen bij hun beoordeling als assistent. De aanbevelingen van de arts-assistenten laten zien dat begeleiding en supervisie bij onderwijstaken onontbeerlijk zijn voor een goede overdracht van kennis aan co-assistenten. Uit de aanbevelingen van de arts-assistenten blijkt dat zij behoefte hebben aan de volgende ondersteunende maatregelen:

- Formatieve beoordelingen met constructieve feedback;

- Duidelijk omschreven en gestructureerde leerdoelen voor hun rol als docent;

- Meer betrokkenheid vanuit faculteit en klinische staf;

- Meer tijd voor onderwijstaken.

In het onderzoek dat in Hoofdstuk vijf wordt beschreven wordt de mening van specialisten gepeild over de onderwijstaken van arts-assistenten. De specialisten zijn van mening dat het zinvol is dat arts-assistenten onderwijstaken vervullen, omdat dit een positieve bijdrage levert aan hun vorming tot clinicus. De specialisten zijn het met de arts-assistenten eens dat arts-assistenten docententraining zouden moeten volgen om hun onderwijsvaardigheden en daarmee de kwaliteit van het onderwijs dat zij geven te verbeteren. Ook vinden de specialisten dat arts-assistenten niet genoeg tijd besteden aan hun onderwijstaken (de ideale hoeveelheid tijd voor onderwijs bedraagt volgens de specialisten 1.7 uur per dag). De oorzaak van de te geringe tijdsbesteding aan onderwijs is volgens de specialisten onvoldoende beschikbare tijd doordat de faculteit de onderwijstaken niet goed definieert en zij zelf te weinig supervisie geven. Hun aanbevelingen richten zich vooral op verbetering van didactische vaardigheden, van communicatic en van hun attitude als docent. $\mathrm{Zij}$ noemen ook andere niet rechtstreeks met het onderwijs verband houdende vaardigheden, die een heilzame invloed op het onderwijsproces zouden kunnen hebben, zoals tijdplanning, een verantwoordelijke beroepshouding, zelfbeoordeling, beoordeling door collegae en beoordeling door studenten.

Hoofdstuk zes behelst een beschrijving van een onderzoek naar de mening van arts-assistenten over supervisie door specialisten. Het doel van het onderzoek is om factoren aan te wijzen die vanuit het perspectief van de arts-assistent van belang zijn voor het realiseren van effectief onderwijs en supervisie. De resultaten laten zien dat kenmerken van goede supervisie zijn dat er rekening gehouden wordt met de behoeften van arts-assistenten en dat zelfstandig leren gestimuleerd wordt. Als belangrijke aspecten van goede supervisie noemen de arts-assistenten de aanwezigheid van specialisten om mee te helpen op de afdeling, het geven van goed gedoseerde en constructicve feedback en een visie waarin de opleiding gezien wordt als volwassenenonderwijs. Volgens de arts-assistenten wordt een goede supervisor gekenmerkt door bereidheid tot samenwerken, geduld en begrip. 
De arts-assistenten zijn van mening dat er onvoldoende supervisie is bij bepaalde klinische handelingen en procedures en ook ten aanzien van communicatievaardigheden en het betrekken van kostenoverwegingen bij het nemen van klinische beslissingen. Daarnaast noemen zij de noodzaak tot verbetering van 'directe supervisie', 'instructie' en 'evaluatie' als punten van aandacht.

Hoofdstuk zeven geeft een overzicht van de literatuur over de onderwijsinspanningen van artsassistenten. In dit hoofdstuk wordt nagegaan of er bewijs gevonden kan worden om het vermoeden te staven dat goede onderwijsvaardigheid garant staat voor een goede beroepsbekwaamheid. De hypothese 'de kans dat een bekwaam docent een bekwaam clinicus wordt, is groter dan de kans dat een bekwaan clinicus een bekwaam docent word' is getoetst met behulp van twee hoofdvragen: 1 . Verbetert het geven van onderwijs de beroepsbekwaamheid van artsen? 2. Hebben artsen supervisic en onderwijs nodig om hun onderwijstaken te kunnen vervullen? Er wordt uitgegaan van de veronderstelling dat onderwijs aan co-assistenten een positieve invloed kan hebben op de beroepsbekwaamheid van arts-assistenten. Het onderzoek levert geen bewijs van het tegendeel, zodat de anname vooralsnog overeind blijft. Verder blijkt uit het literatuuronderzoek dat die medisch specialisten als bekwaam docent worden beschouwd die effectief onderwijs geven en blijk geven op de hoogte te zijn van theorieẽn en inzichten betreffende onderwijs en leren. Deze bevinding bevestigt het belang van dergelijke kennis voor arts-assistenten. Kennis van onderwijskundige concepten en theorieẽn wordt gezien als een voorwaarde voor het verbeteren van onderwijsvaardigheden.

Het onderzoek dat beschreven wordt in dit proefschrift is ook gericht op mogelijkheden om de onderwijsvaardigheden van arts-assistenten te verbeteren. Hiertoe zijn de leerbehoeften van de arts-assistenten geïnventariseerd. In Hoofdstuk acht wordt het onderzoek beschreven waarin de problemen en tekortkomingen in de specialistenopleiding op het gebied van onderwijsvaardigheden geïnventariseerd worden. Op basis van de uitkomsten van dit onderzoek is een plan van aanpak opgesteld dat geleid heeft tot het ontwikkelen van een tweedaagse workshop docententraining voor arts-assistenten. Deze workshop wordt beschreven. De beschrijving laat zien hoe de aanbevelingen van de arts-assistenten en specialisten uit de eerdere onderzoeken samen met bevindingen uit de literatuur en de meningen van deskundigen de basis gevormd hebben voor het ontwerp van deze interventie met als doel de doceervaardigheden van arts-assistenten te verbeteren.

Hoofdstuk negen beschrijft een proefonderzoek waaruit blijkt dat de tweedaagse workshop zoals beschreven in hoofdstuk 8 effectief en uitvoerbaar is. In het proefonderzoek worden de inhoud en de kwaliteit van de workshop onderzocht. De arts-assistenten die deelnemen aan de workshop geven een positief oordeel. Ook hebben zij gevraagd of een dergelijke workshop toegevoegd kan worden aan alle specialistenopleidingen. De onderwijsvaardigheid van som- 
mige deelnemers neemt toe na deelname aan de workshop. Ook geven de arts-assistenten aan dat zij nieuwe onderwijsmethoden geleerd hebben die geschikt zijn om toegepast te worden bij hun onderwijstaken. Het programma van de workshop wordt als effectief en nuttig beoordeeld. Ook zijn de deelnemers van mening dat de workshop een effectieve en uitvoerbare aanpak is om docententraining te geven aan arts-assistenten.

In Hoofdstuk tien ten slotte wordt de invloed van de tweedaagse workshop op de onderwijsvaardigheid van de arts-assistenten onderzocht. Het doel van deze studie is om te onderzocken in hoeverre er veranderingen waarneembaar zijn in de onderwijsactiviteiten van de arts-assistenten die tocgeschreven kunnen worden aan de interventie. Hiertoe hebben co-assistenten de onderwijsvaardigheid van de arts-assistenten zowel voorafgaand aan als na afloop van de workshop beoordeeld. De resultaten laten zien dat de verwachtingen bevestigd worden dat de kwaliteit van het onderwijs gegeven door de workshopdeelnemers verbetert ten opzichte van de onderwijsvaardigheid van hun collegae die de workshop niet hebben gevolgd. De gevonden verbeteringen laten zien dat de interventic een positieve invloed heeft op de onderwijsvaardigheid. De gevonden effectgrootte laat een matig verschil zien tussen de uitkomsten voor de deelnemers en de niet-deelnemers in het voordeel van de deelnemers. Het verschil tussen de onderwijsvaardigheid van de deelnemers voor en na de workshop is groot. De conclusie lijkt dan ook gerechtvaardigd dat de workshop een positieve invloed heeft op de onderwijsprestaties van arts-assistenten. 
Addendum - Chapter 8

THE TWO-DAY WORKSHOP ON TRAINING SKILLS FOR MEDICAL RESIDENTS 


\section{DAY ONE}

Aim: to familiarize the medical resident with background knowledge of the theory of education, the profile of the resident and the process of knowledge acquisition and transfer.

Blocks: 1) Effective teaching, 2) Self-knowledge \& teaching ability, 3) Feedback.

Training Materials: lectures, videotapes, small group interactive session, role-playing

\section{Effective teaching:}

Rationale: This block introduces the medical resident to the concept of teaching. The residents shall be exposed to the theory of teaching and learning using one of the educational theories as an example'. They shall learn of the following principles of effective teaching ${ }^{2}$ :

- Interest and explanation

- Concern and respect for students and student learning

- Appropriate assessment and feedback

- Clear goals and intellectual challenge

- Independence, control and active engagement

The residents shall also be introduced to the concept of learning within a context, and how they can facilitate student learning and participation within the leaning context ${ }^{3,4}$.

Instructional method: lecture, interactive discussion, case-simulation

\section{Teaching strategies:}

- The process of teaching and learning always takes place in a particular setting. This environment or setting referred to as the context and could be the classroom, ward, or consultation room. It is important to note that the context is an integral part of the discourse where transfer of information occurs and it gives meaning and structure to the event. In the "transfer of learning", the learner must experience the use of a bit of information in many different settings before that bit of information has contextual breadth'. Since most residents are unfamiliar with these new concepts in medical education an introductory lecture shall be provided for a good understanding of these concepts.

- The residents shall learn about the skills that can improve their teaching. In an interactive group discussion, they shall reflect on their prior knowledge and skills important for effective teaching. They shall then formulate new skills considered essential for effective teaching.

- The concept of patient based-teaching shall be treated to provide a better understanding of "teaching in context". Concrete examples such as how teaching at the patients' bedside augments and reinforces learning in students shall be highlighted ${ }^{6}$. 
- Acknowledging students as adult learners motivates and induces their readiness to learnt. The residents shall be shown how and why student autonomy should be acknowledged. They shall formulate the attitudes that they consider, form barriers to learning', and through role-playing demonstrate how to resolve them.

- The residents shall receive instructions on how to identify and acknowledge their limitations; for example, they shall learn about ways of effectively admitting to not having answers to students' enquiries and how to come up with strategies to provide answers, In an interactive session, they shall be made to see how honest and open rapport with students demonstrates goodwill and creates a friendly atmosphere. They shall also see how this also facilitates a better understanding of each other's shortcomings.

Duration: 90 minutes

\section{Self-knowledge and teaching ability:}

Rationale: This block will focus on how to improve the residents teaching abilities. It will elaborate on the profile of the resident and on methods of improving their teaching ability. It shall also deal with factors that can facilitate learning in medical students, for example the distance and homogeneity between residents and students. Residents shall be exposed to these factors and how they can exploit them to improve their teaching abilities ${ }^{6,4, ?}$.

Instructional method: lecture, interactive discussion, and video presentation

\section{Teaching strategies:}

- Using a lecture format, residents will receive instruction on the fundamental concepts of educational theories and how it can improve their teaching. For example, the process of how knowledge is organized and compiled shall be discussed. As an illustration of this process, Neves \& Anderson's theory of knowledge compilation shall be explained'.

- Through interactive discussion, the residents shall define surface and deep approaches to learning. Instruction shall also be provided on the different approaches students' use in learning and how they influence the learning process.

- Through interactive discussion, the residents shall re-construct the principles of effective teaching treated in the first block ${ }^{2}$. They will elaborate on the different components and formulate strategies for applying them in practice. Through this process, residents' can recruit, remodel and actively apply their prior knowledge on teaching.

- The residents shall reflect on and define the factors that can improve their teaching abilities i.e. clinical ability, pedagogical ability and personal qualities (table 1). Through interactive discussion, they shall understand how these factors can improve there teaching abilities. They should also be able to define ways for developing or improving these factors in themselves e.g. adapting a friendlier attitude towards students in order to encourage them to learn. 


\section{Table I. FACTORS THAT CAN IMPROVE TEACHING ABILITY}

\begin{tabular}{|l|l|l|}
\hline Clinical Abilities & Pedagogical abilities & Personal qualities \\
\hline - Good dinician & - Active participant in teaching & - Enthusiasm for work \\
- Up to date theoretical & - Individualises teaching & - Able to assess own strengths \\
knowledge & approach & and weaknesses \\
- Up to date dinical knowledge & - Identifies strength and & - Self improvement \\
- Holistic approach & weaknesses & - Warm and respectful \\
- Flexible & & - Listens \\
- Integration of preventive and & & - Expresses own emotions \\
curative aspects & & appropriately \\
- Critical and analytical & & - Interacts with others \\
& & - Manages stressful situations \\
& & - Gets support when necessary \\
& & - Balances personal and \\
\hline
\end{tabular}

Modified from Cote, 1993.

Duration: 60-90 minutes

\section{Feedback}

Rationale: Teaching and learning is an interactive and dynamic process. This is because newly taught concepts have to be regularly monitored to ensure that the learner comprehends and masters the new task or skill. Feedback is an educational tool that is used to monitor learning. It ensures that comprehension or the mastery of a skill occurs. It provides the learner with the necessary information on the progress of learning and significantly influences the transfer and acquisition of knowledge (see fig. 1) Whether it is reinforcement for correct performance or criticism of errors, feedback should be specific, should occur frequently, should be administered both formally and informally and should include explanations and remedies ${ }^{10,11}$. In this block the concept of feedback in its various forms and the way it influences the educational process shall be dealt with. Also, issues that would be given extra attention include ways of providing and accepting feedback, the positive and negative effects of feedback, and how feedback influences the style and approach to learning ${ }^{12.13}$.

Instructional method: Videotapes, lecture, interactive discussion, role-playing

\section{Teaching strategies:}

- Using a lecture-format, the residents shall receive instruction on the theory and process of feedback. They should understand why feedback should be applied appropriately and certain factors that can facilitate effective feedback will be discussed 
1. Providing a balance between positive and negative feedback they provide shall be discussed.

3. They shall understand how being honest while providing feedback creates an atmosphere for open communication while it facilitates learning.

4. The residents will understand why it is important to establish clarity i.e. formulating clear objectives at the onset of the discourse with students

5. They will Learn how to achieve a partnership with the students (constructivism)

- A video presentation of a case shall be shown to demonstrate positive and negative ways of providing feedback. Following this, a combined session of interactive discussion and role-playing shall be used to discuss strategies for incorporating the above-mentioned principles in practice. The residents will practice

- Identifying positive and negative feedback.

- They shall practice providing balanced feedback to one another.

- How to explore and identify the expectations the students while agreeing upon common learning goals

- Through role-playing, the residents should recognize inappropriate methods of providing feedback and experience the related undesirable effects e.g. hostility or ridicule. They will also be coached on how to pay more attention to the students' way of reasoning and provide feedback appropriately.

Duration: 120 minutes

Fig. I FlowChart OF THE RELATIONSHIP OF FEedBACK

AND THE LEARNING PROCESS

LEARNER

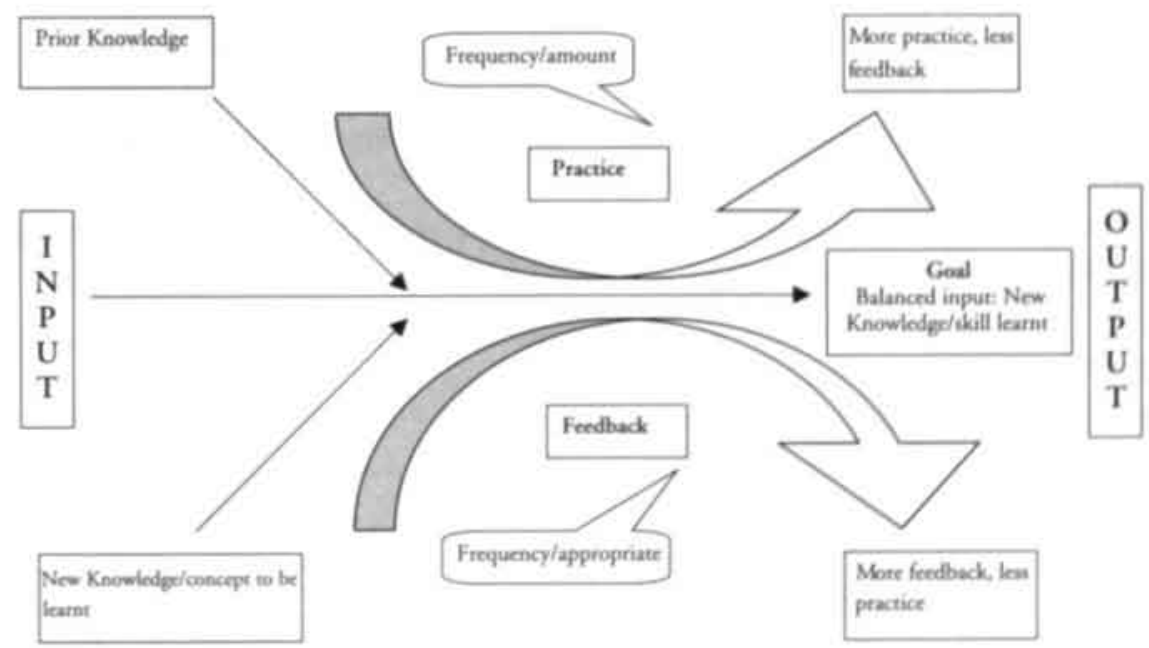

TEACHER 
Aim: To facilitate effective teaching in residents by introducing them to new teaching strategies and how the knowledge of the theory can be applied in practice.

Blocks: 4) Assessing prior knowledge 5) Trouble-shooting 6) Time management.

Training Materials: Videotapes, small group interactive session, lectures

\section{Assessing prior knowledge:}

Rationale: This block focuses on the acquisition of complex clinical skills and how the retrieval of previously learnt skills or knowledge facilitates this process. The reactivation of existing knowledge relevant to a concept that is being newly learnt has been shown to have important advantages in the problem solving process ${ }^{14}$. 15, Such recall of prior knowledge facilitates clarification and better understanding of the problem or task at hand. However, the amount and kind of prior knowledge and the structure in which it is available for retrieval determines how it is applied in learning the new concept. It also determines the quality and quantity of what the students learn from the new concept ${ }^{16,17}$.

Instructional method: lecture, interactive discussion, case treatment

\section{Teaching strategies:}

- Using a lecture format, the residents shall be informed on the concept of prior knowledge and how it initiates learning in students (see fig 2 ). The residents would be shown why it is important to have an idea of students' prior knowledge and how it can influence feedback, and consequently learning.

- Through interactive discussion, the residents will generate different methods through which they can assess students' prior knowledge e.g. formal enquiry of students prior experience, specific questioning of domain related knowledge, and observation of students performance.

- Through role-playing, they shall practice how the generated methods of assessing prior knowledge can be applied in practice.

Duration: 60-90 minutes 
Fig. 2 Prior KNOWLedge AND ITS RelationshiP WITH THE ACQUISITION OF NEW SKILLS \& KNOWLEDGE

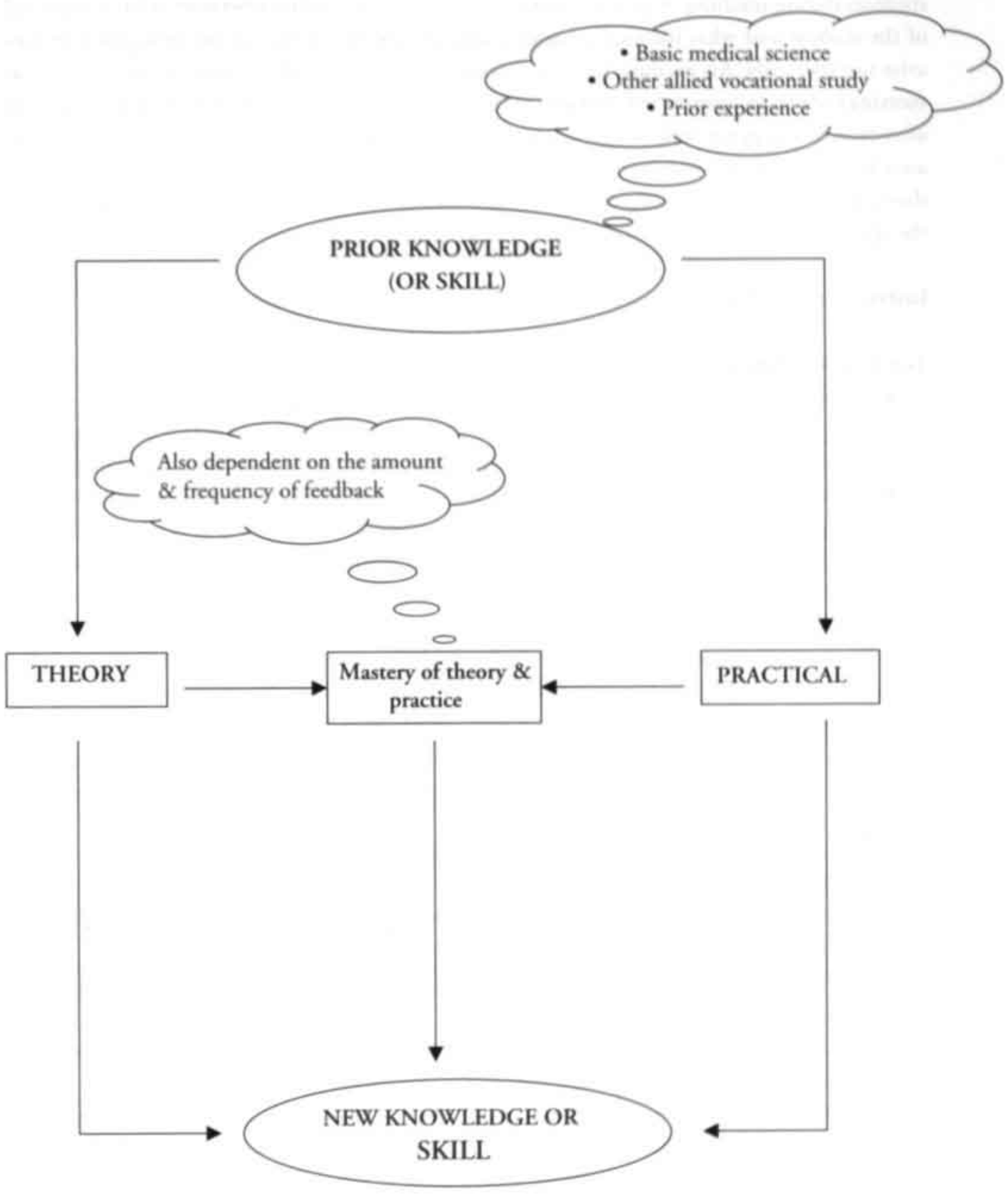




\section{Troubleshooting:}

Rationale: This block focuses on how to deal with the problems that arise between residents and students during teaching. A problem arises when there is discordance between what is expected of the student and what the student does. Some of these problems can be anticipated or may arise unexpectedly. An example of an anticipated problem is students arriving late for clinical meetings while an unexpected problem is for example, an insecure student losing motivation after receiving negative feedback. It is important that residents can figure out where the discrepancy lies in such a situation in order to find a solution to the problem. An approach to achieving this is identifying, acknowledging and recognizing the cause of the problem and then applying the appropriate intervention (see fig. 3)

Instructional method: lecture, interactive discussion, and role-playing

\section{Teaching strategies:}

- Using a combined lecture and interactive discussion format, the residents would receive instruction on a 4 -step approach to troubleshooting. The definition of performance problems and the difference between measurable and observable problems would be discussed.

- Problem identification - Residents are closer to students and are in a better position than attending physicians to identify the problems students encounter. The residents shall discuss ways of detecting problems in students' performance e.g. by reflecting on their own personal experiences or by defining the learning objectives /expectations that should be achieved with the students at the onset.

- Problem acknowledgement - The problems students encounter could be professional (related to the clerkship) or personal (not related to the clerkship). Furthermore, they could be behavioural and /or educational in nature. Acknowledging students problem entails distinguishing the nature of the problem and accepting it with the aim of finding a solution.

- Identifying the cause - The residents would learn how to identify the causes of problems in students' performance. This would aid them in finding the appropriate solutions to deal with them. Students performance problems can be distinguished by answering the following questions;

I. Is the problem due to an absent or incomplete professional behaviour, or a skill or behaviour that was incorrectly learnt or taught (professional + behavioural)

2. Is it due to a knowledge or skill that has diminished with lack of use and time (professional + educational)

3. Is it due to a problem that is not educational in nature but which affects knowledge or skill e.g. health or family issue (personal + educational)

4. Is it due to a problem that is not related to education but affects professional conduct or behaviour e.g. religious or cultural beliefs (personal + behavioural)

- Finding the solution. The residents should possess the skills to differentiate the nature of students' problems and intervene appropriately. Solutions for some of the students' 


\title{
Fig. 3 Flowchart on troubleshooting: HOW TO ANALYZE PERFORMANCE PROBLEMS
}

\author{
Problem identification
}

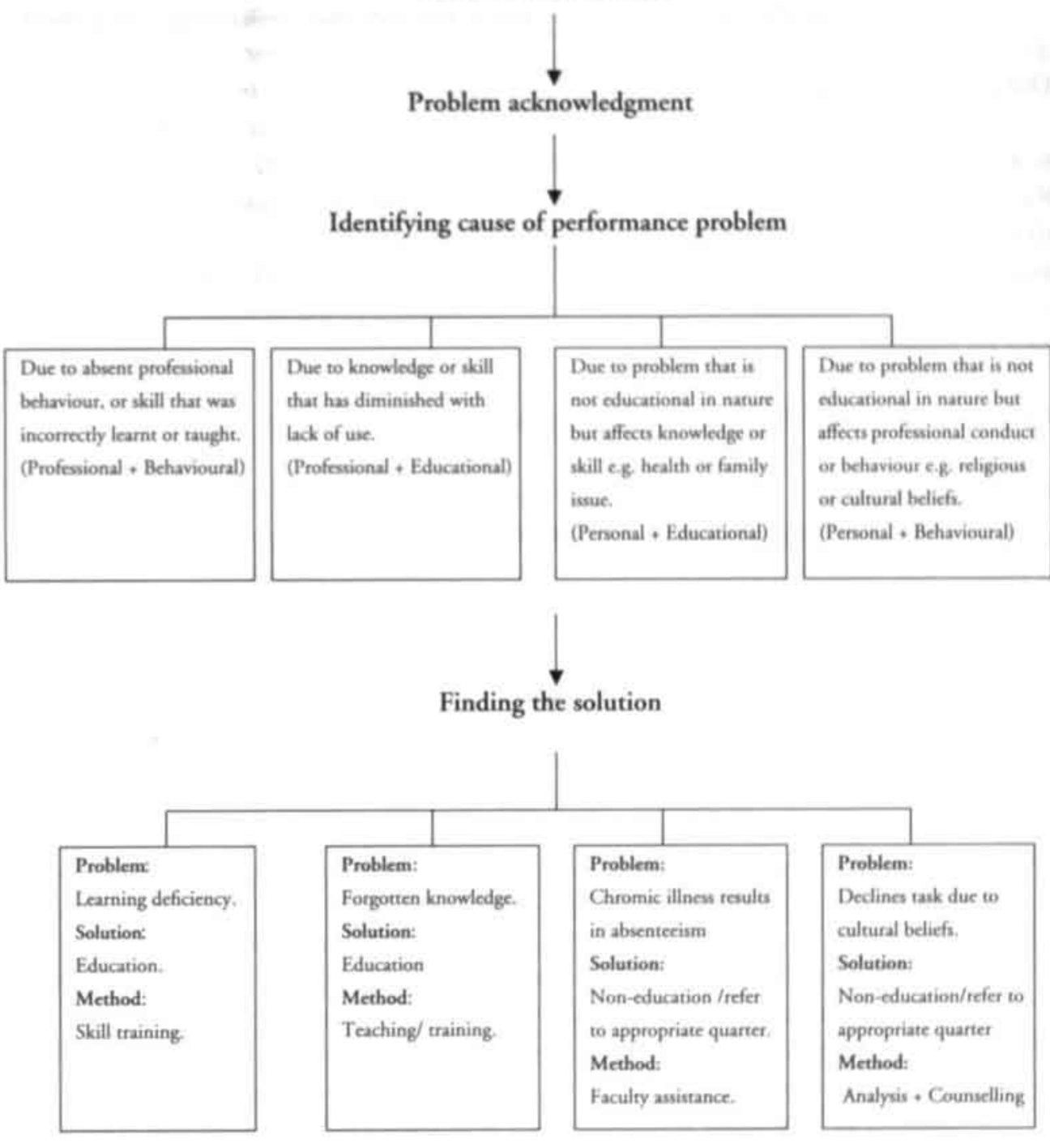


problems are however beyond the responsibility of residents. Such problems should be channelled to the appropriate quarters for solutions e.g. counsellors office. Solutions for performance problems can be categorized as:

1. Those remedied by education e.g. educational intervention, skill training ( $\& \& 2$ above)

2. Those remedied by non educational strategies e.g. feedback, counselling ( $3 \& 4$ above)

\section{Duration: 90 minutes}

\section{Time management:}

Rationale: Residents usually face the dilemma of teaching medical students in situations where there is little or no time allocated for teaching. It is however possible to make effective use of the available time for teaching by adjusting and reorganizing their work schedule. In this session, the residents shall generate strategies that would enable effective use of the available time they have for teaching.

Instructional method: Lecture, interactive discussion

\section{Teaching strategies:}

- Through interactive discussion. residents would outline the effects of time shortage on teaching. They would list its consequences for residents e.g. working under pressure and poor quality of teaching as well as the perceived consequences for the students. They would formulate strategies that can improve the quality of their teaching based on the outlined effects above.

- Finally, the generated strategies would be compared with the some practical tips on how to effectively make use of the available teaching time, namely:

1. Define clear learning objectives and expectations at the onset

2. Limit the number of learning objectives per encounter. An average of 2 learning objectives per encounter is ideal.

3. Establish a partnership with the students e.g. the teaching provided by residents in exchange for the students assistance in carrying out routine clinical activities

4. Share the responsibility of finding answers to difficult topics with students. Students can be of immense help in finding information faster for residents.

5. Delegate tasks and share patient responsibilities with students. Students benefit from the experience, it motivates them and spares time that can be used for teaching

6. Establish an honest and open atmosphere with students. This ensures that there is understanding and consideration for the available time for teaching that the resident has at his/her disposal.

Duration: 60 minutes 


\section{EVALUATION OF THE WORKSHOP}

An assessment of the workshop would be conducted to assess the quality of instruction and the perceived effectiveness of the workshop on the teaching skills of the medical residents. Self-assessment questionnaires shall be used to evaluate

1. The perceived benefit(s) of the workshop by the residents i.e. whether the residents felt that there was improvement in their teaching ability after the workshop

2. The perceived effectiveness of the workshop and its individual sessions

3. How effective the quality of instruction for the individual sessions was as perceived by both the residents and instructors.

In addition, students' ratings of medical residents teaching abilities prior to, and after the workshop, would be used to assess the impact of the workshop.

\section{Conclusion}

In designing this educational program, we made use of the adult learning model described by David and Patel (1995) 4 . It involved strategies that tapped on the prior knowledge of learners, encouraged their active participation and saw the role of instructors as facilitators. The participants of the workshop would work in small groups (not exceeding ten), and shall be exposed to stimuli in the form of video or case problems. The objective is to stimulate their prior knowledge and experiences, which can enhance learning. By including sessions for brainstorming in the program, we intend to encourage the active participation of the leaner in the educational process. The facilitative role of instructors in this program is intended to encourage the autonomy of the learners and acknowledge their identity as adult learners. This training program represents an intervention that has been developed through a needs assessment strategy. It is also a guideline for course developers on how to develop a training program in teaching skills for medical professionals. 


\section{REFERENCES}

I. NEVES, D.M.\& ANDERSON, J.R. (t98t). Knowledge compilation: Mechanisms for the automatization of cognitive skills. In J.R.ANDERSON (Ed.) Cognitive skills and their acquaitition, 86-102, Hillsdale, NJ: Erlbaum.

2. RAMSDEN, P. (1992). Chapter 4: Approaches to learning in Learning To Teach In Higher Education, 3862, London: Routledge.

3. FRANSSON, A. (1977). On qualitative differences in learning. IV - Effects of motivation and test anxiety on process and outcome. British Journal of Educational Prychology, 47: 244-57.

4. DAVID. T.J. \& PATEL, L. (1995). Adult learning theory, problem based learning and paediatrics. Anchives of Diseatse in Childhood, 73, 357-363.

5. DUNCKER, K. (1945) On problem solving. Prychological Monograph, $58(5)$

6. STRITTER, F.T, HAIN, J.D. \& GRIMES, D.A. (1975). Clinical Teaching re-examined. Journal of Medical Education, 50: 876-82.

7. DOUGL.AS, K.C. HOSOKAWA, M.C. \&. LAWLER F.H (1988). The elements of learning setting. A practical guide to clinical teaching in medicine, (Chapter 6), 44-51, New York: Springer Verlag.

8. STEWARD, D.E. \& FELTOVICH, PJ. (1988) Why residents should teach: the parallel processes teaching and learning. In J.C. EDWARDS \& R.L. MARIER (Eds.) Clinical Traching for Medical Residents: Roles. Techniques and Prognami, 3-14, New York: Springer Verlag.

9. FOLEY, R.P., \& SMILANSKY, J.(1979). Teacher-student interaction in a medical clerkship. Journal of Medical Education, 54, 622-626.

10. DINHAM, S.M. \& STRITTER, F.T. (1986). Research on Professional Education. In M.C. WITTROCK (Ed.). Handbook of Research in Teaching 952-70, New York: Macmillan.

u. DOUGL.AS, K.C. HOSOKAWA, M.C. \&. LAWLER F.H (1988). Learning in the clinical setting in A practical guide to clinical teaching in medicine, (Chapter 2), 7-18, New York: Springer Verlag.

12. ENTWISTLE, N, \& RAMSDEN, P, (1983). Understanding student learning London: Croom Helm

13. MARTON, F. \& SALJO, R. (1984). Approaches to learning. In F. MARTON, D. HOUNSELL \& N. ENTWISTLE (Eds.) The experience of learning, 36-55, Edinburgh: Scottish academic press

14. ANDERSON, R.C. (1977) The notion of schemata and the educational enterprise: general discussion of the conference. In R.C. ANDERSOM. R.J. SPIRO \& W.E. MONTAGUE (Eds.) Schooling and the acquisition of knowledge, Hillsdale, NJ: Erlbaum.

15. SCHMIDT, H.G. (1983). Problem-based learning: rationale and description. Medical Education, 17:11-16

16. DOOLING, D.J. \& LACHMAN, R. (1971). Effects of comprehension on retention of prose. Journal of Elucational Pychologx, 77, 514-521

17. RUMELHART, D.E., \& ORTONY, A. (1977) The representation of knowiedge in memory. In R.C. ANDERSON, R.J. SPIRO \& W.E. MONTAGNUE (Eds.) Schooling and the acquisition of knowledge. Hillsdale, N]: Erlbaum 
Curriculum vitae 
Jamiu Busari was born on the 28 th of June 1968 in London, England. He travelled to Nigeria in 1975 with his parents, where he completed his primary and secondary school education. He began his medical education at the Ogun state University medical school, Nigeria in 1985 and graduated as a doctor in 1991. As a medical student, he participated in several academic activities and held various functions in the senate and executive body of his medical school's student association. As a result of his involvement in academic activities and enthusiasm for teaching, he was invited as a pioneer student to join in the Master's of Health professions Education (MHPE) program at the university of Maastricht, the Netherlands. He began the MHPE program in 1992 and obtained his masters degree in 1994. His master's thesis was entitled "the comparative study of medical education as perceived by students at three Dutch universities".

As an educationalist, Jamiu continued his research and educational activities in medical education. In 1998, he formally began his $\mathrm{PhD}$ programme in medical education, at the faculty of Medicine, University of Maastricht. His area of interest was in investigating and developing strategies to improve the quality of professional training and teaching skills of medical residents. Till date, he has been actively involved in the development of teaching strategies for medical undergraduates, residents and peers and has published a number of papers on the subject. He has served in a number of educational committees, including the working group on "medical education in a multi-ethnic society" of the Dutch association of medical education (NVMO). He was also appointed medical resident's representative to the committee on medical education, in St. Elisabeth hospital (SEHOS), Curacao. Furthermore, he has developed and implemented a number of medical educational programs, including a two-day training workshop in teaching skills for medical residents.

As a physician, Jamiu continued the pursuit of his specialist career in paediatrics in the Netherlands. After an 8-month elective rotation in intensive care paediatrics at the university of Maastricht academic hospital (AZM), he enrolled into the university's medical school for the clerkship (co-schappen) in 1994. In 1996 he obtained his certification to practice as a Dutch medical graduate and began his pre-residency training in paediatrics the same year in AZM. In 1999, he began his formal residency training in paediatrics at the Emma children's hospital, AMC, Amsterdam. He underwent 2 years of his residency training at the St. Elisabeth hospital, Curacao, Netherlands Antilles between 2000 and 2002, and completed his training in Amsterdam in October 2003. As a medical resident at the Emma children's hospital, he was involved in different projects and has served in different committees. Some of his activities included serving as chairman in the committee that organized the "first national football competition for paediatric clinics/hospitals, in the Netherlands," a fund raising activity for children of HIV seropositive mothers in Suriname. He was also actively involved in setting up the yearly "Emma supervisor awards" at the Emma Childrens Hospital, AMC; an educational initiative whereby medical residents reward deserving attending physicians for their outstanding supervisory activities. In addition, he co-founded the Children ${ }_{4}$ Children foundation, Curacao Netherlands Antilles, which is a non-profit organisation dedicated to supporting underprivileged children in Curacao. The author is presently working as a paediatrician (chef de clinique) at the St.LucasAndreas Hospital, Amsterdam, in the Netherlands. 
LIST OF PUBLICATIONS 


\section{List of publications}

- The impact of western technologies in a non-western context" J.O. Busari (1994). Tough Questions, Student Pugwash USA quarterly newsletter, fall edition

- "A Nigerian perpsective of overcoming barriers to health care education and delivery" J.O. Busari (1995). Student Pugwash USA Global lssues Guidebook, ist edition,

- "Hoe voelen studenten zich voorbereid op de praktijk? Een vergelijking tussen drie faculteiten geneeskunde" A.J.J.A Scherpbier, J.O. Busari, H.P.A. Boshuizen, R.J. Hiemstra, \& J.C.M. Metz (1996) Bulletin Medisch Onderwijs, 15, 17-22

- "Comparative study of medical Education as perceived by students at Three Dutch Universities" J.O. Busari, A.J.J.A. Scherpbier, \& H.P.A. Boshuizen (1997) Advances in Health Sciences Education, 1, 141-151

- "Clerkship in a clinical discipline - Paediatrics. A student centred approach" J.O. Busari. (1997) Current Implementations of Student-Centered Education, Conference proceedings, Maastricht University 20 th Anniversary Conference

- "General practice in Maastricht; The community, the culture, and the delivery of health care services" J.O. Busari, F.Vissers, \& G. Peeters (1997) Medisch Contact, 35,1050-52

- "Klinisch Onderwijs door assistenten: een exploratief onderzoek" J.O. Busari, A.J.J.A Scherpbier, \& C.P.M. van der Vleuten (1997), Conference proceedings, Gezondheidsonderwijs congres.

- "Residents perception of their role in teaching undergraduate students in the clinical setting" J.O. Busari, A.J.J.A. Scherpbier, C.P.M. van der Vleuten, \& G.G.M. Essed (2000) Medical Teacher, 4, 348-353

- "Revisiting analogy as an educational tool - PBL and the game of basketball" J.O. Busari. (2000) Medical education, 34; 12, 1029-31

- "Medical education in the new millennium - a Caribbean perspective" J.O. Busari, M. Vervoort, S.M. Hermans, \& J.R. Blom. (2001) Medical education, 35; 7, 703-706

- "How residents perceive their teaching role in the clinical setting - a qualitative study Jamiu O. Busari, Katinka Prince, Albert J.J.A. Scherpbier, Cees P.M. van der Vleuten, \& Gerard G.M. Essed (2002) Medical Teacher, 24 (1): 57-61 
- "The perceptions of attending doctors on the role of residents as teachers of undergraduate clinical students. Jamiu O. Busari, Albert J.J.A. Scherpbier, Cees P.M. van der Vleuten, \& Gerard G.M. Essed (2003) Medical Education, 37; 241-247.

- "Why medical residents should teach: A literature review" Jamiu O. Busari \& Albert J.J.A. Scherpbier (2004) Journal of Postgraduate Medicine, 50(3); 205-210.

- "How medical residents perceive the quality of supervision provided by attending doctors in the clinical setring" Jamiu O. Busari, Nielske M. Weggelaar, Petra-marije Greidanus, Andrieke C. Knottnerus \& Albert J.J.A. Scherpbier (In Press, Medical Education, 2004)

- "How to investigate and manage the child who is slow to speak". Jamiu O. Busari, \& Nielske M. Weggelaar (2004) British Medical Journal, 328; 272-276.

- "Ethics and Law in Paediatrics", J. Busari in C. Baxter, M.Brennan \& Y Coldicott (Eds.) The Practical Guide to Medical Ethics and Law, for junior doctors and medical students, (2002) 174175 (Cornwall, MPG books Ltd)

- "Speech and Language Delay in Children", J.O. Busari in T.J. David (Ed.) Recent Advances in Paediatrics 22 (In Press) (Royal Society of Medicine Press Ltd)

- "EOSINOPHILIA - Its hematological significance in the diagnosis of Pediatric HIV infection J.O. Busari, R.N.J, van Andel, H.J. Scherpbier (2000) Pediatric Clinics of Amsterdam, Vol. II; 2, 6-7

- "Hemorrhagic colitis with severe anemia - a rare complication of rotavirus enteritis" O.J. Busari, E. van den Brink, F.D. Muskiet (2001). Pediatric Clinics of Amsterdam, Vol. 12; 4, 1-3 



\section{ACKNOWLEDGEMENTS}


When I proceeded to write the acknowledgements, I did not realise how difficult it would be to express my gratitude to all the people who played vital supportive roles, in the process of completing this dissertation. As 1 later found out, choosing the right words to express myself was not as easy as initially thought. Squeezing into words, the heartfelt appreciation for all the support I received, became an uphill task. Therefore, it is my hope that the things I have mentioned in this section adequately reflect how much I am indebted to all those who have covertly and overtly contributed to the completion of this book.

My Parents. I want to thank my mum who is and has always been there for me. She always told me to be happy and satisfied with whatever I had. She was right at that, as I discovered that it was not how much you had that mattered, but how you made use of what you had. Dad, I always knew you were proud of me. You provided me with the best gift a parent could give a child... the possibility of a good education. I cannot thank both of you enough.

My Uncle, Mr. K Badaru. Like a guardian angel, you watched over me and guided me until it was time for me to face to life's challenges alone. Unfortunatley, you passed on before I could defend this thesis... To you I dedicate this book. Thank you, and I wish you a smooth onward journey.

Mrs Sodeinde, my aunt. You have always been there for me and dutifully, you have traversed the English channels each time to demonstrate how proud you are of me. Thank you

A very special person, Miss A. Hurkens. Facing life's challenges alone was not easy. At a time I needed someone to lean on, you were there. You have always believed in me. You were there as support to me when I began my career as an educationalist. Despite the distance and my "globetrotting", you have been following the progress of my career behind the scenes supportively... I thank you for your generosity.

Henrika van Dam, thank you for your unflinching belief and trust in me. It meant a lot more to me than money could buy.

My supervisors, the "three Musketiers". Albert Scherpbier (Athos), Cees van der Vleuten (Porthos) and Gerard Essed (Aramis), the three of you were an overwhelming and inspiring trio. Authorities in your own right, and experts in your respective fields, it was a great priviledge to learn and work at close proximity with the three of you.

Albert, our journey together dates back to 1993 when you supervised my final thesis for my MHPE degree. Since then like a snail and its shell, we have been stuck together. You are a great role model for young educators, and a lot of fun to be around! Albert, although I know that compliments make you uncomfortable, I still have say... that you are A GREAT TEACHER! 
Cees, in my perception, your objective and constructive feedback cannot be equalled! Your remarks in the several preliminary versions of my manuscrpt, with your famous "red" ink, have resulted in my love for the colour red! You have a sharp eye for detail, structure and above all logic. This you clearly demonstrated in the ways you effortlessly clarified very complex and nearly impossible research dilemma's. Your honesty, zeal and commitment as a supervisor and coach was clearly felt. I admire your person and the work you do very much.

Gerard, the silent force at the background, rarely seen, ever present, and always felt. Your were the one who kept pulling me up each time frustration and exasperation knocked on my door. You were always there ready to listen, encourage and above all, push me back into the battle field. Your slogan was always "Jamiu, keep up the good work". Amazingly, it worked! Your experience as a clinician and educationalist was of immense benefit to me and also a source of inspiration.

Professor Hugo Heymans, as head of department of Emma Childrens Hospital in Amsterdam, you were in charge of my paediatric professional training. During this period that spanned 5 years, you showed true commitment to your role as a teacher, mentor and friend. You were always available to help and were never at a loss for ingenious ideas or solutions. You were always encouraging in your words and incessantly nudged me to break new frontiers. Thank you for seeing what you saw in me. You were and remain a great source of inspiration.

Professor Heineman, as a one-time tutor of mine in Maastricht, you always demonstrated your passion for teaching alongside your profession as a paediatric surgeon. Thank you for being a great example...

Professor Kootstra, you were my mentor when I did my surgical clinical rotation in the teaching hospital of Maastricht University, way back in 1993. I remember you asking me then, what other things I was involved in besides medicine. I am glad to present you with an answer in the form of this thesis. Thank you for being a good mentor...

My tutors in the MHPE program, Maastricht University (1992-94). My gratitude goes to all of the individuals who made up the MHPE teaching staff, when the program was initiated in 1992. It was a privilege to be a pioneer student of the program and to be taught by a bunch of enthusiastic and wonderful people. Irma Kokx, I thank you for the warm reception I was given when I joined the program. Els Boshuizen, you were always bubbling with energy and enthusiasm. You showed me how refreshing teaching could be. Jan van Dalen, you were a great teacher and friend. Your door has always been open to receive me and I thank you. Ineke Wolfhagen and Diana Dolmans, my dynamic duo! Thank you for all the things you taught me about medical education. Geke Blok, Henk Schmidt, Wim Gijselaers, Willem de Grave, Henk van Berkel, Scheltus van Luijk, and everyone else I have failed to mention I thank you all. Tonny de Vries I thank you too, without a great secretary, I would have been lost as an MHPE student. 


\section{Acknowledgments}

Dr Gerard Majoor, You played an instrumental role in the course of my academic career in the Netherlands. Thank you very much. Annechien Deelman, I celebrate this achievement with you. Thank you for your kindness.

Mereke Gorsira, I owe you a lot of credit for most of the studies presented in this thesis. You were the brain behind the editorial revision of most of the manuscripts presented in this book. Humble as you are, I hope I can do justice in adequately expressing how wonderful you are as a person and how grateful I am for your generosity.

Katinkha Prince. Colleague and friend. You surely understand the amount of work that goes into fulfilling the requirements supervisors like Cees and Albert demand.... Plenty of hard work! The rewards however, are bountiful. You have been a great help to me on a number of occasions, especially in conducting the training workshops. I thank you very much and wish you all the best in completing your thesis.

Arnoud Muitjens, I want to thank you for your assistance and the statistical advice you provided in preparing the last manuscript of this thesis.

Mike Vervoort, "stretch". A unique friendship we have. We first met in Cape Town, South Africa in 2000 during the 9 th OTTAWA international congress on medical education. The next time we would meet was in Curacao, Netherlands Antilles the same year. Somehow we needed to travel thousands of kilometres from the Netherlands to be able to share our experiences in medical education. I thank you for your helpful contributions as a (then) medical student in developing the workshops presented in this thesis.

Sabine Valks, I have seen you grow from a medical student into a resident in paediatrics! Thank you for your support.

Gijs Vos and Han Hendriks, thank you for believing in me.

Professor Bleker, a clinician and educationalist yourself, you understood my plight as educationalist doing research work. You were a strong supporter of my activities from a distance. I thank you for all the efforts you made in encouraging the participation of your department in my investigations.

Ivan Bank, Ivanovitch. The first time we met, I thought you were a clinical staff member in OLVG. Little did 1 know then, that you were still a medical student. Since that first encounter, we have been best friends. We have shared high and low times together. I thank you for all the moral and insightful support you offered me. 
Nielske Weggelaar, we grew to become very good friend towards the tail-end of my residency training. That friendship lead to many great developments that included a clinical review we prepared together in the $B M J$ and the organisation of the yearly Emma awards for the best supervisors in Emma children's hospital, Amsterdam. You also demonstrated your affinity for medical education resulting in our working together in some of my studies. A great colleague you have been and I thank you very much.

Petra-Marije Greidanus, It was always fun working with you and I thank you for your contributions towards the completion of my thesis. Andrieke Knottnerus and Irene Schiering. My EKZ "research team" would be incomplete without mentioning both of you. It was a privilege working with both you. I also wish to thank Petra Biewenga, Irene de Graaf, Gabriela Dias Piereira, Mimg Tjiong, Babette Lisman, Jeroen van de Riet, Astrid Vollebregt, Janne-Meije van Weert, Josanne Brinkman, Frank Scheurman, Nielske Weggelaar, Tim de Meij, Merit Tabbers, Niels Rutjes who made the teaching workshop in Amsterdam a reality.

Dr Fred Muskiet, mentor, teacher and friend. I thank you for your wise guidance and support during my residency training in Curacao. Through you, I learnt to appreciate the clinical teacher in the Caribbean setting. Shirley Lo-a- Njoe, Ingemar Merkies and Ashley Duits, I thank all of you very much for your assistance in conducting the pilot workshop training in Curacao. Your enthusiasm and joy in teaching was very inspiring. Professor Rojer, you gave my research activities the much-needed impetus in Curacao. I thank you for your support and the trust you had in me. Els Statius-Muller, without you, the pilot workshop in Curacao would have been impossible. Masha Danki.

Inge de Boer, "Ingy Pingy". Our friendship started the first day we met four years ago. We have remained very close friends since. You have been a great support to me in many ways and I am very grateful to you. I thank you and Dr Ram Sukhai for helping in organising the teaching workshop in LUMC, Leiden.

Bart Wolf, Monique op de Coul, Hanneke Wennink, Marian Sanders, Eric Ree, Erna Langius and Kete Ramaker (Pediatric staff, SLAZ), my "Brady bunch". I want to thank you all for the opportunity and support you offered me in being able to realise the completion of my thesis. It was great working with you all.

For all those I have failed to mention in this list, I send you all my heartfelt appreciation. Your support and positive thoughts were felt and valued!

\section{Jamiu Busari}




\section{LIST OF SPONSORS IN ALPHABETICAL ORDER}

- Ivax Farma B.V.

\section{Meadohnnson}

- Mead Johnson Nutritionals, Bristol-Myers Squibb

- Norvo Nordisk Farma B.V.

- Novartis Pharma B.V.

\section{NUTRICIA}

- Nutricia Nederland B.V.

- Vakgroep Onderzock van Onderwijs, Faculteit Geneeskunde, Universiteit Maastricht

- Viatris B.V. 


\section{The Medical Resident as a Teacher Teaching and Learning in the Clinical Workplace}

Clinical teaching is an important component of the thedical professional's responsithitity. and in the clinieul setting. a lot of specialists ansl medical residents perform this duty. Despite their obvicus participation in this process however, most medical professionais tack the formal exposire and basic tearhing skills nequired, to perform this dury effectively,

Experts in medical edwation suggest that educational knowledge, knowledige of the generat principles of teacting, and the proper understanding of ones clinical discipline. are the features that consizute the cote principles of seaching. Theories of adult learning also show, that in ockler to he able to teach effectively, dinical teachers require (training in) basic teaching skitls. Several studies in the medical litenature have demonstrated the benefits of teaching for, and by, medical professionals. Despite the reported beneficial findings however, muny specialist-training programs still lack formal training programs in clinical teaching for medical reaidents.

So far, there has been no sydematic explotation of the pole of medical residents as teachers in the clinical serting, and of their contribution as stakeholders to the (medicat) educational process. This book provides a series of studies that illuminate the role of the medical resident as a clinical teacher, In particular, the extent to which medical residents are involved in teaching and the factors that facilitate or hinder theit contributions to the educational process are described. In addition, a description is prowided of how to develop and validate an evidence based educational tool for inproving medical residents teaching ahilities.

\section{Jamiu O. Busari}

